11.

تأثير خدمات الإرشاد الزراعي على تعزيز رأس المال الاجتماعي ببعض قرى محافظة الفيوم

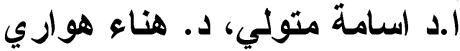

قسم الاقتصاد الزر اعي - كلية الزر اعة - جأمعة الفيوم

استهدفت الدراسة:التعرف على بعض الخصائص الثخصية و الإقتصادية والإجتماعية المميزة

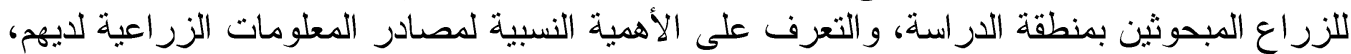

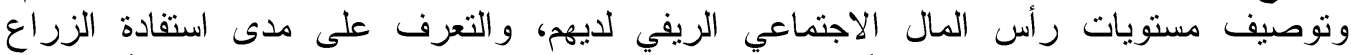

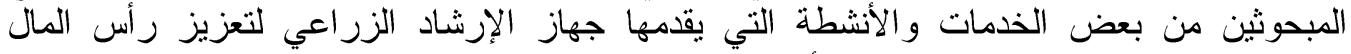

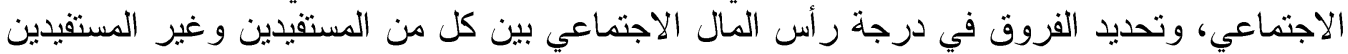

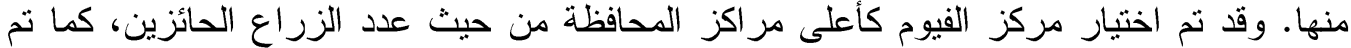

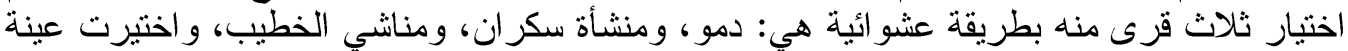

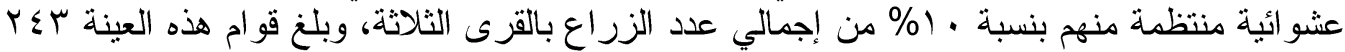

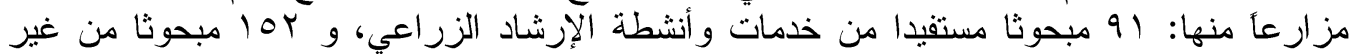
المستقيدين منها.

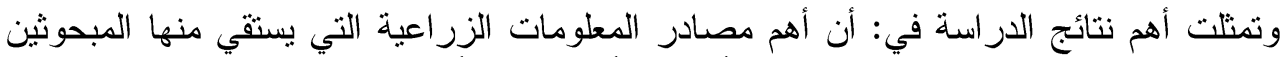

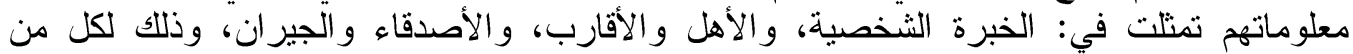

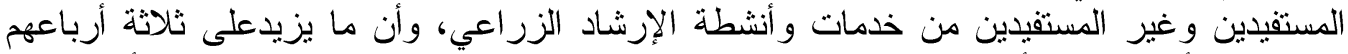
(\%VV,乏)

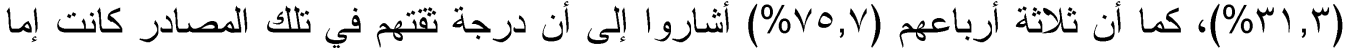

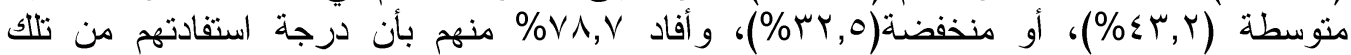

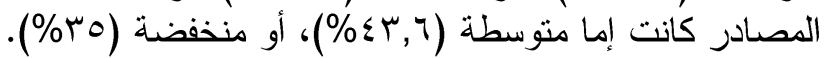

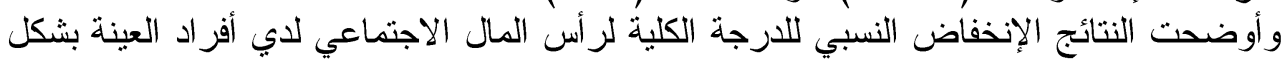

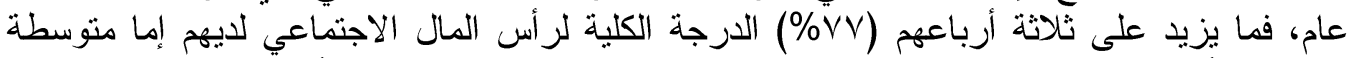

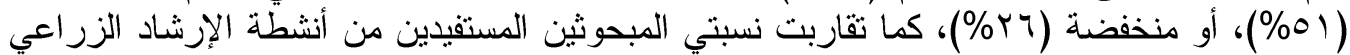

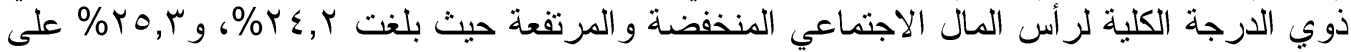

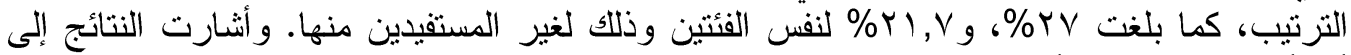

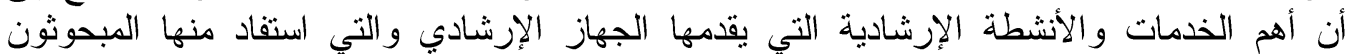

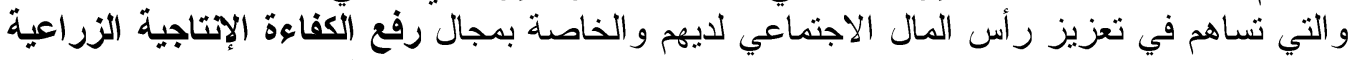

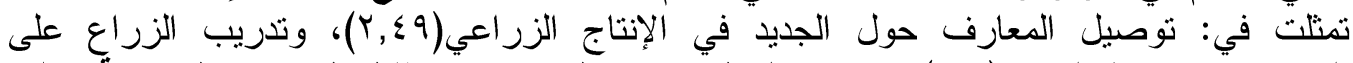

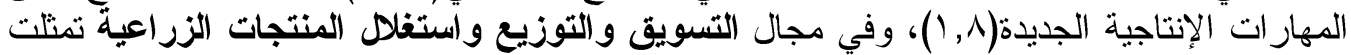

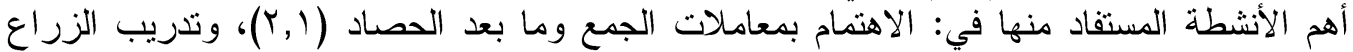

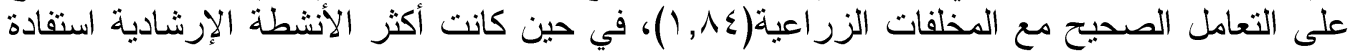

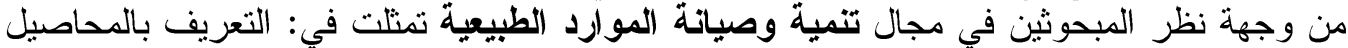

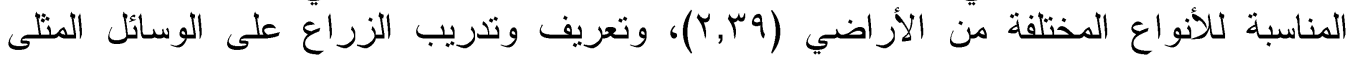

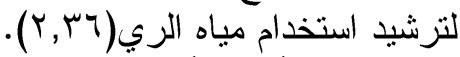

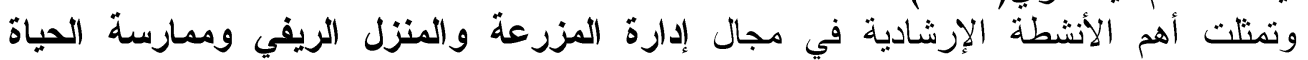

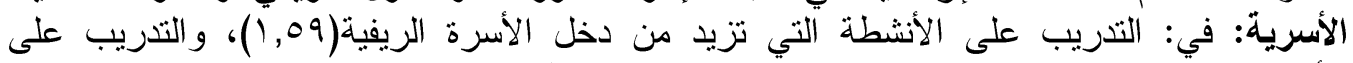

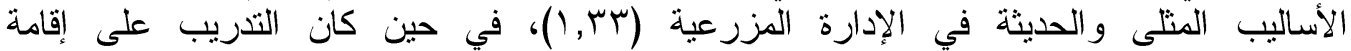

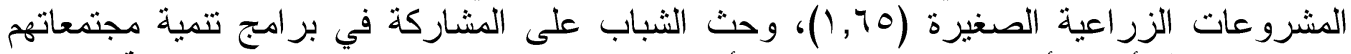

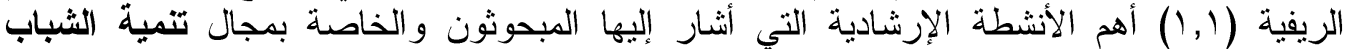
الريفي، كما تمثلت أهم الأنشطة الخاصة بمجال الأنهامة الأنهام في الثئون العامة وتنمية المجتمع الريفي

Fayoum J. Agric. Res. \& Dev., Vol. 33, No.2, July, 2019 
111

في: الاهتمام بالجوانب التعليمية والتثقفية لأفر اد المجتمع الريفي (Y r, ())، وحثهم على المشاركة في

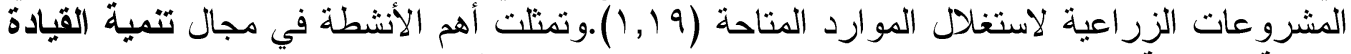

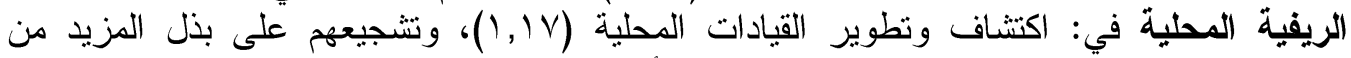

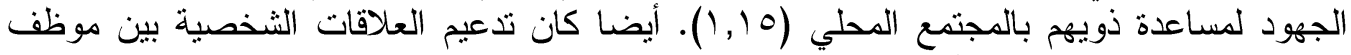

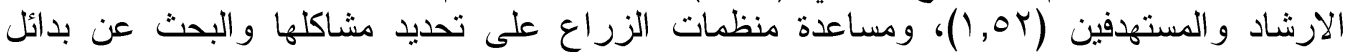

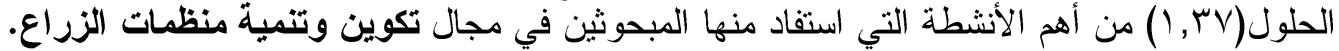

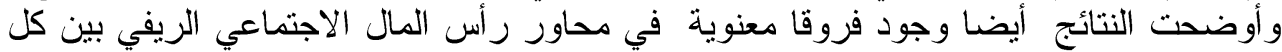

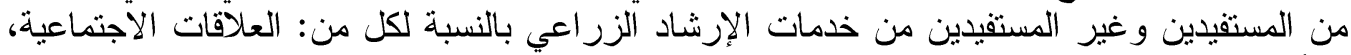

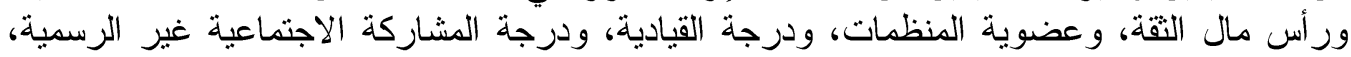

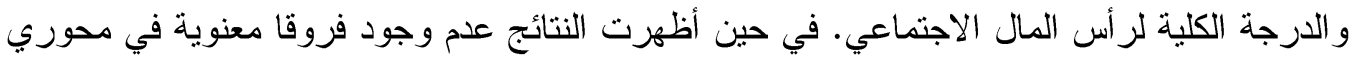
درجة المشاركة في المشروعات التتموية، ودرجة المشاركة السياسية وذلك بين المستفيديدين وغير فئري

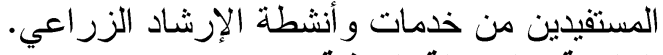

المقدمة و المشكلة البحثية

كانت تقاس التتمية حتى وقت قريب بـتهية بمعايير مادية بحتة مثل متوسط الدخل الفردي، و الزيادة

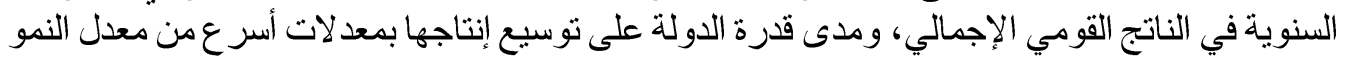

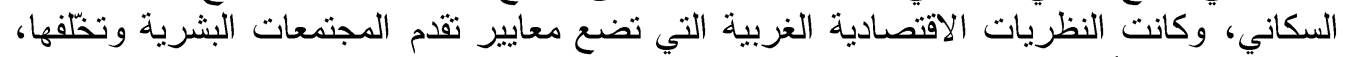

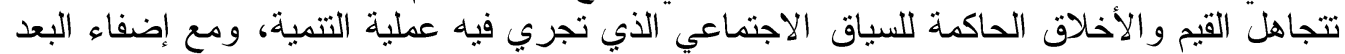

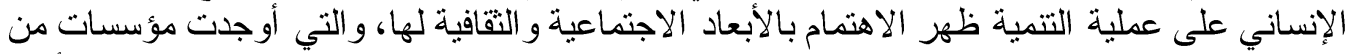

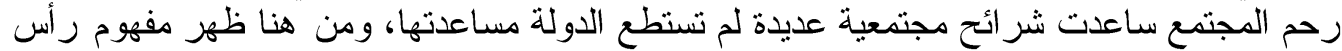

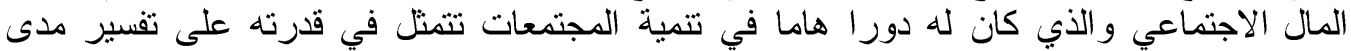

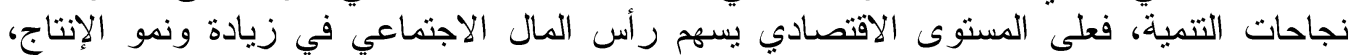

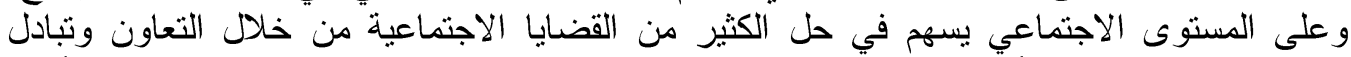

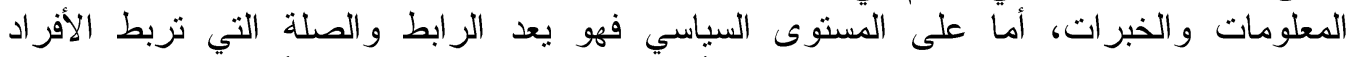

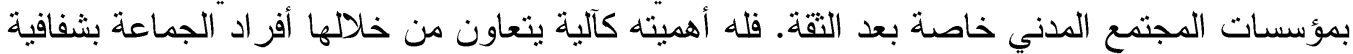

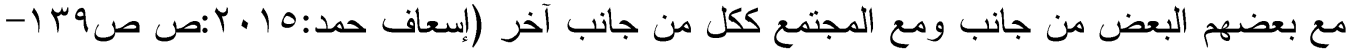

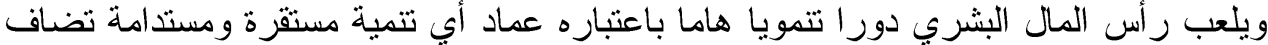

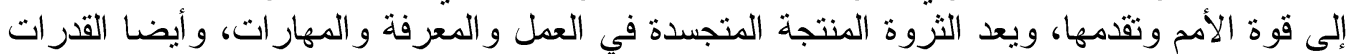

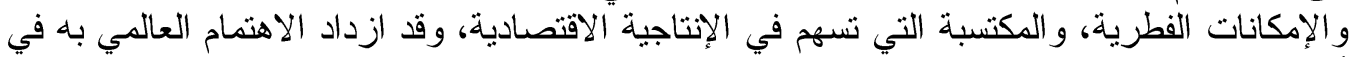

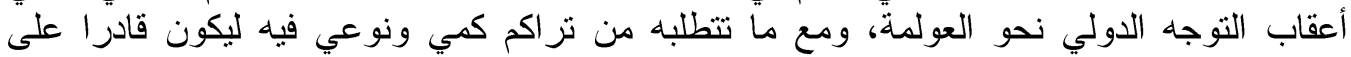

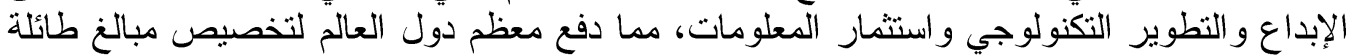

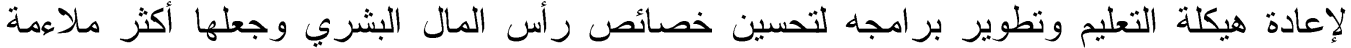

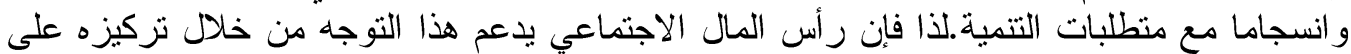

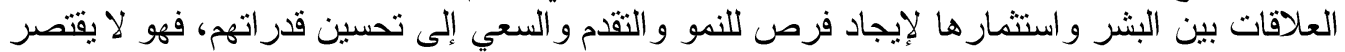

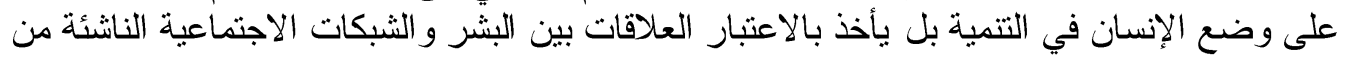

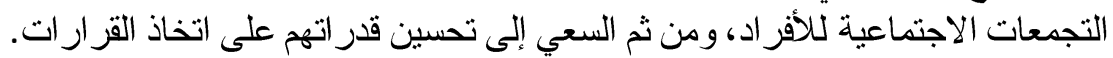

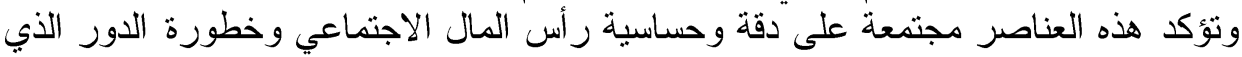

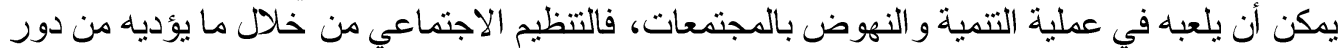

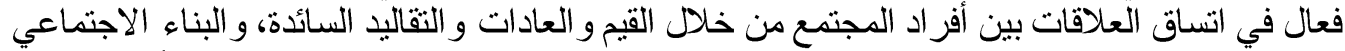

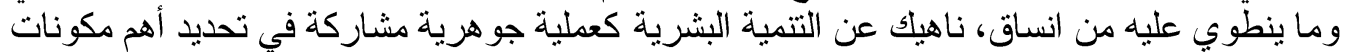

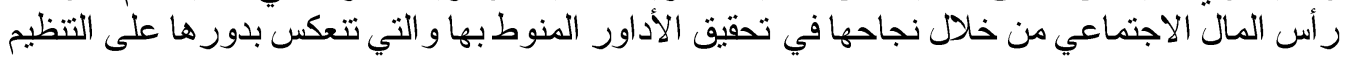

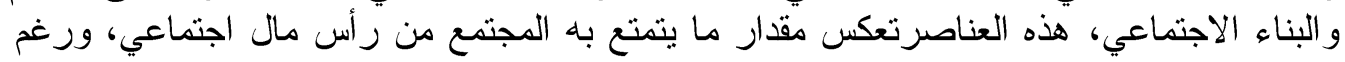

Fayoum J. Agric. Res. \& Dev., Vol. 33, No.2, July, 2019 
$11 r$

الصعوبة التي يشير إليها المهتمين بمحاولة قياس رأس المال الاجتماعي كونه لا يتجسد و اقعا ماديا

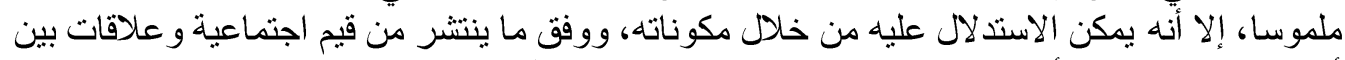

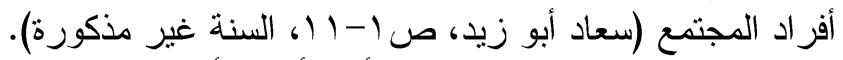

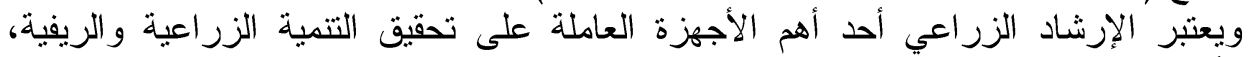

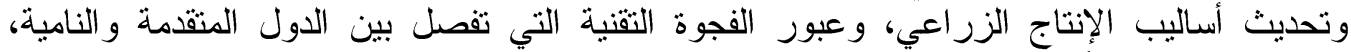

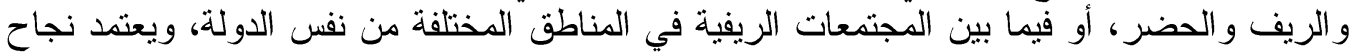

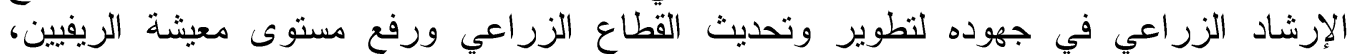

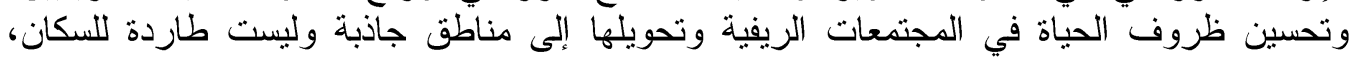

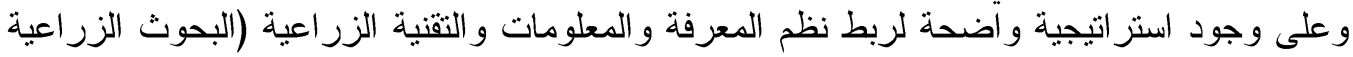

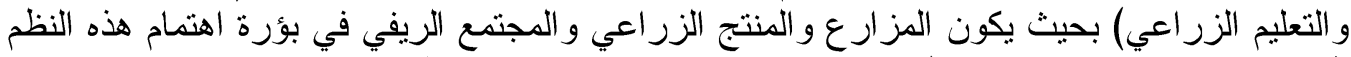

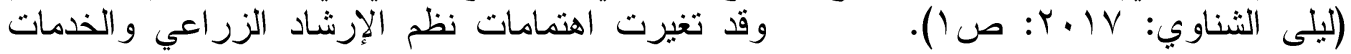

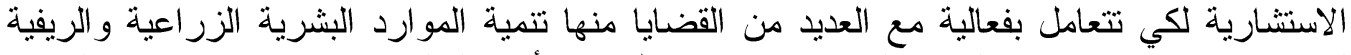

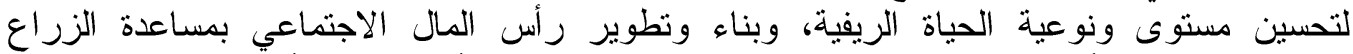

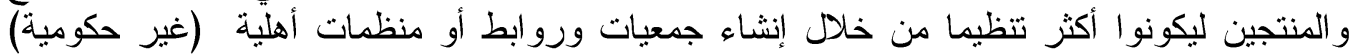

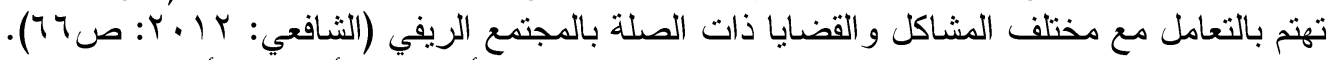

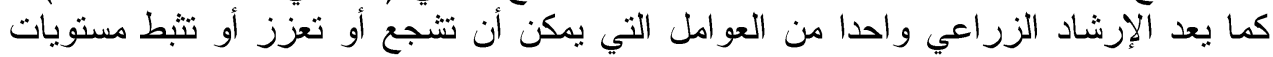

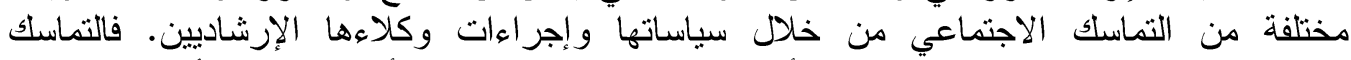

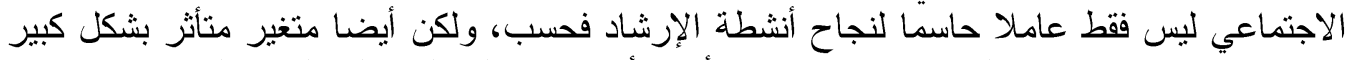

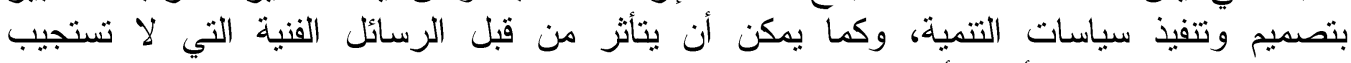

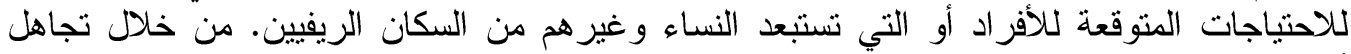

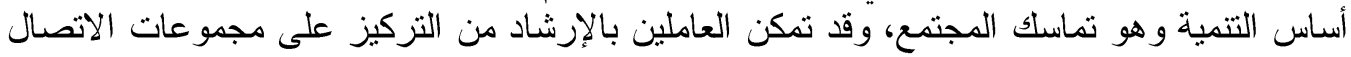

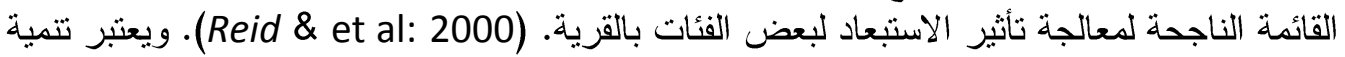

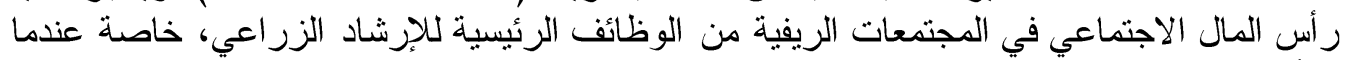

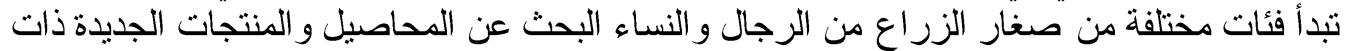

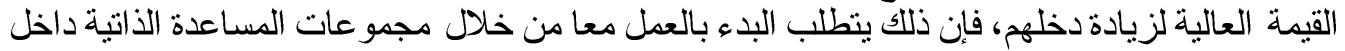

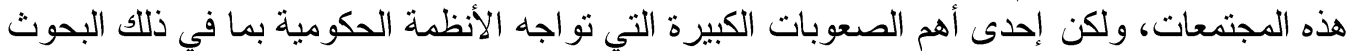

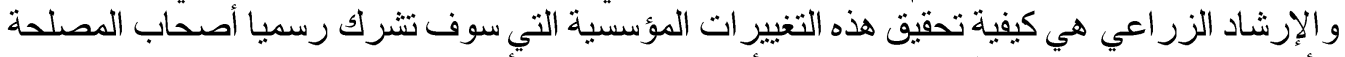

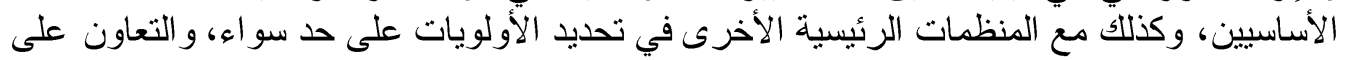

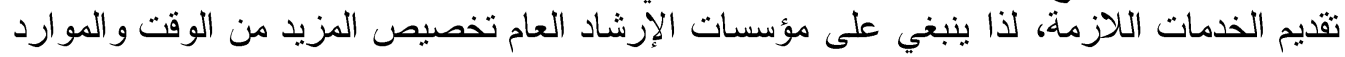

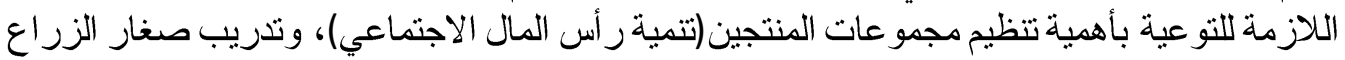

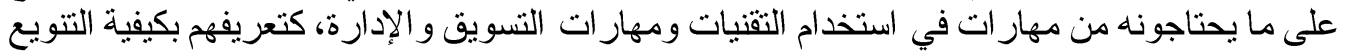

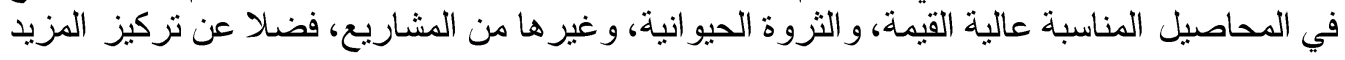

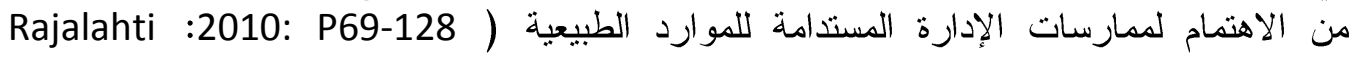

(Swanson\&

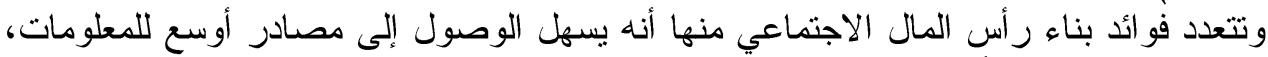

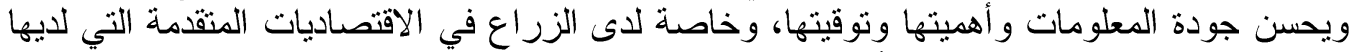

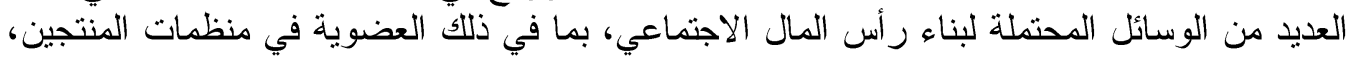

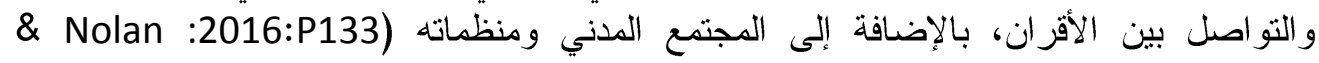
العicheels

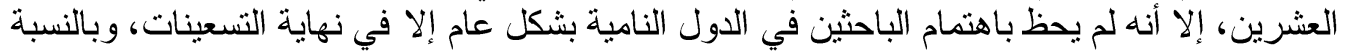

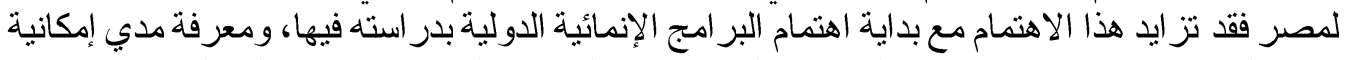

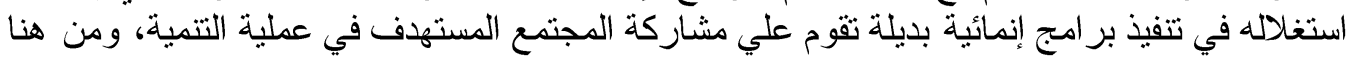

Fayoum J. Agric. Res. \& Dev., Vol. 33, No.2, July, 2019 
$11 \%$

جاء التركيز علي رأس المال الإجتماعي نظر آ لأهمية شبكات العلاقات الإجتماعية التي يمتلكها كل

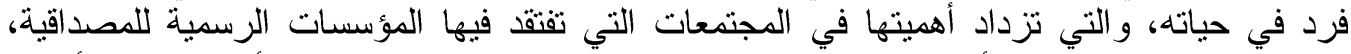

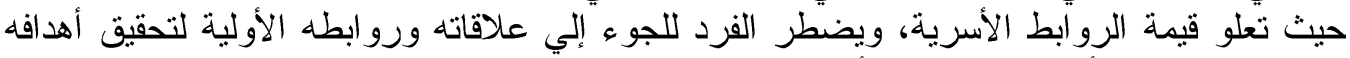

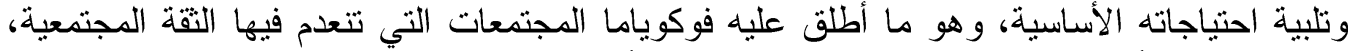

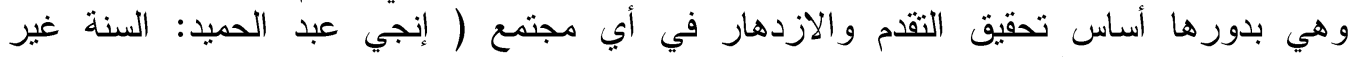

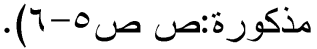

وعلى الرغم من أهمية رأس المال الاجتماعي، إلا أنه لوحظ عدم اهتمام الإرشاد الزراعي

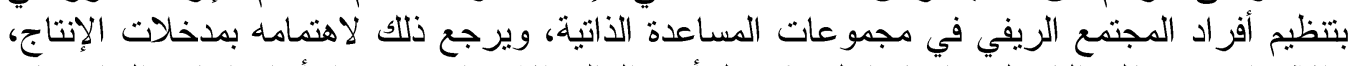

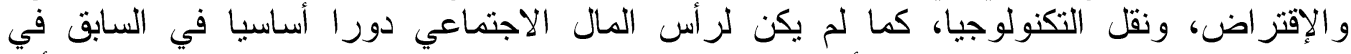

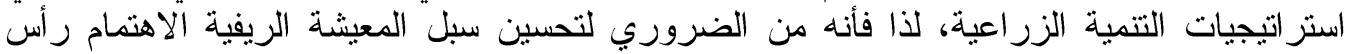

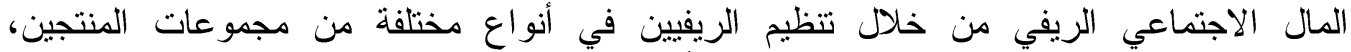

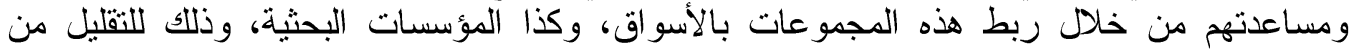

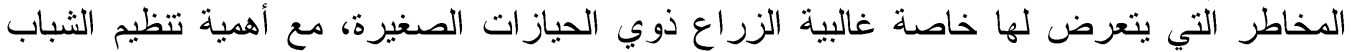

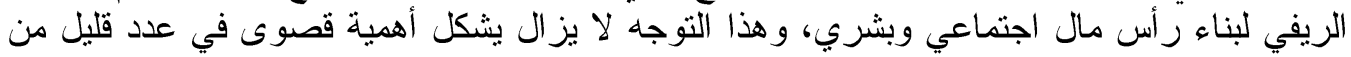

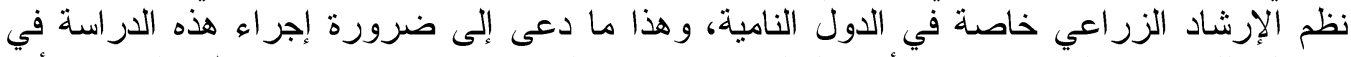

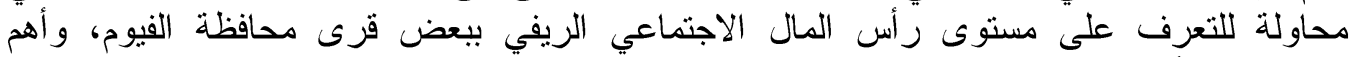

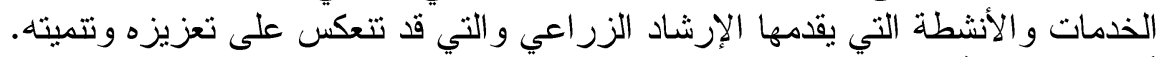

أهداف الادراسة الأنة

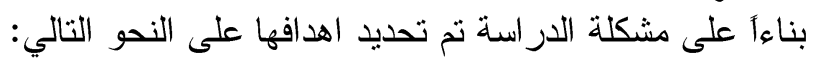

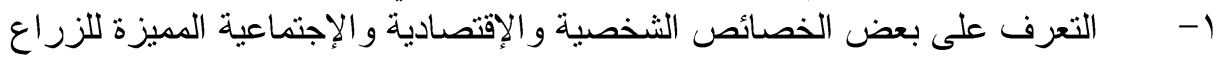
المبحوثين بمنطقة الدر استة.

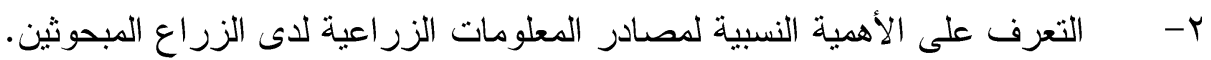

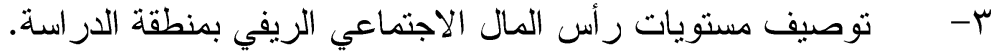

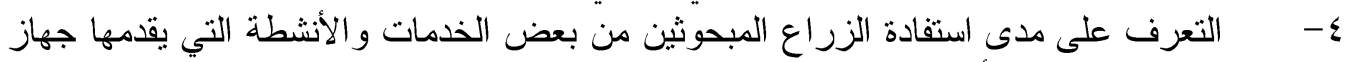
الإرشاد الزر اعي لتعزيز رأس المال الاجتماعي.

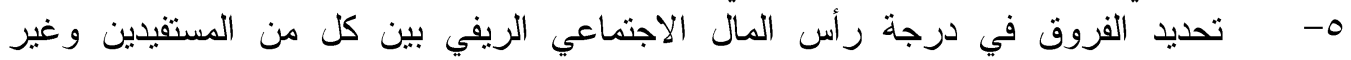

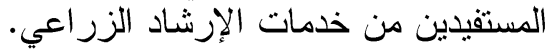
الاستعر اض المرجعي يتتاول هذا الجزء مفهوم رأس المال الاجتماعي وأشكاله، بالإضافة إلى دوبلى دور الإرشاد

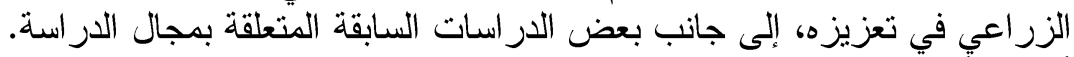

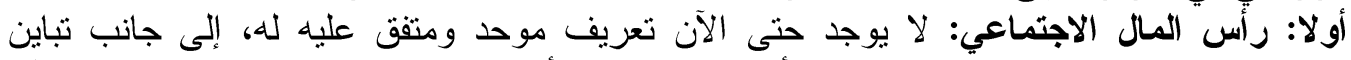

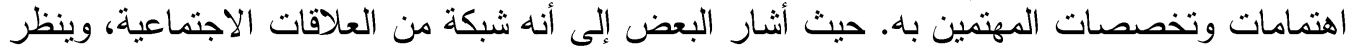

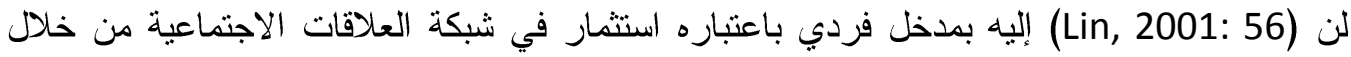

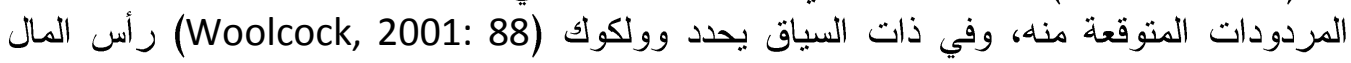

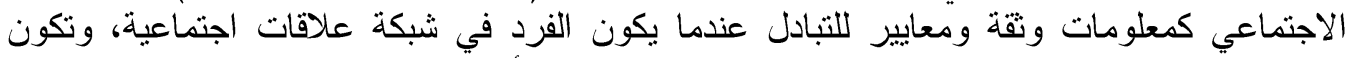

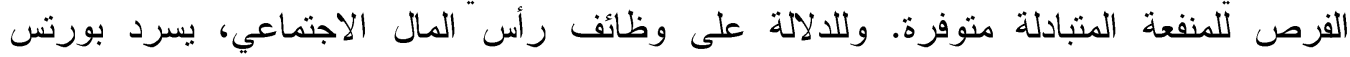

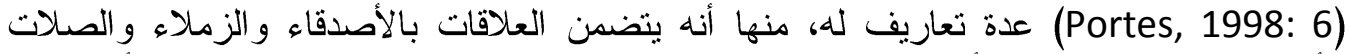

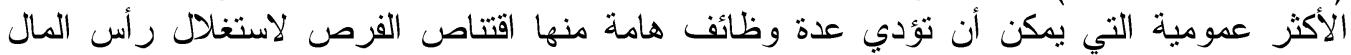

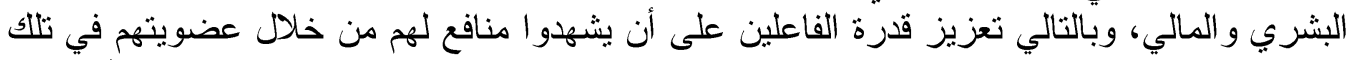

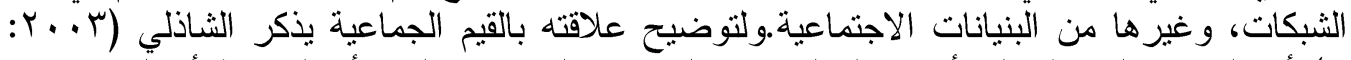

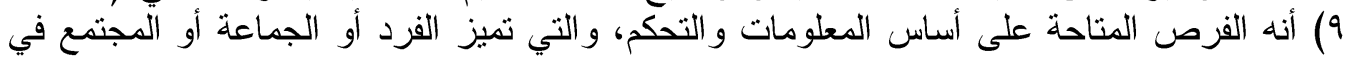

Fayoum J. Agric. Res. \& Dev., Vol. 33, No.2, July, 2019 
$11 \varepsilon$

علاقاته بالآخرين، ويُضيف أيضاً أن القيم التي ثُكله تعكس قيماً ر أسمالية عقلانية، وذلك باعتبار أنه

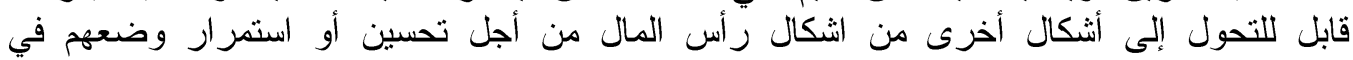

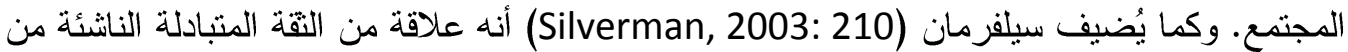
القيم المشتركة التي هي جزء لاء لا يتجز أ من الثبكات الاجتماعية.

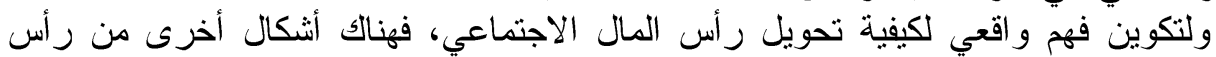

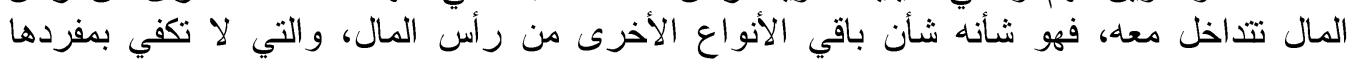

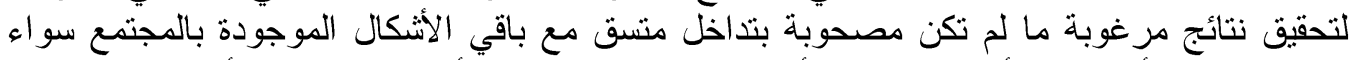

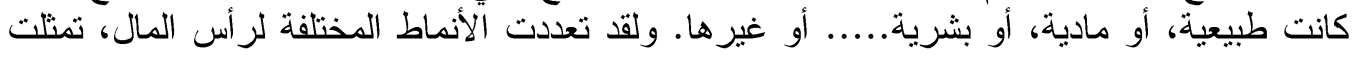

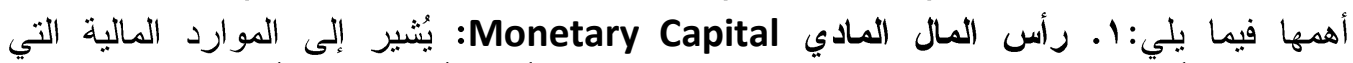

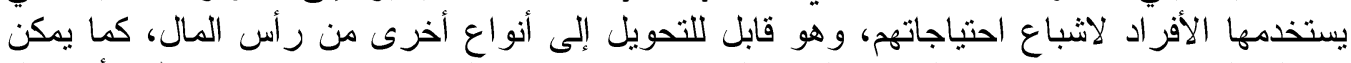

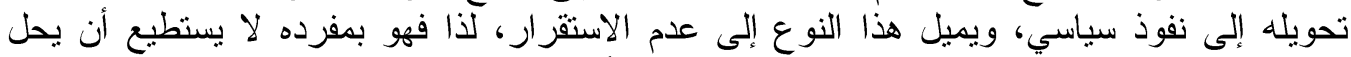

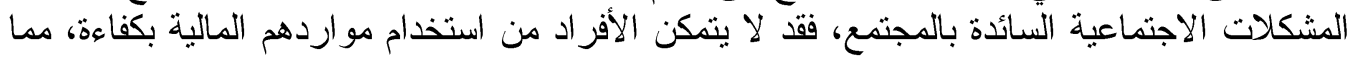

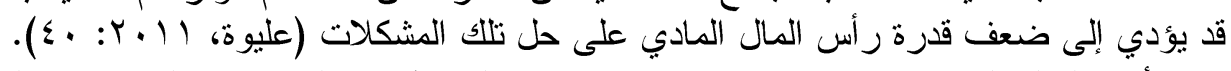

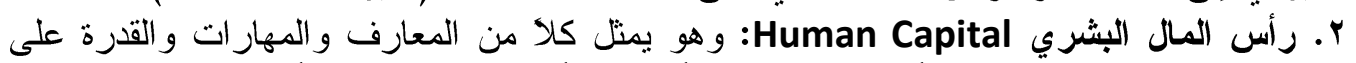

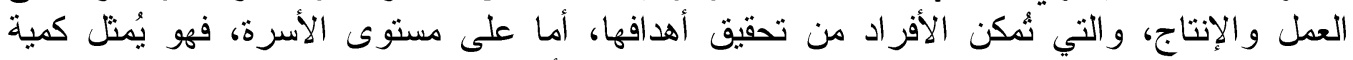

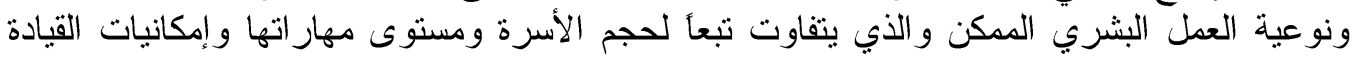

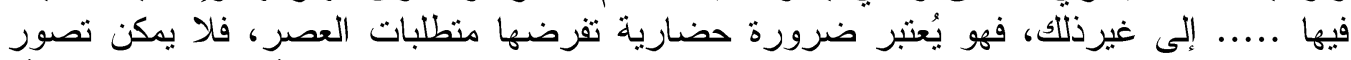

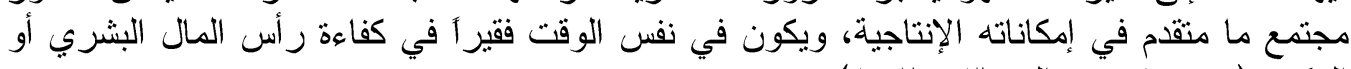

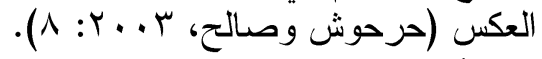

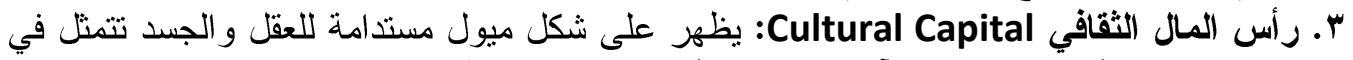

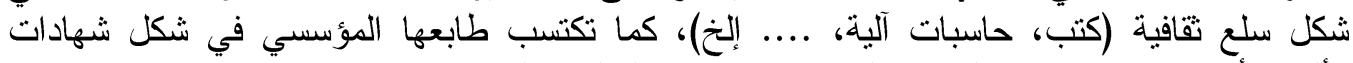

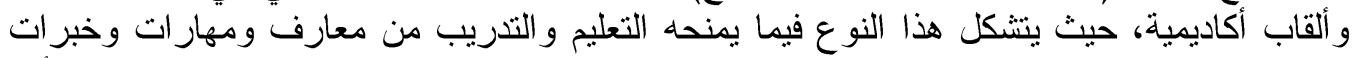

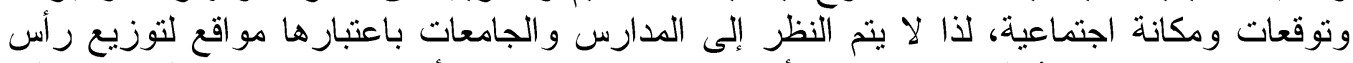

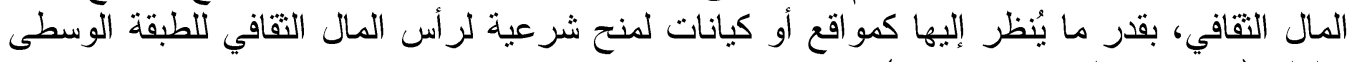

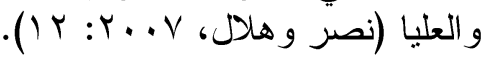

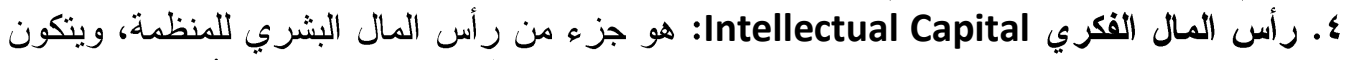

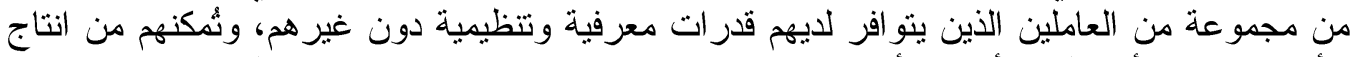

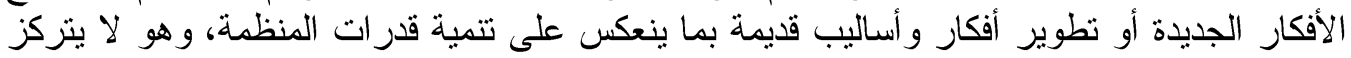

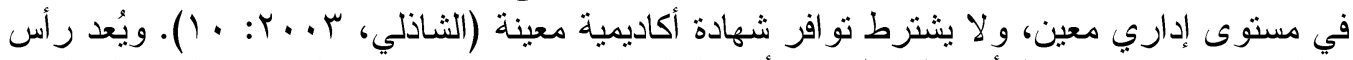

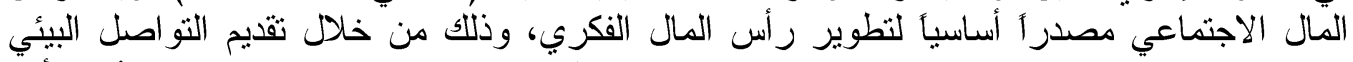

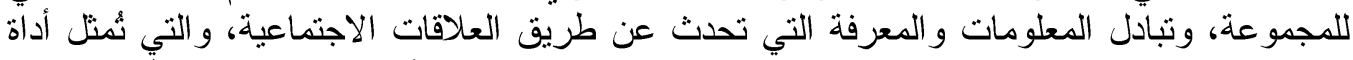

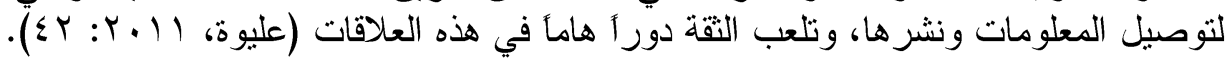

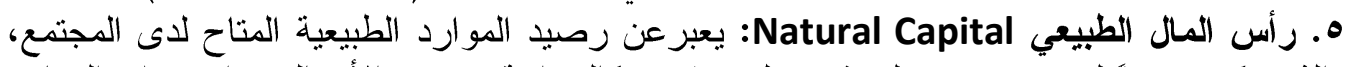

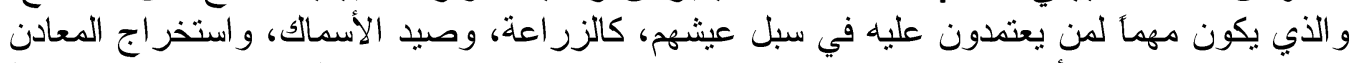

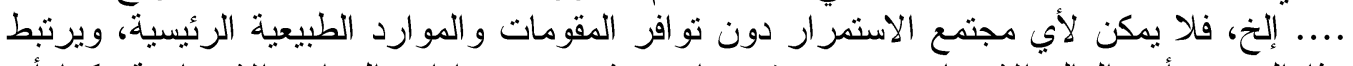

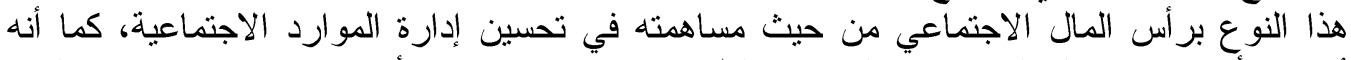

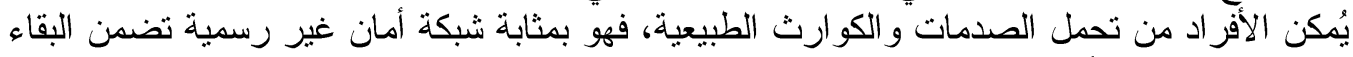

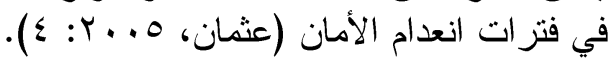

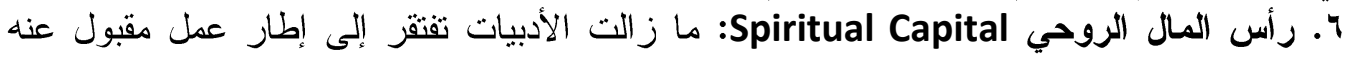

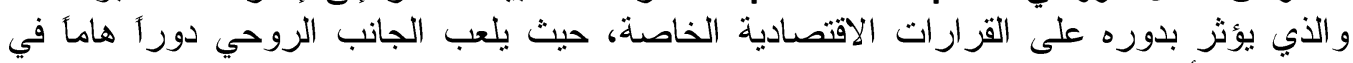

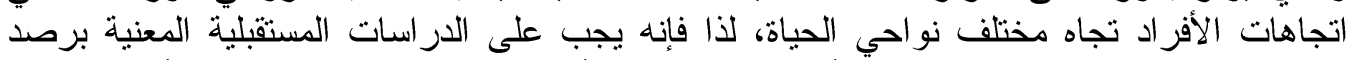

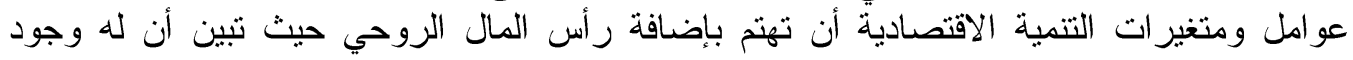
Fayoum J. Agric. Res. \& Dev., Vol. 33, No.2, July, 2019 
110

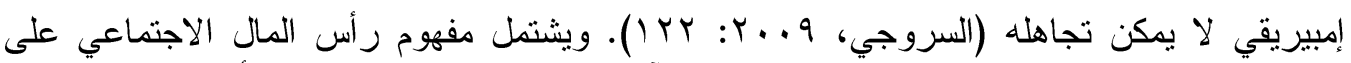

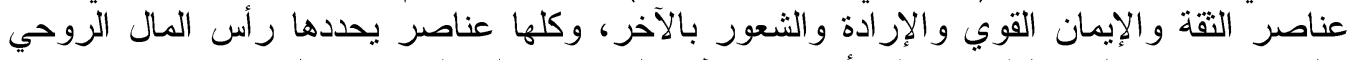
و الدين لاهتمامه بالمسئولية ورعاية الأفر اد في إطار المتغير ات الدئ الدينية، مما يجعل منه منبع رئيسي في والي

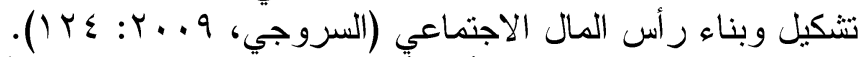

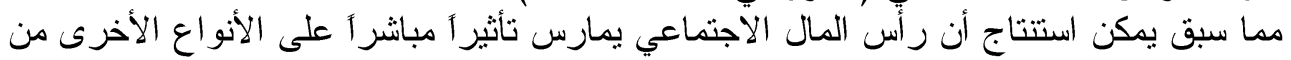

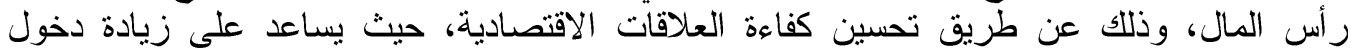

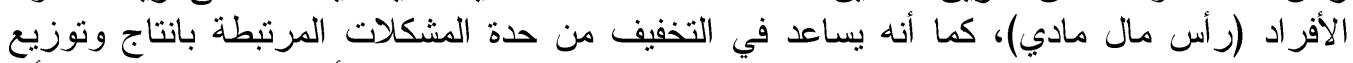

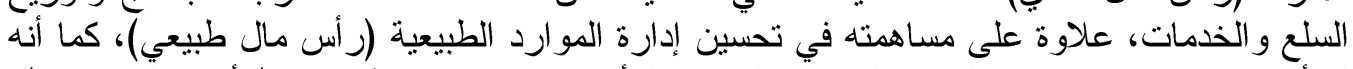

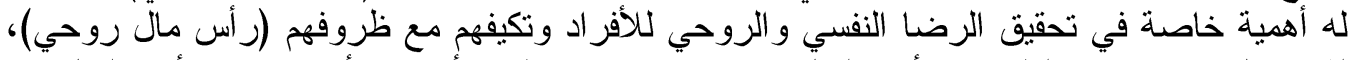

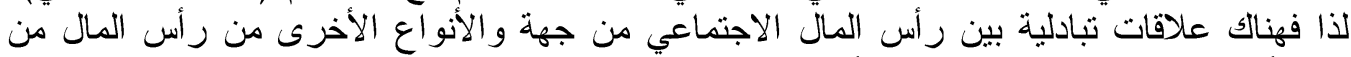

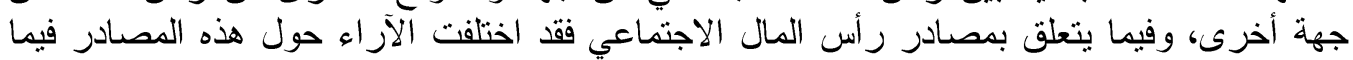

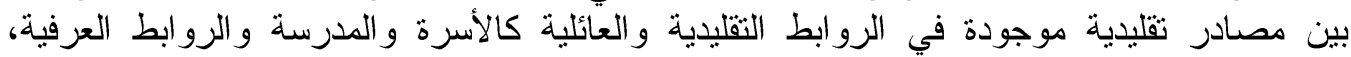

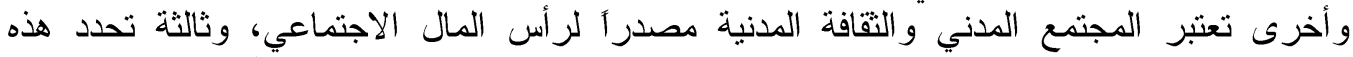

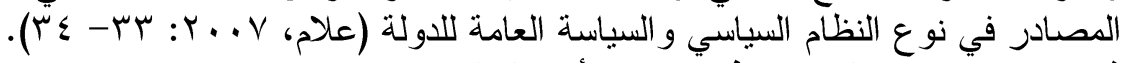

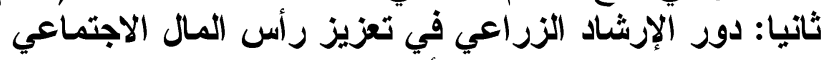

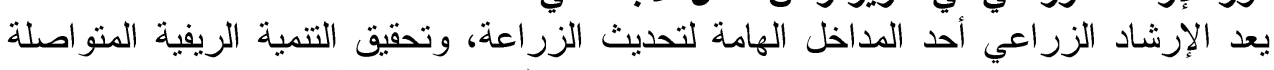

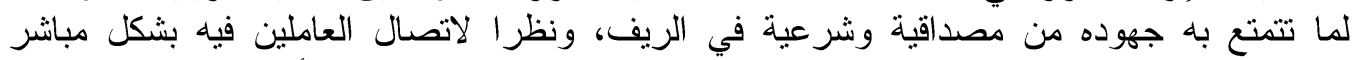

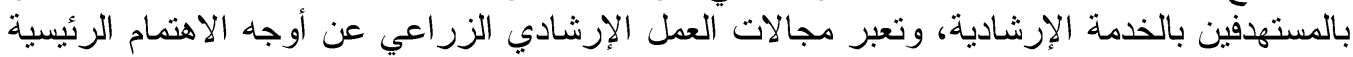

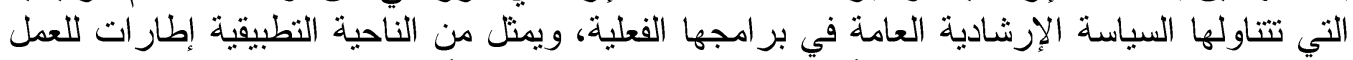

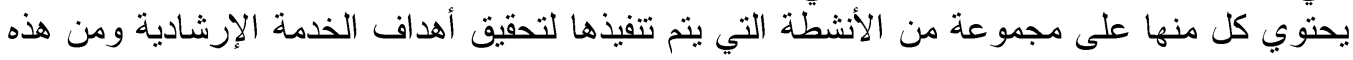

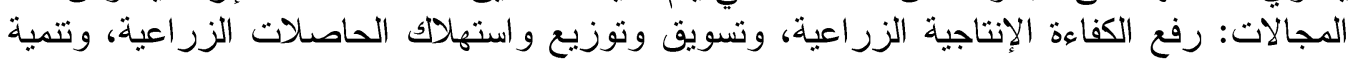

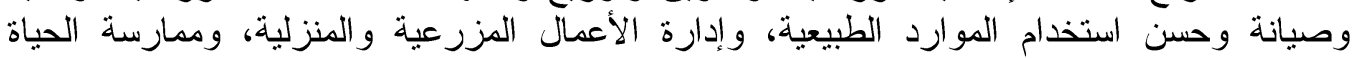

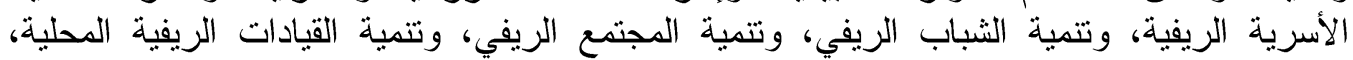

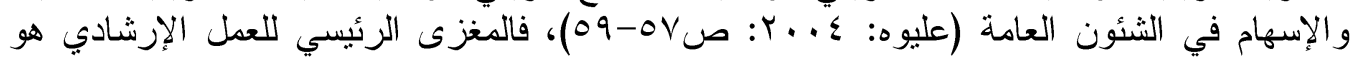

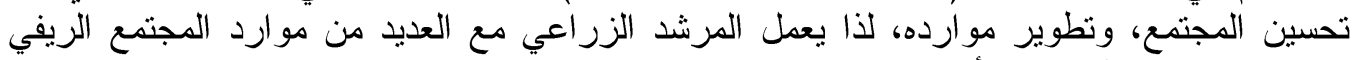

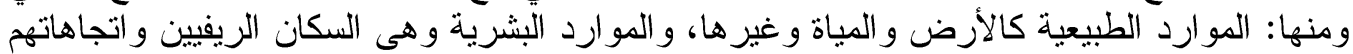

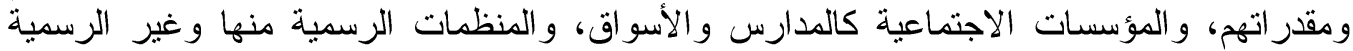

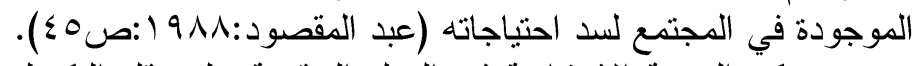

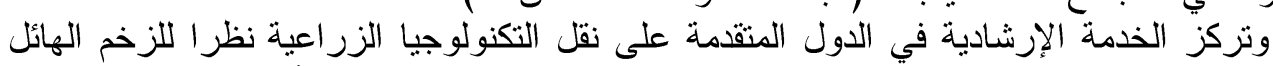
في التقنيات المنتجة، فضلا عن تطور المراكز البحثية وتتظيم نشاطها، و أيضا لتقدم مجتمعاتها

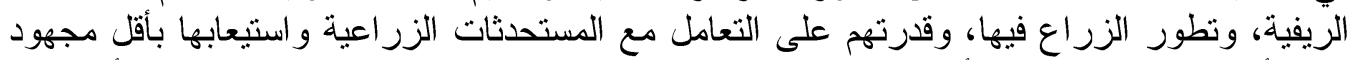

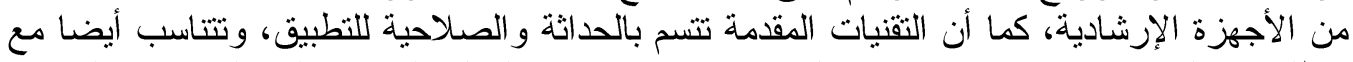

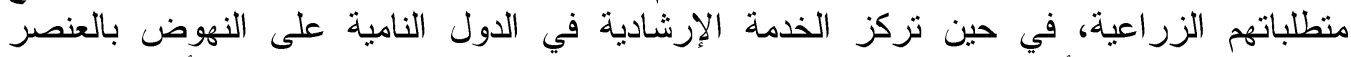

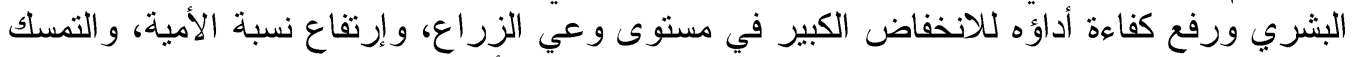

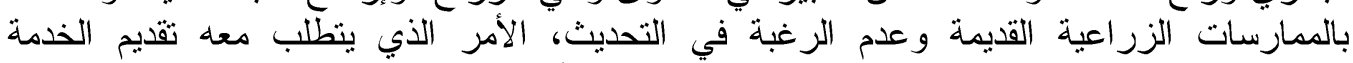

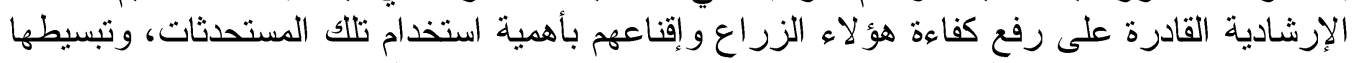

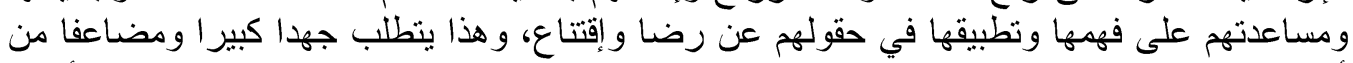

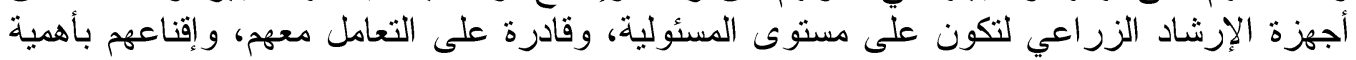

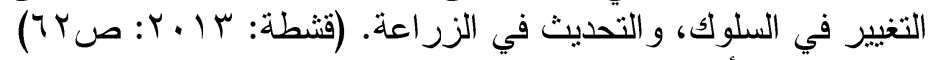

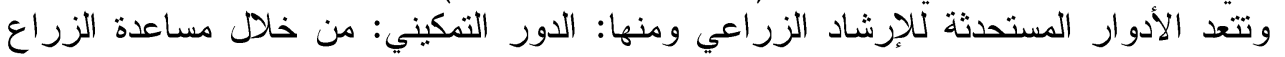

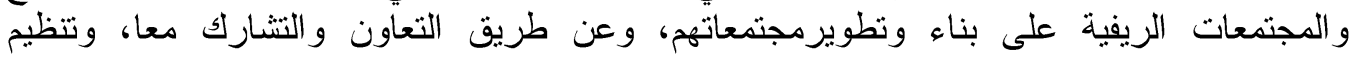

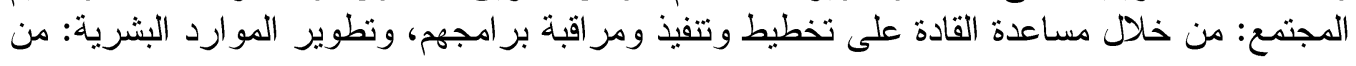

Fayoum J. Agric. Res. \& Dev., Vol. 33, No.2, July, 2019 
117

خلال تطوير مهارات الإدارة لدى الأفراد والجماعات لتتجيعها على فهم أساليب إدارة نفسها،

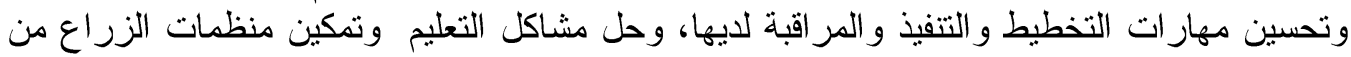

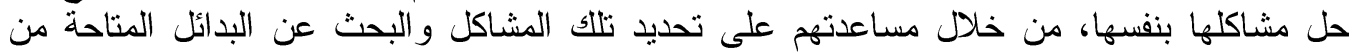

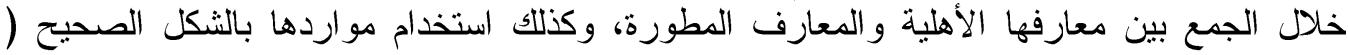

.(Swanson\& et al :1997

ثالثا: الار اسات السابقة

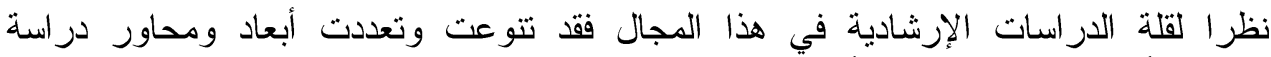

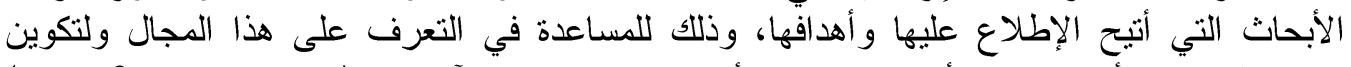

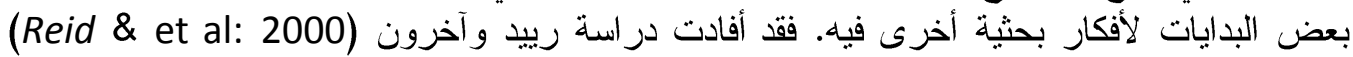

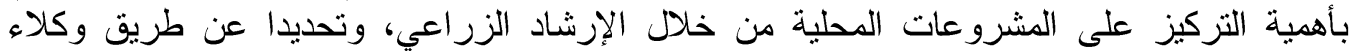

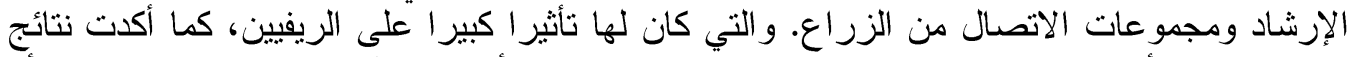

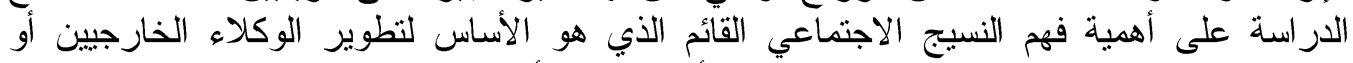

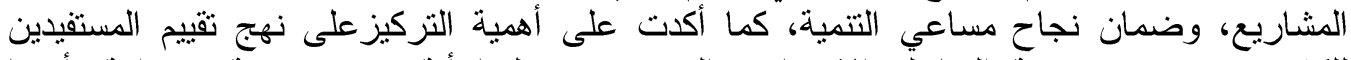

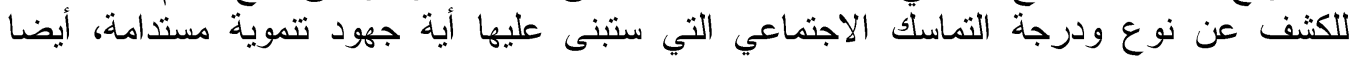

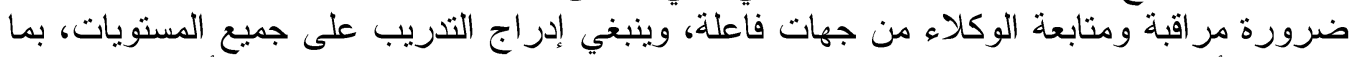

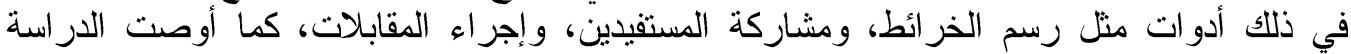

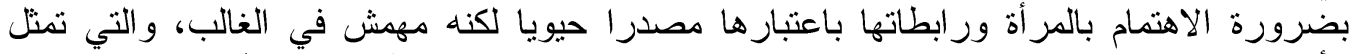

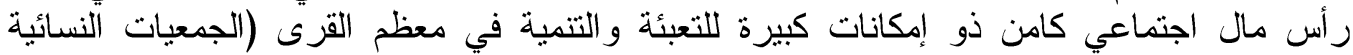

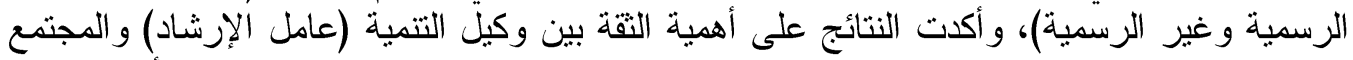

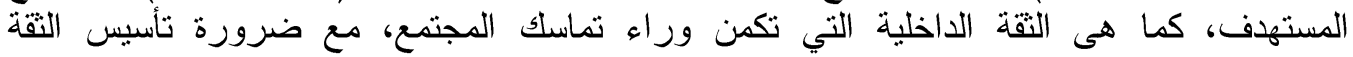

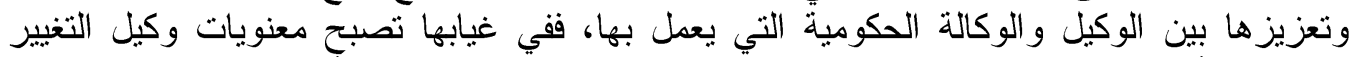

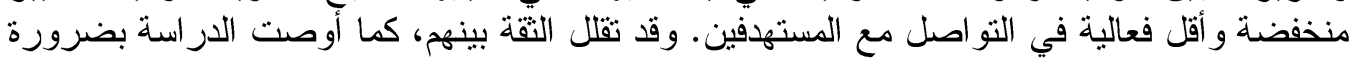

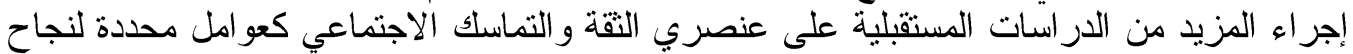
أنشطة الإرشاد الزر اعي و التنمية الريفية.

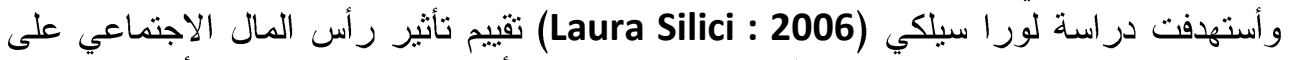

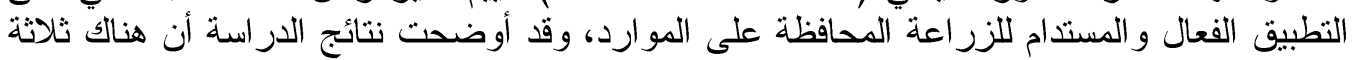

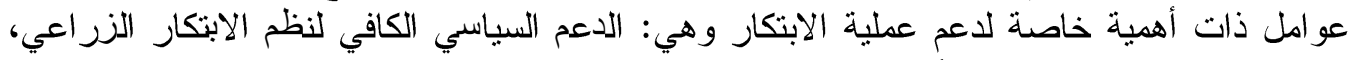

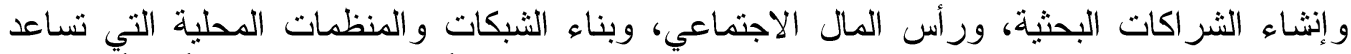

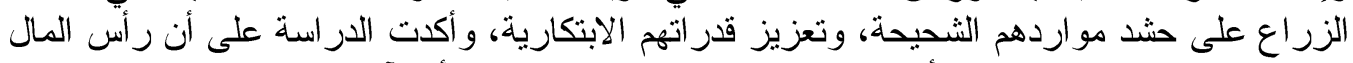

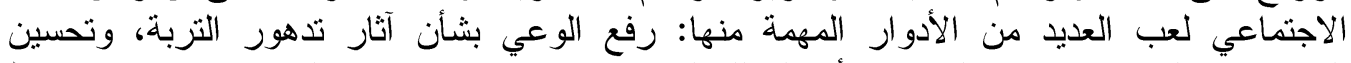

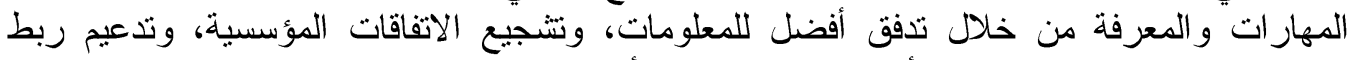

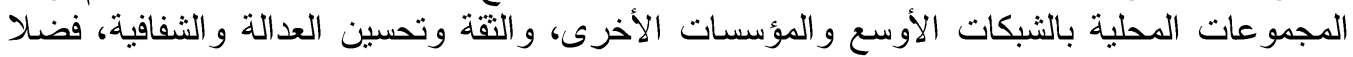

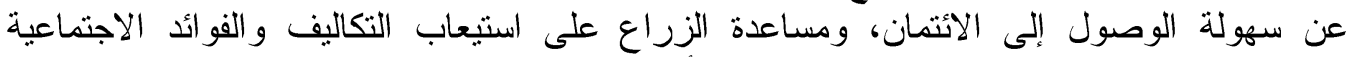

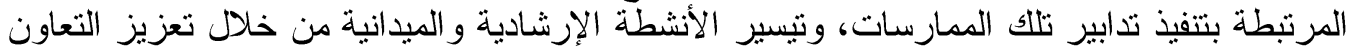

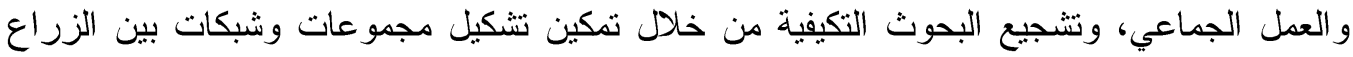

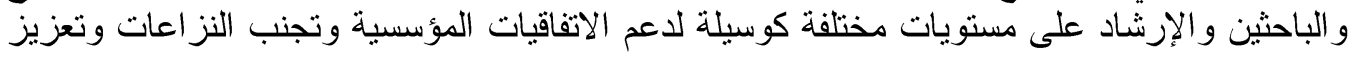

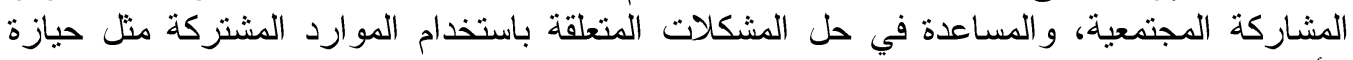

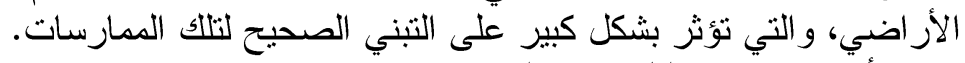

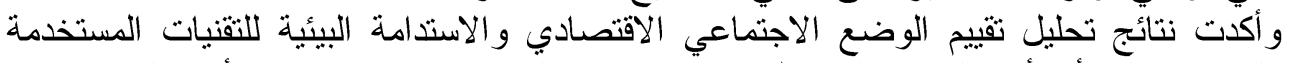

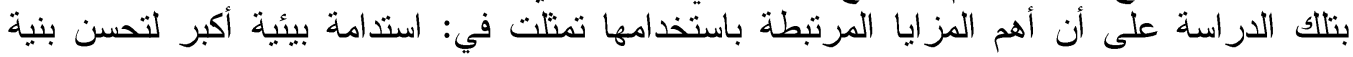

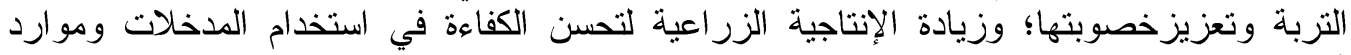
آخرى؛ وزيادة الاستدامة الاجتماعية بسبب إمكانية وصول الجميع إلى التّكنولوجيا، بما في ذللك الفئات

Fayoum J. Agric. Res. \& Dev., Vol. 33, No.2, July, 2019 
$11 \mathrm{~V}$

الأكثر ضعفا، وأظهرت النتائج أن كلا من أبعاد رأس المال الاجتماعي (الثبكة والثقة) مرتبطة

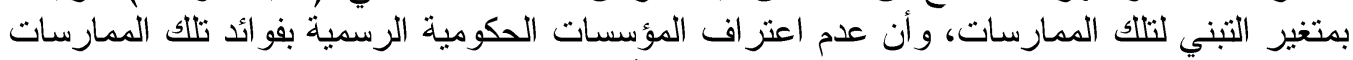

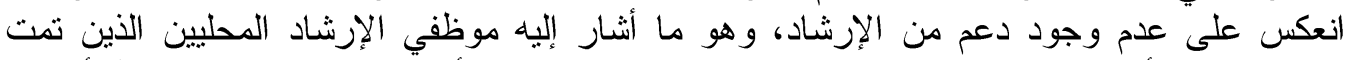

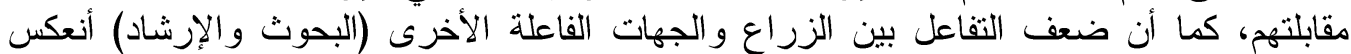

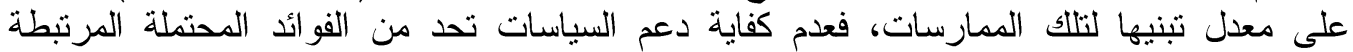

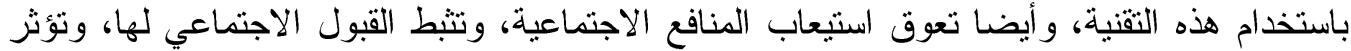

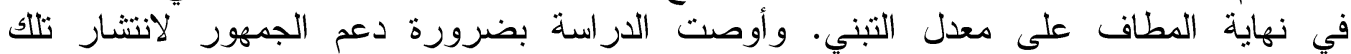

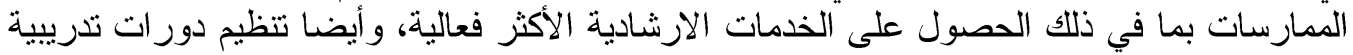

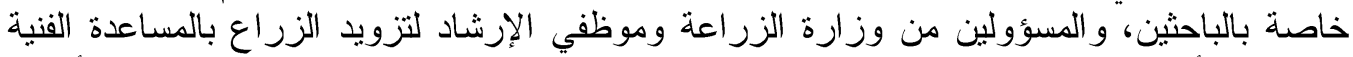

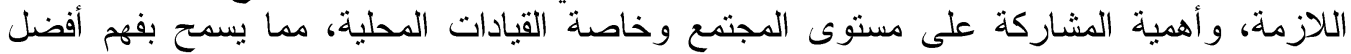

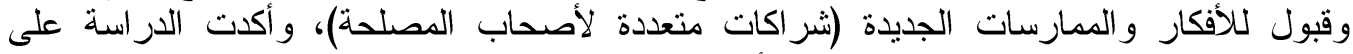

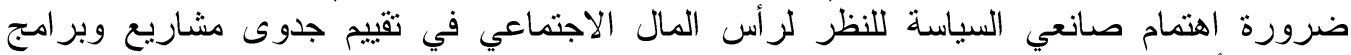

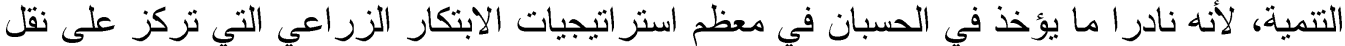

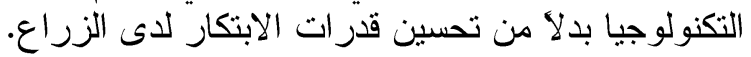

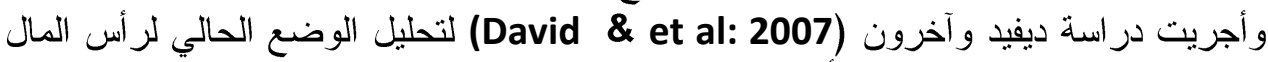

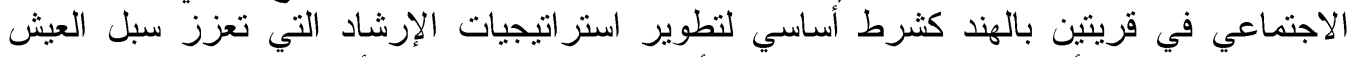

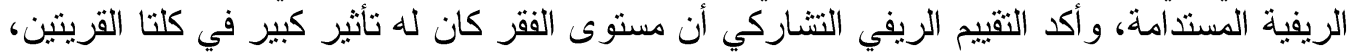

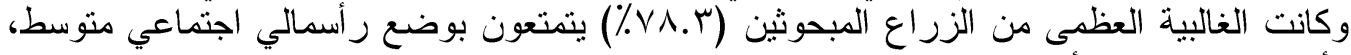

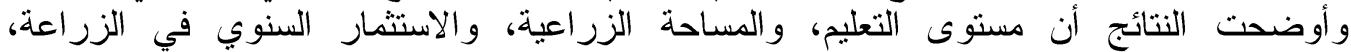

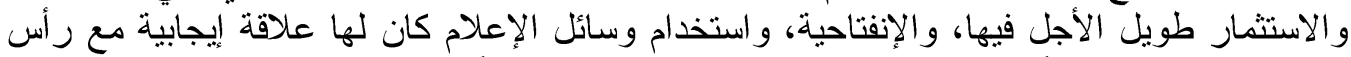

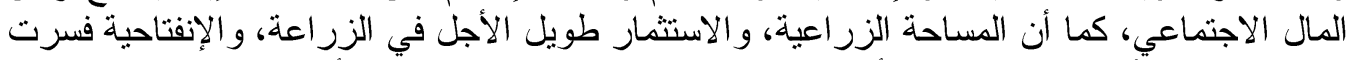

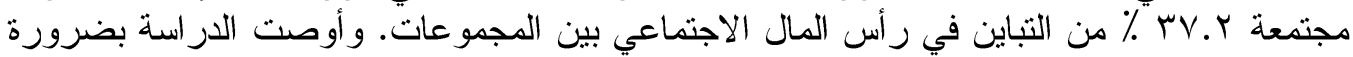

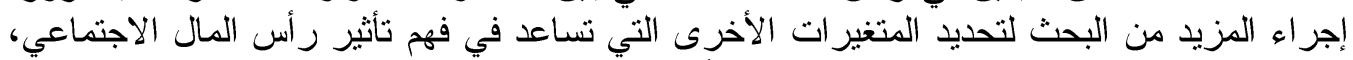

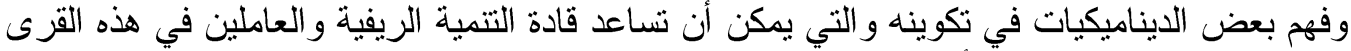
على تصميم مداخل إرشادية أفضل.

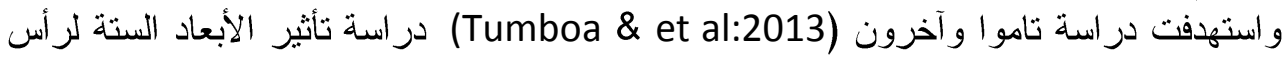

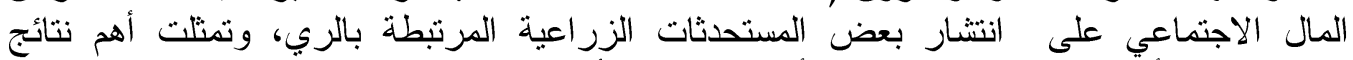

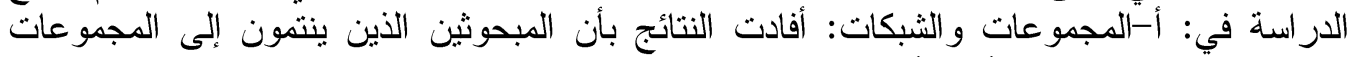
المشاركة في إدارة المياه أكثر أهمية في نشر وتبني الابتكارات، لمشاركتهم في قضايا إدارة الثيان المياه

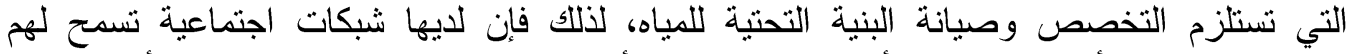

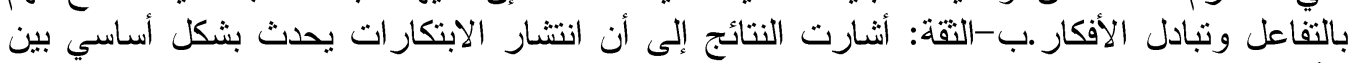

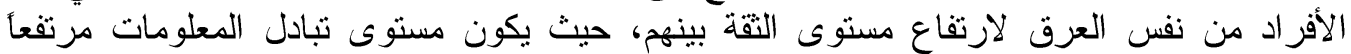

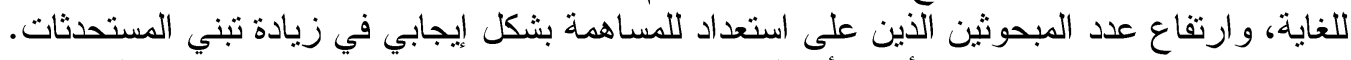

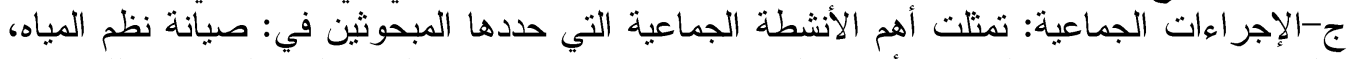

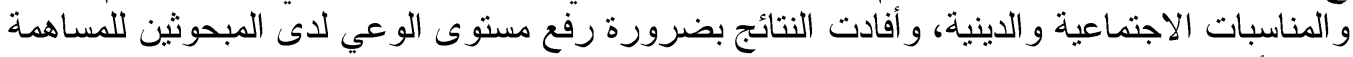

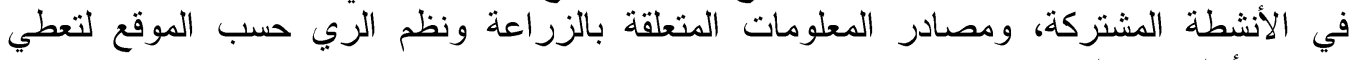

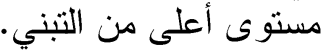
د-مسارات المعلومات والاتصالات: كانت أكثر المصادر التي يلجأ إليها الزراع الاع المبحوثين منمثلة في:

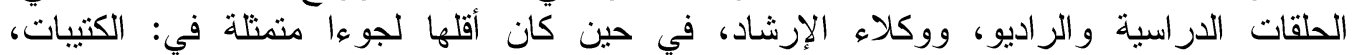

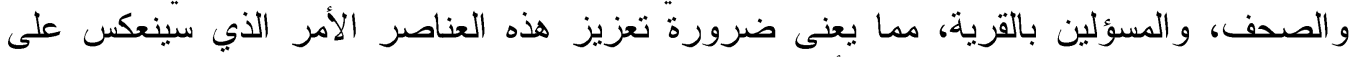

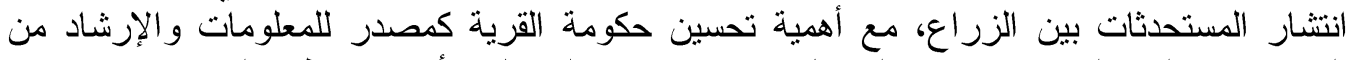
المزارعين إلى المزارعين.هـ-التماسك الاجتماعي و الثمول: أثنار معظم المبحوثين بإنغلاق

Fayoum J. Agric. Res. \& Dev., Vol. 33, No.2, July, 2019 
111

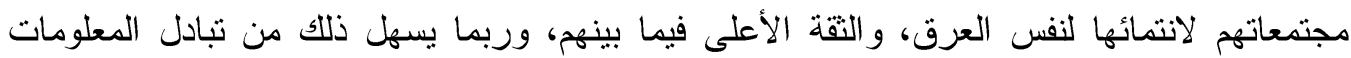

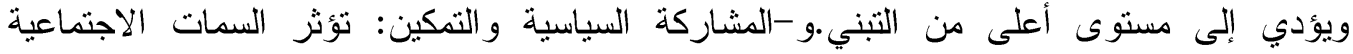

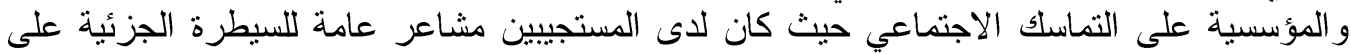

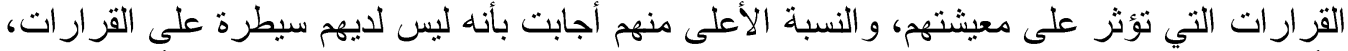

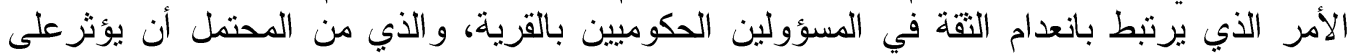

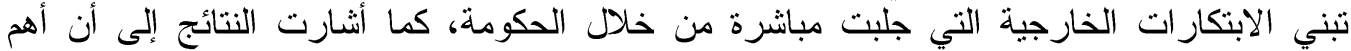

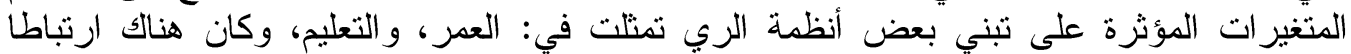

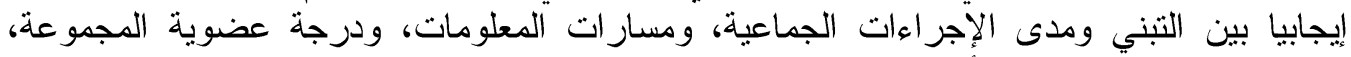

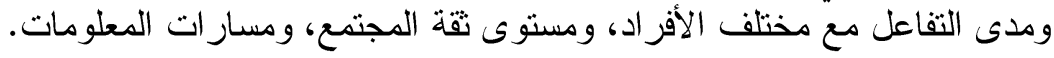

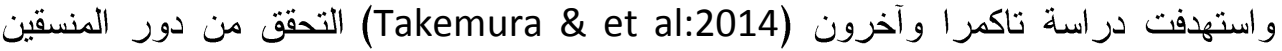

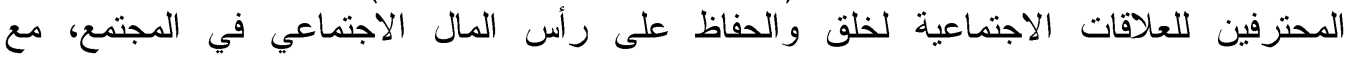

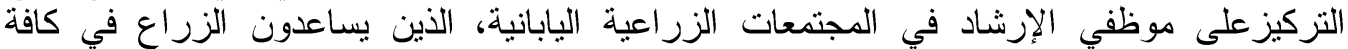

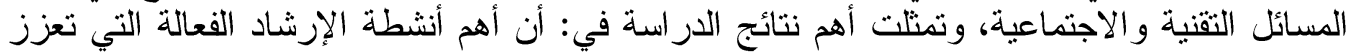

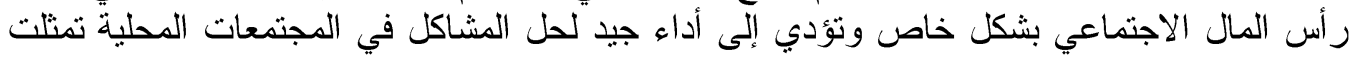

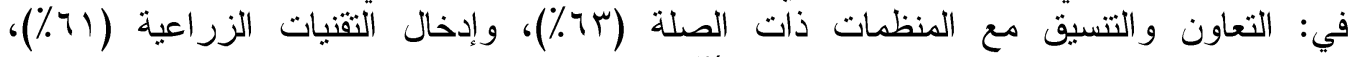

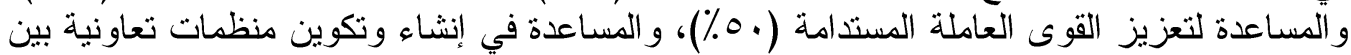

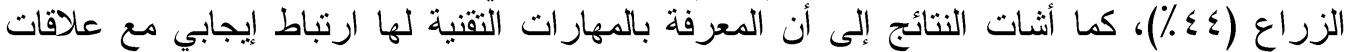

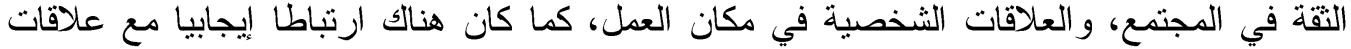

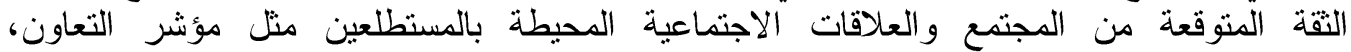

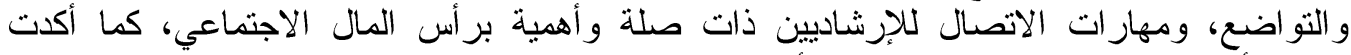

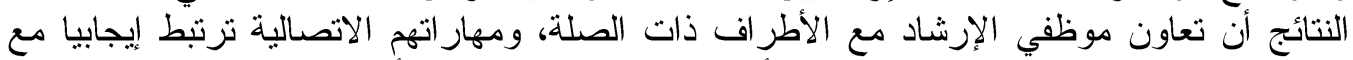

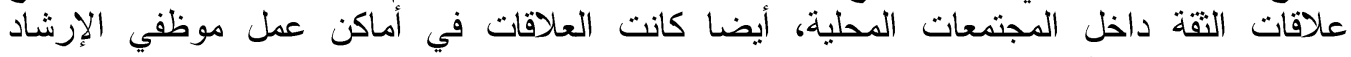

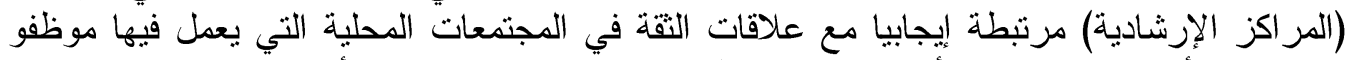

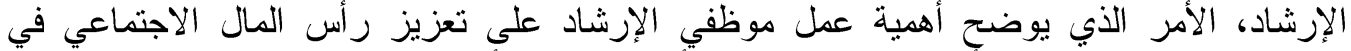

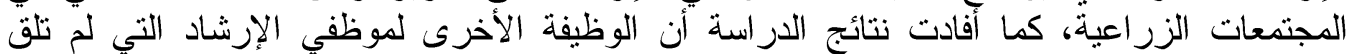

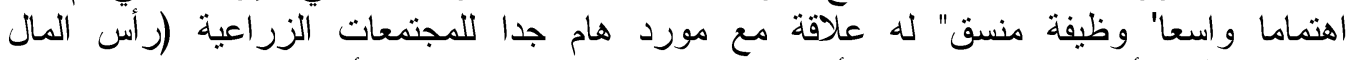

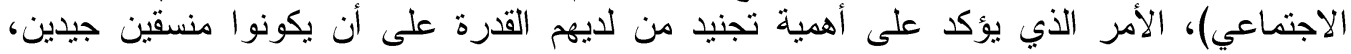

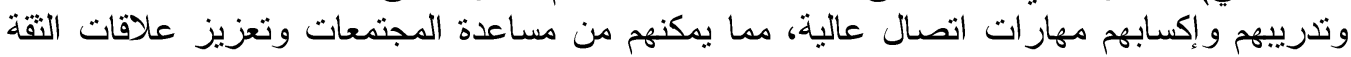

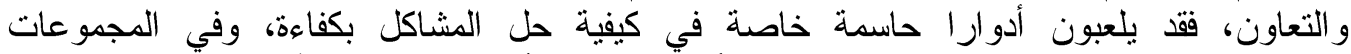

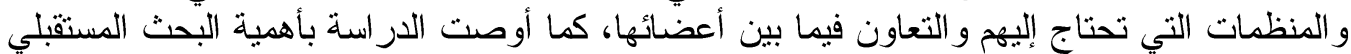

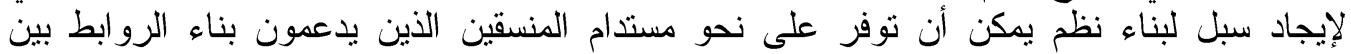
الناس. و استهدفت دراسة أليز اديه (Alizadeh:2014) تحديد العلاقة بين رأس المال الاجتماعي و أداء

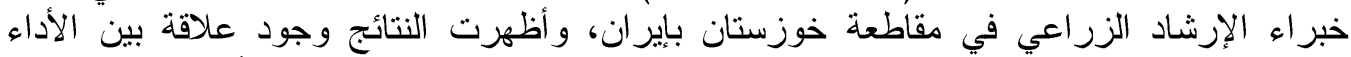

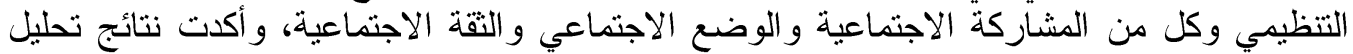

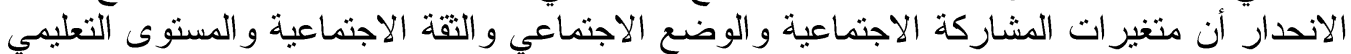

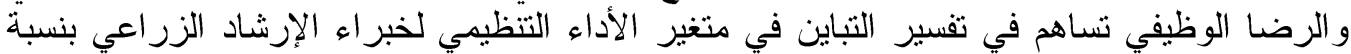

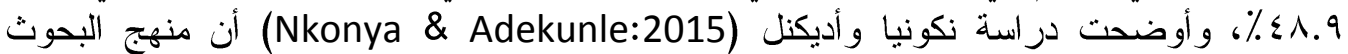

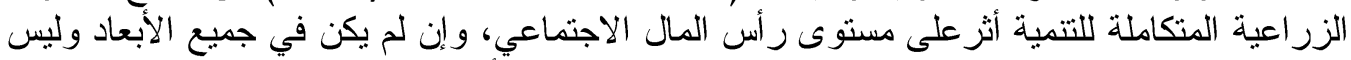

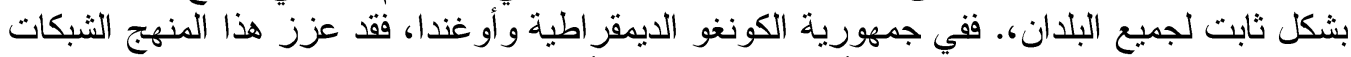

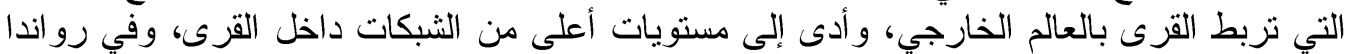

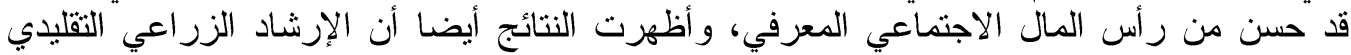

Fayoum J. Agric. Res. \& Dev., Vol. 33, No.2, July, 2019 
119

كان أقل نجاحا من منهج البحوث الزر اعية المتكاملة للتتمية، وأشارت الدراسة إلى أن عدم التجانس

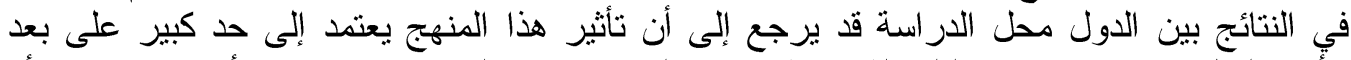

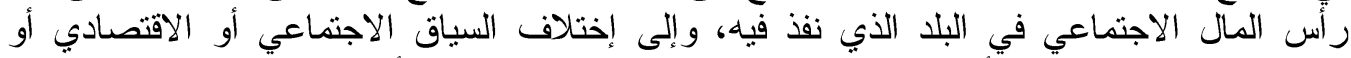

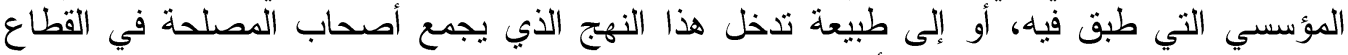

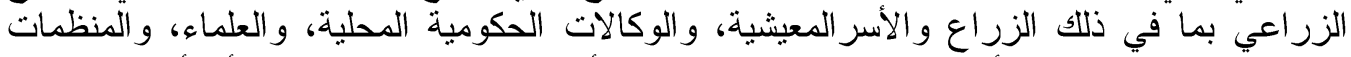

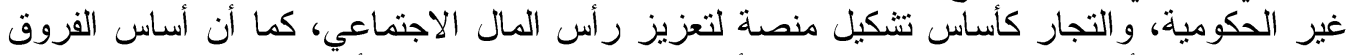

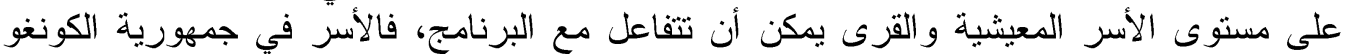

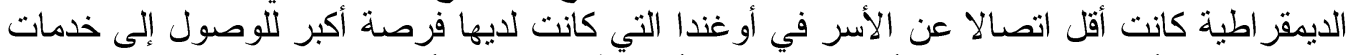

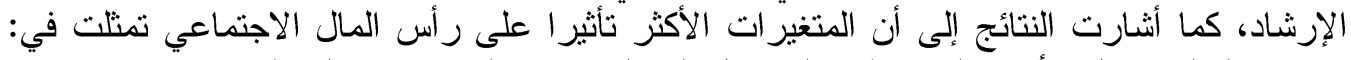
مستوى التعليم داخل الأسرة المعيشية، و الوصول الإنى إلى المدارس على الإنى مستوى القرية.

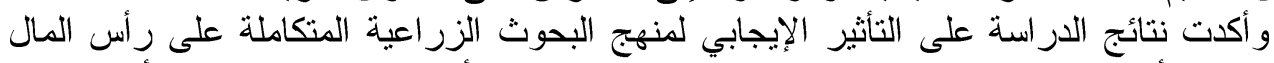
الاجتماعي، وأن العديد من خدمات الإرشاد الزراعي التقليدي في أفريقيا لا تز ال تفترض اعن أن أن البحوث و نقل وتبني التكنولوجيا هي أنشطة مستقلة. على ألرغم من أن الإرشاد عملية ترابط بين الإن الجهات

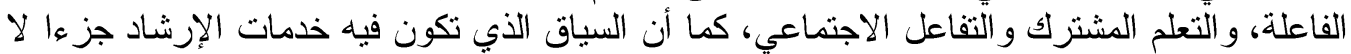

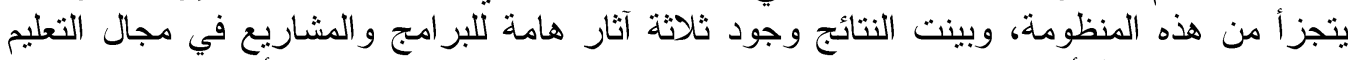

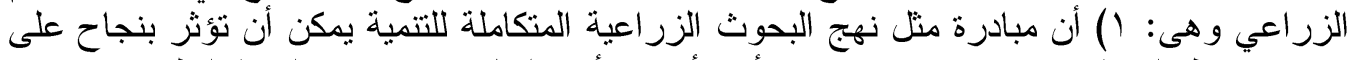

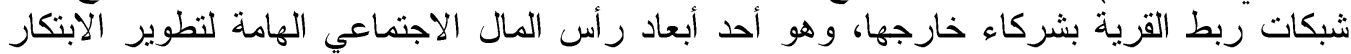

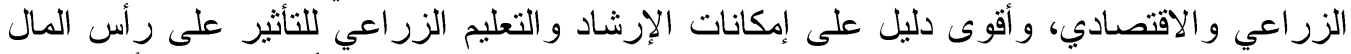

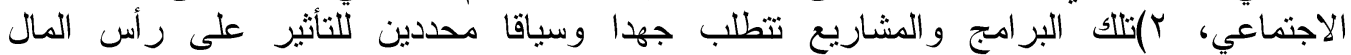
الاجتماعي، ب) يجب على المنظمات أن تدرك أن مثل هذه المبادرة قد لا تكون ناجحة في التأثير على

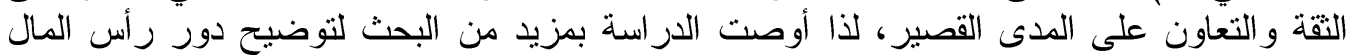

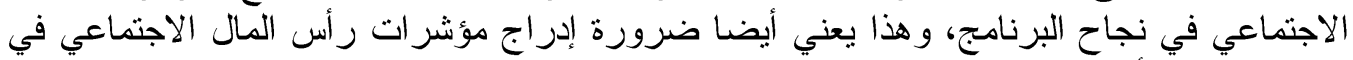

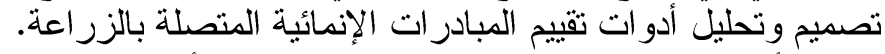

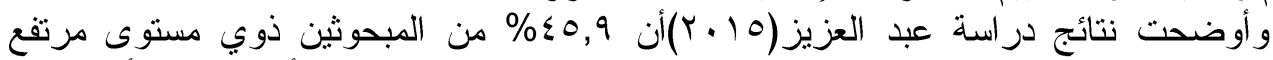

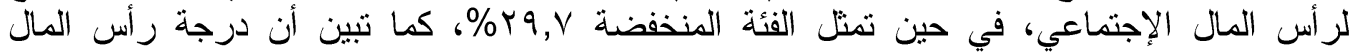

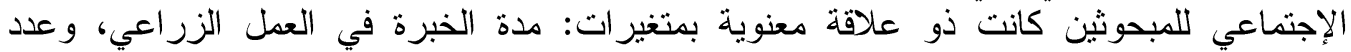

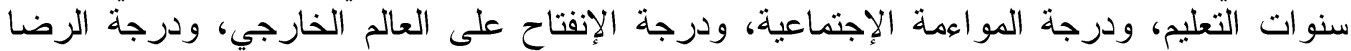

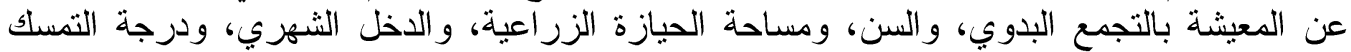
بالعادات و التقاليد البدوية، ودرجة الطموح الإتصادي، في حين كانت العلاقة غير فير معنوية بمتغير

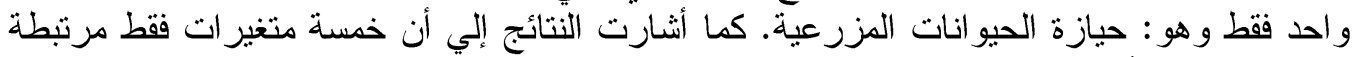

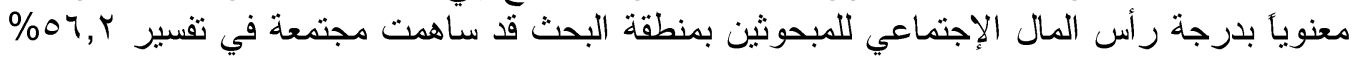

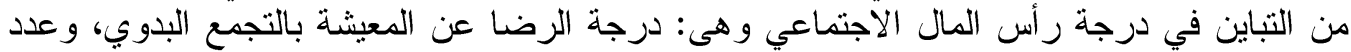

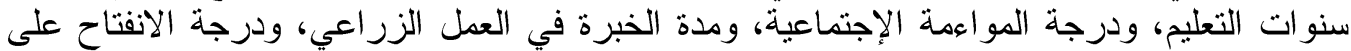

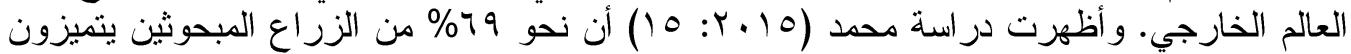

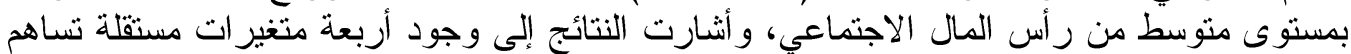

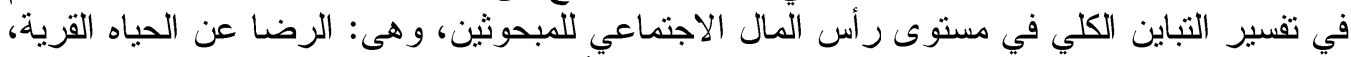
و المهنة الرئيسية، وعدد سنوات التعليم الرسمي، وحجم الأسرة.

وبينت در اسة أرلتي وآخرون ( Arlette \& et al: 2016 أن اختلاف أشكال رأس المال

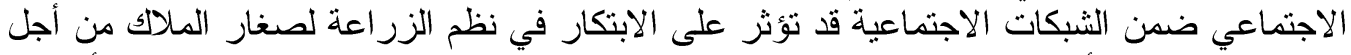
دعم الغذاء بشكل أفضل في منطقة البحر الكاريبي، وتم التزكيز على مجتمعين ريفيين، و أشارت

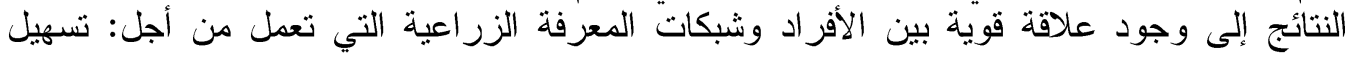

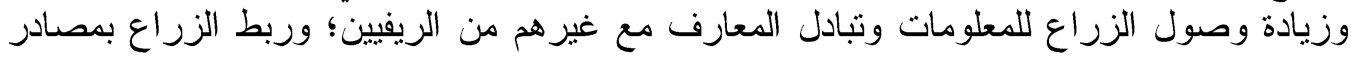

Fayoum J. Agric. Res. \& Dev., Vol. 33, No.2, July, 2019 
Ir.

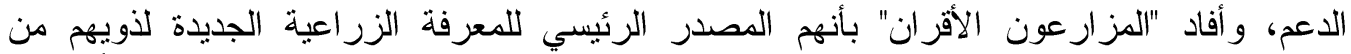

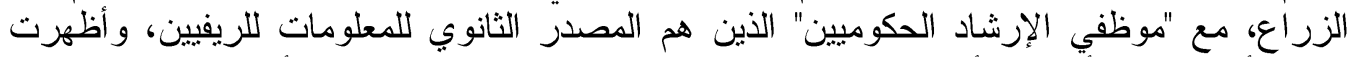

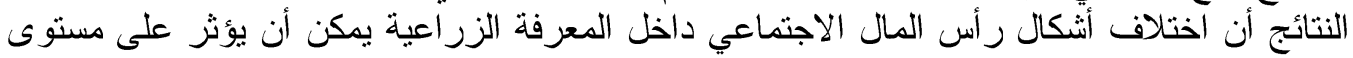

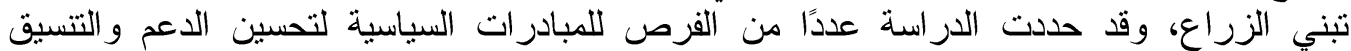
وتعزيز فرص الابتكار بين أصحاب الحياز ات الصغيرة بهدف زيادة تلكيفها وقدرتها على مواجهة

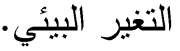

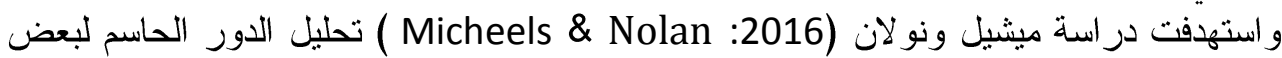

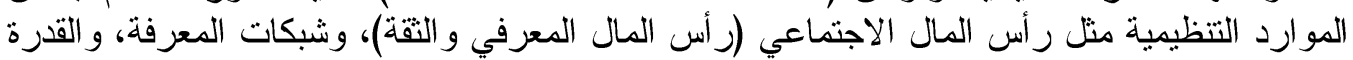

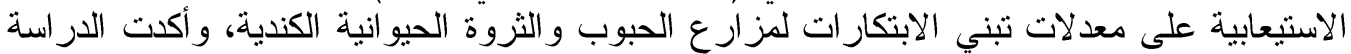

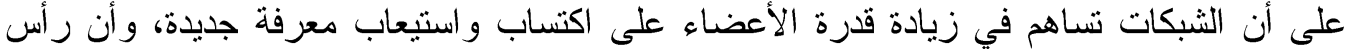

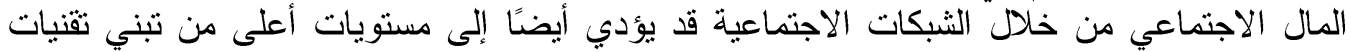

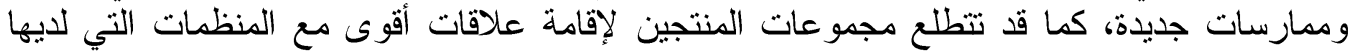

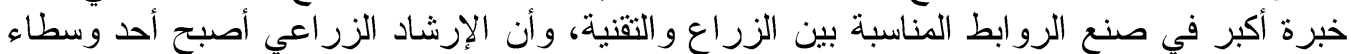

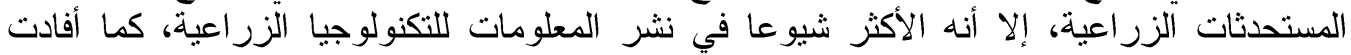

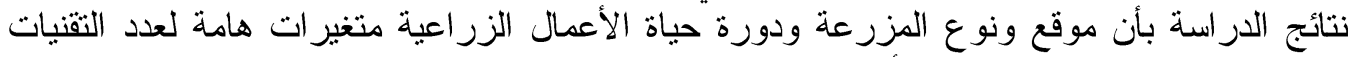

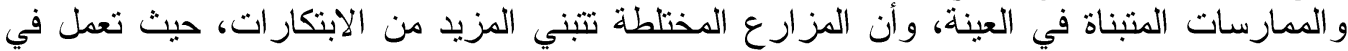

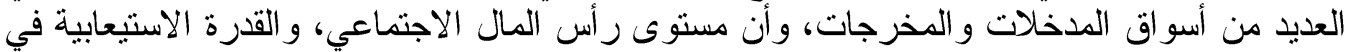

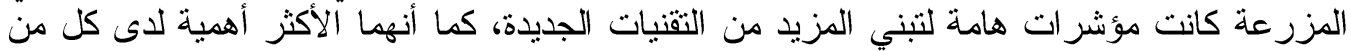

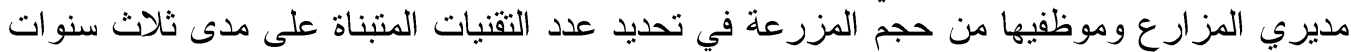

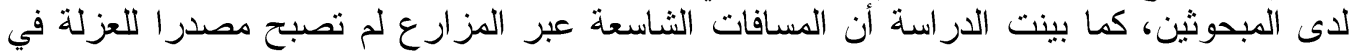

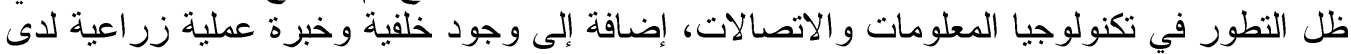

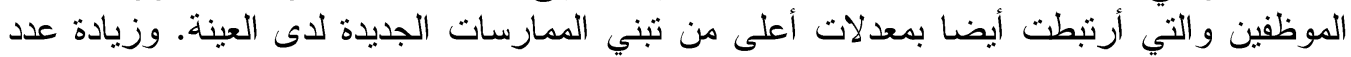

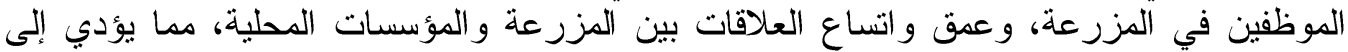

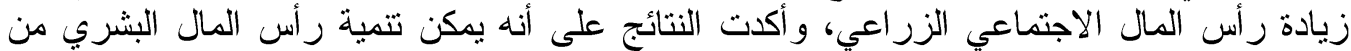

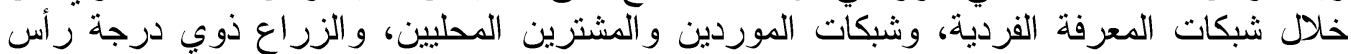

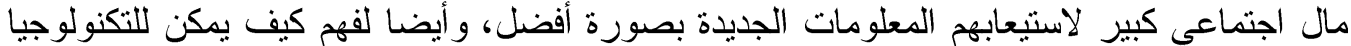

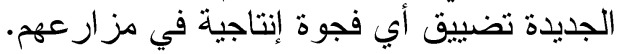

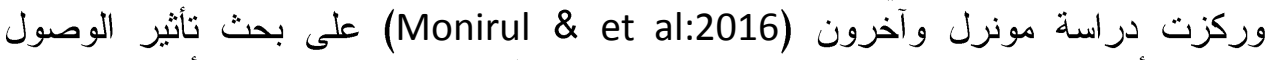

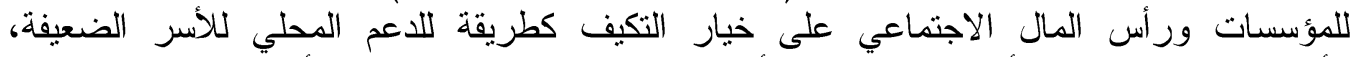

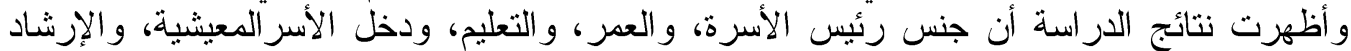

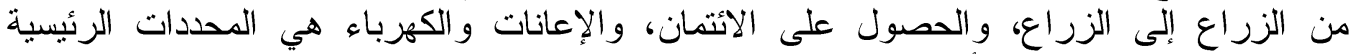

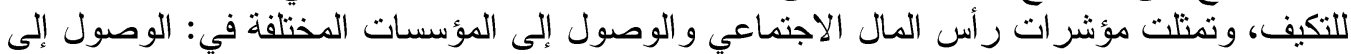

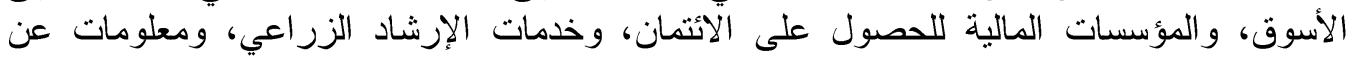

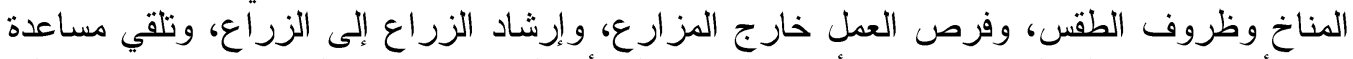

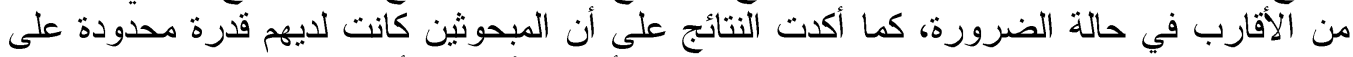

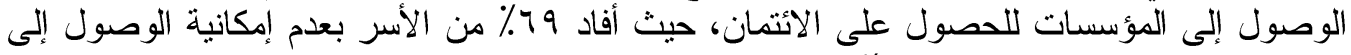

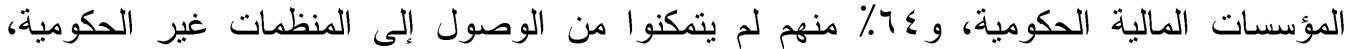

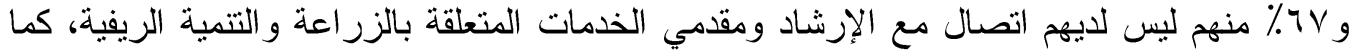

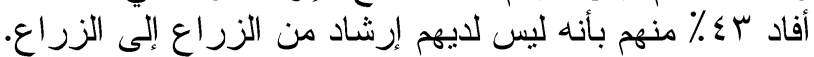

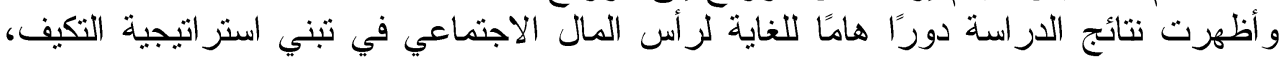

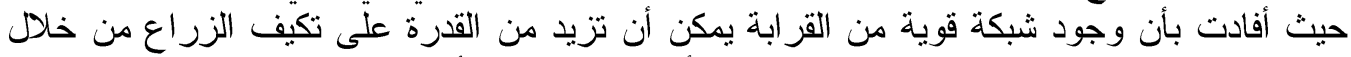

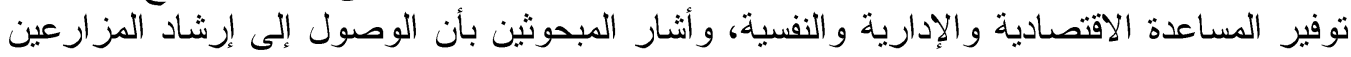

Fayoum J. Agric. Res. \& Dev., Vol. 33, No.2, July, 2019 


\section{$|r|$}

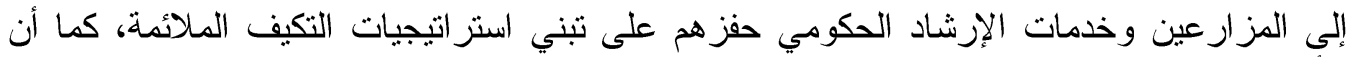

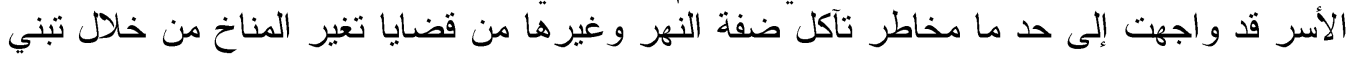

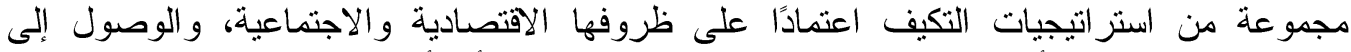

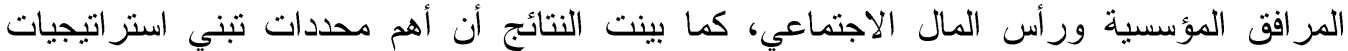

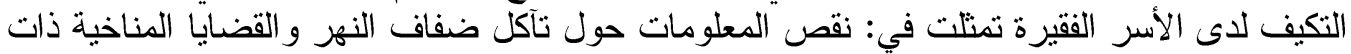

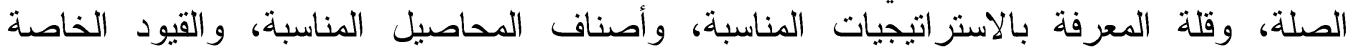

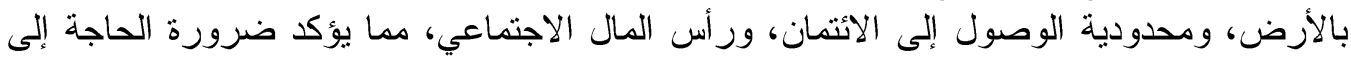

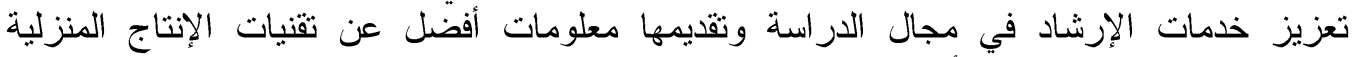

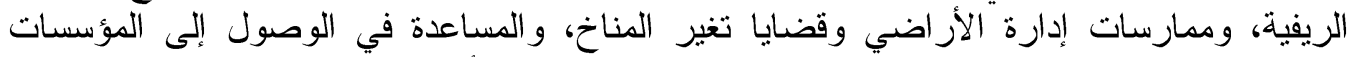

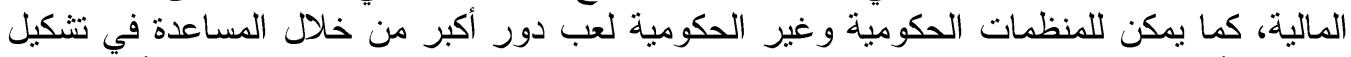

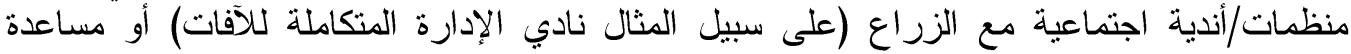
المزارع التعاونية في هذه الظروف النئة السيئة لاعتماد استر اتيجيات التكيف.

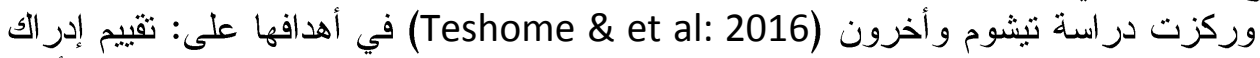

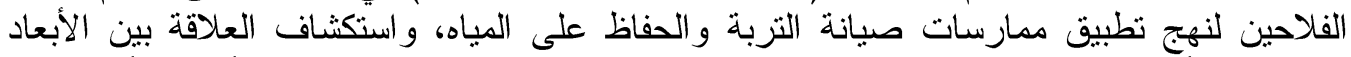

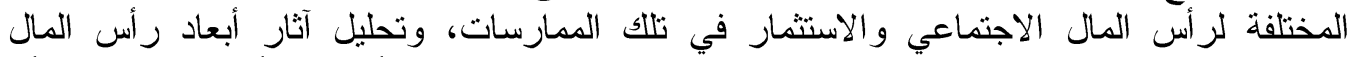

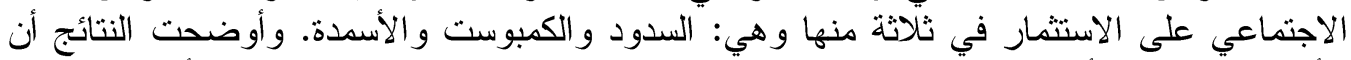

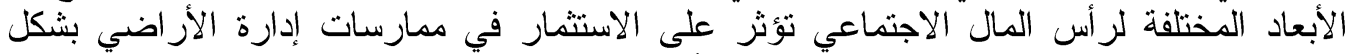

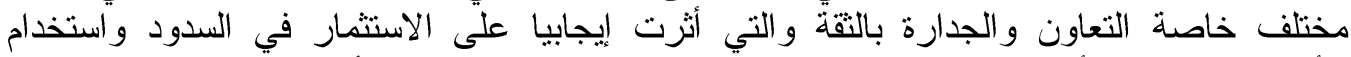

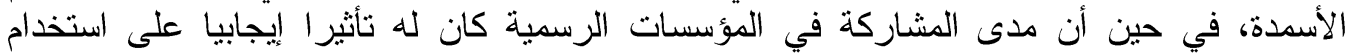

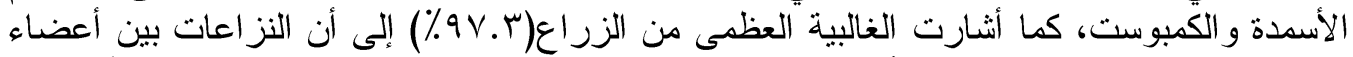

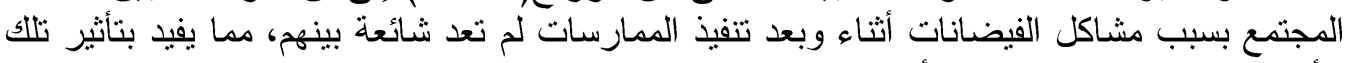

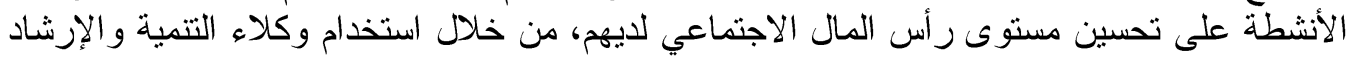

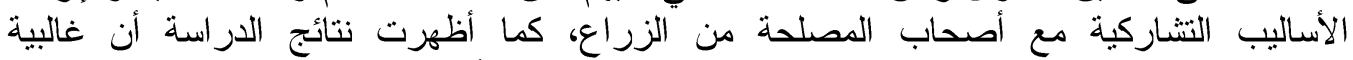

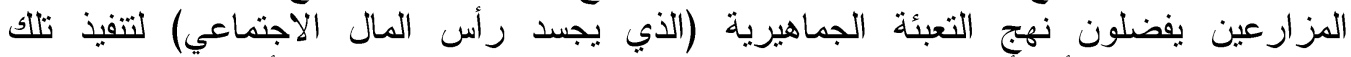

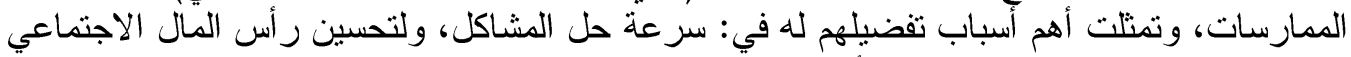

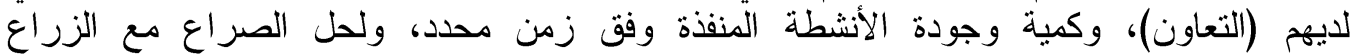

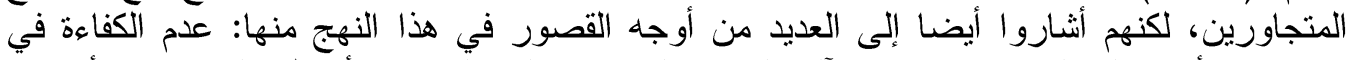

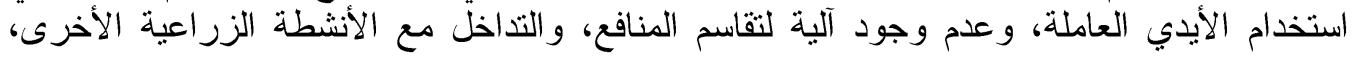

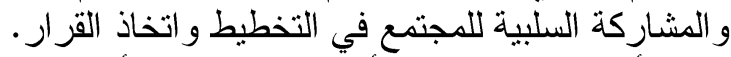

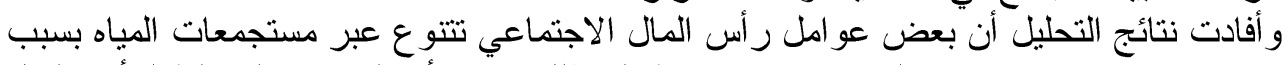

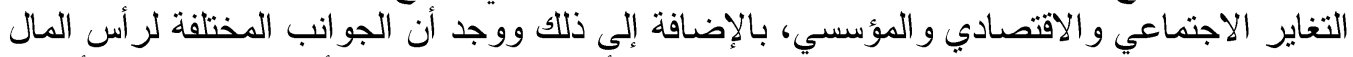

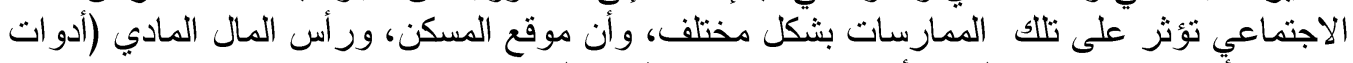

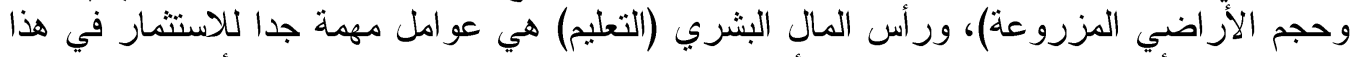

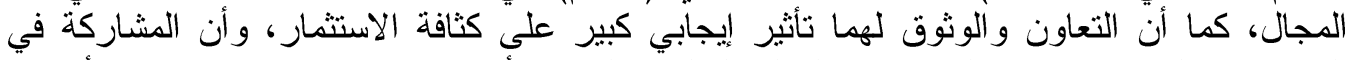

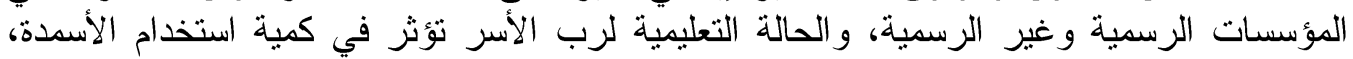

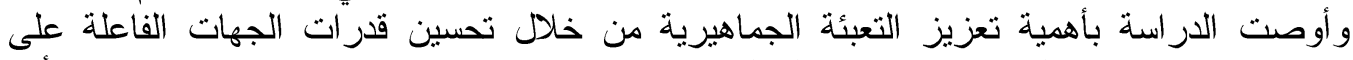

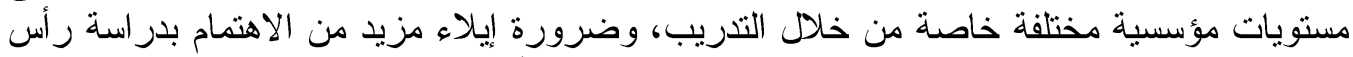

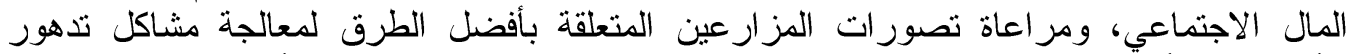

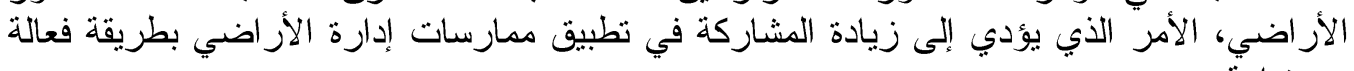

وأهتمت دراسة هنكيا وآخرون (Huneckea \& et al:2017 ) بدراسة تأثير رأس المال الاجتماعي على تبني تكنولوجيا الري بين منتجي النبيذ في وسط شيلي، وحددت الدراسة سبرة سبعة

Fayoum J. Agric. Res. \& Dev., Vol. 33, No.2, July, 2019 


\section{IrY}

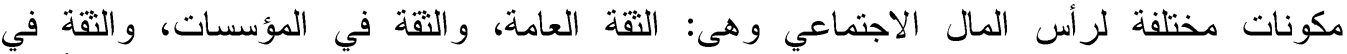

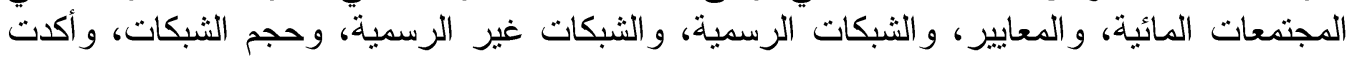

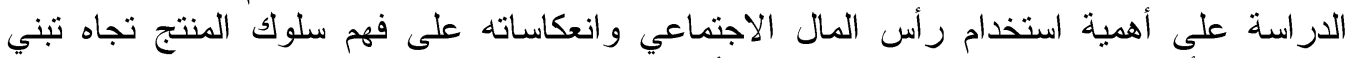

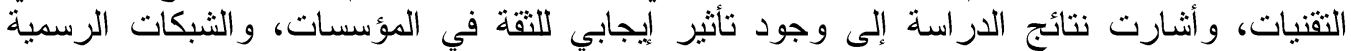

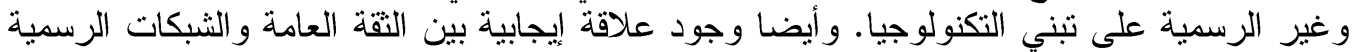

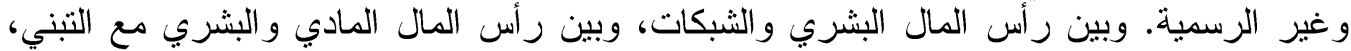

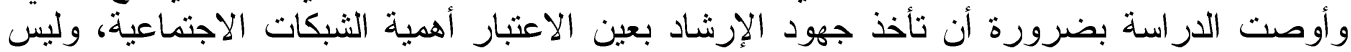

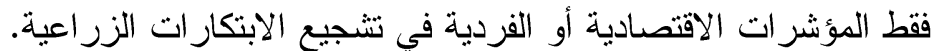

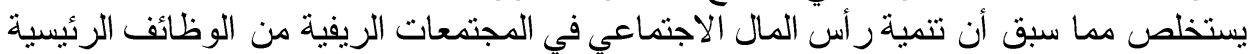

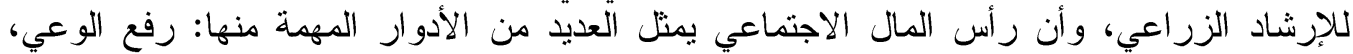

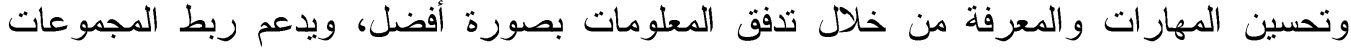

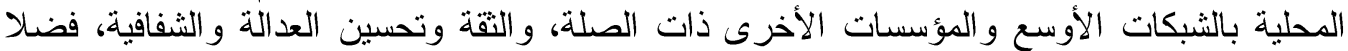
عن تيسير الأنشطة الإرشادية والميدانية من خلال تعزيز السلوكيات التعاونية كالمشاركة والعات العمل

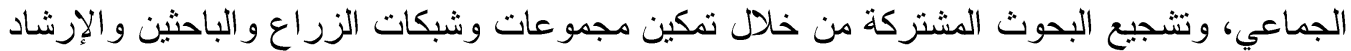

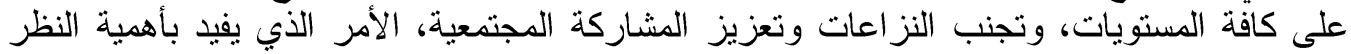

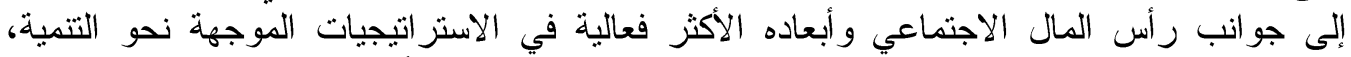

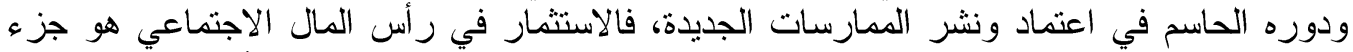

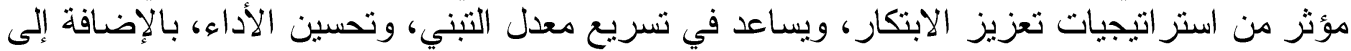

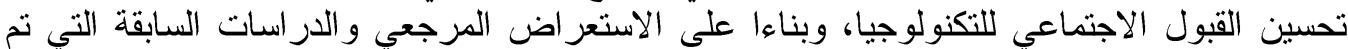

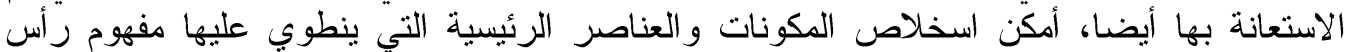

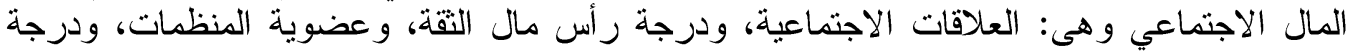
القيادية، ودرجةٌ المشاركة في المشروعات التماتهوية، ودرجة المشاركة الاجتماعية غير الرسمية،

ودرجة المشاركة السياسية. الأسلوب البحثي

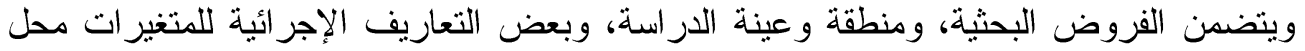

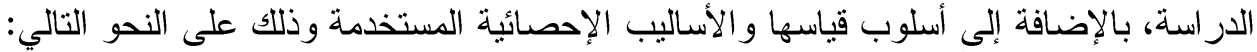
أولا: الفروض البحثية: -لا توجد فروقا معنوية في متوسطات درجة رأس الأس المال الاجتماعي الرئي الريفي

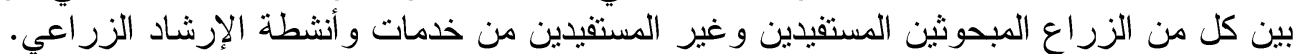

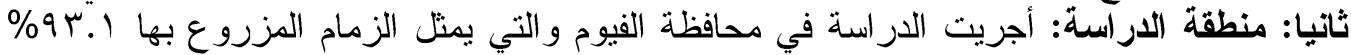

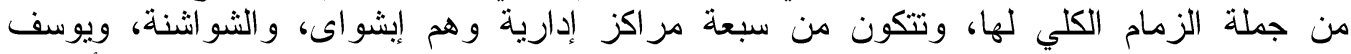

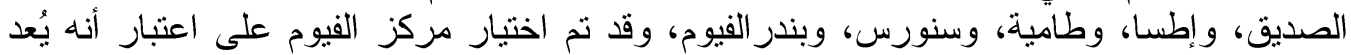

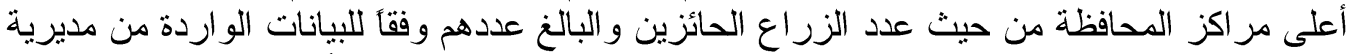

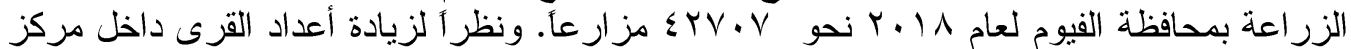

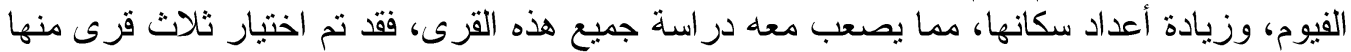

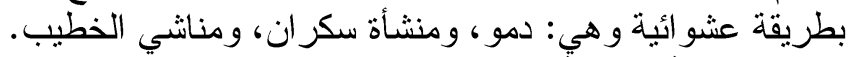

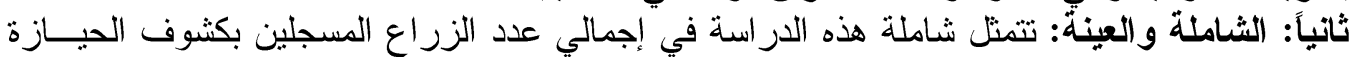

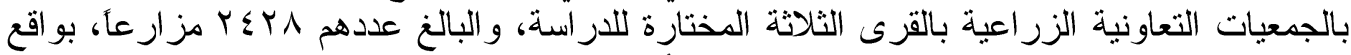

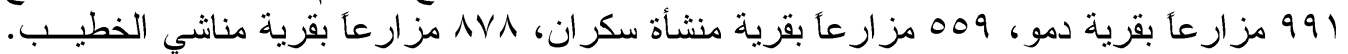

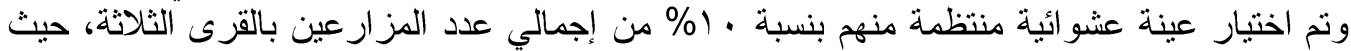

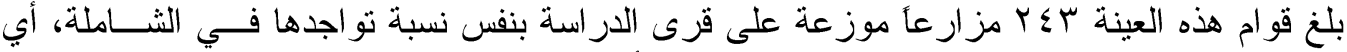

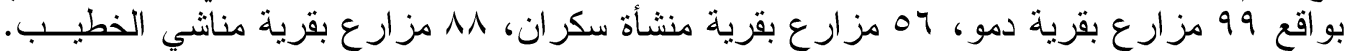
ويوضح جدول (1) حجم الثاملة وحجم العينة بالقرى الثثلاثة للار اسة.

Fayoum J. Agric. Res. \& Dev., Vol. 33, No.2, July, 2019 


\begin{tabular}{|c|c|c|c|}
\hline \multicolumn{4}{|c|}{ يول (1) حجم الشاملة وحجم العينة بقرى الارساسة } \\
\hline عدد الزراع بعينة الدراسة & عدد الزراع بشاملة الار سـة & 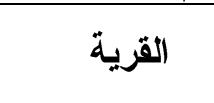 & \\
\hline 99 & 991 & دمو & أ. \\
\hline 07 & 009 & منشأة سكر ان & ب. \\
\hline$\wedge \wedge$ & $\wedge \vee \wedge$ & مناشي الخطيب & ج. \\
\hline$r \leq r$ & $r \leqslant Y \wedge$ & الإجمالي & \\
\hline
\end{tabular}

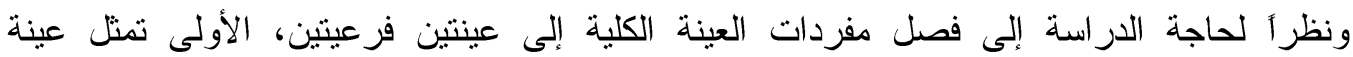

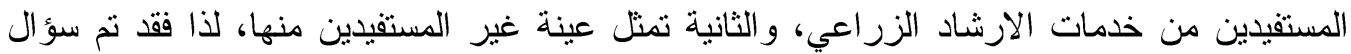

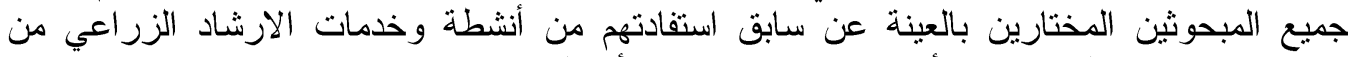

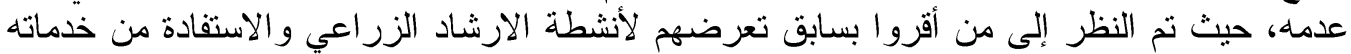

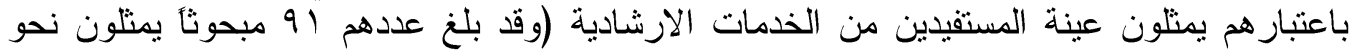

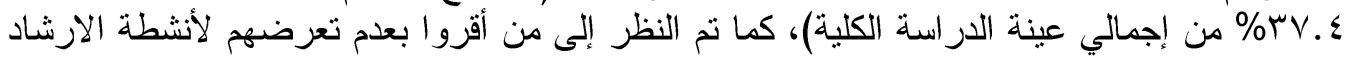

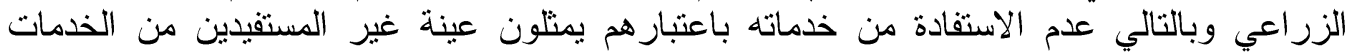

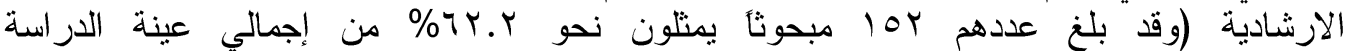

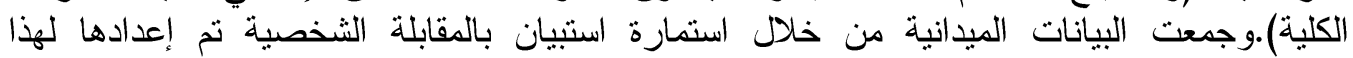

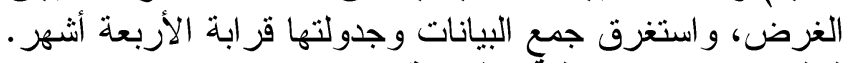

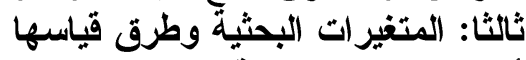

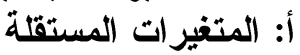

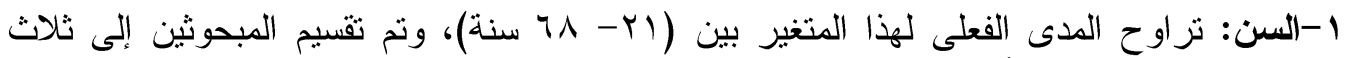

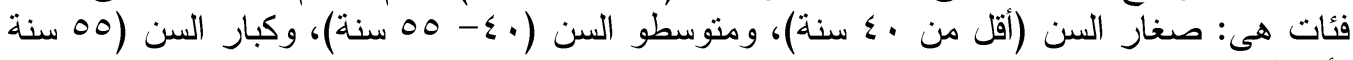

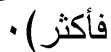
r-الحالة التعليمية للمبحوث: ويقصد به حالة المبحوث من حيث كونه أميا أو يقر أ ويكتب أو حاصل

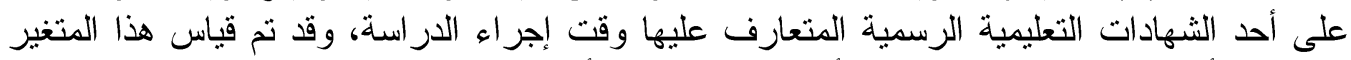

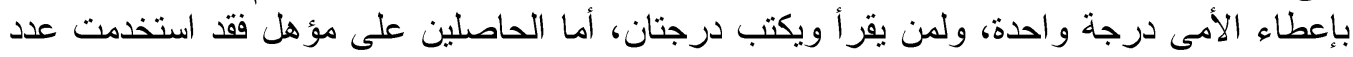

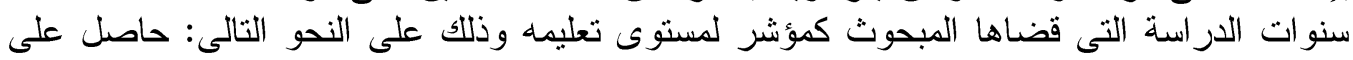

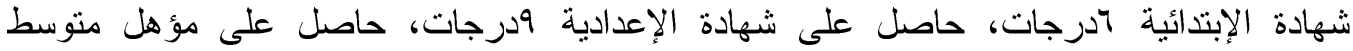

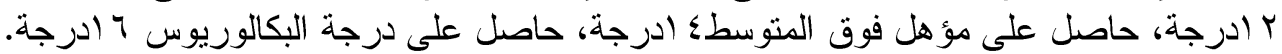

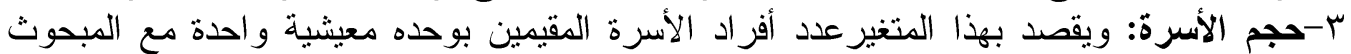

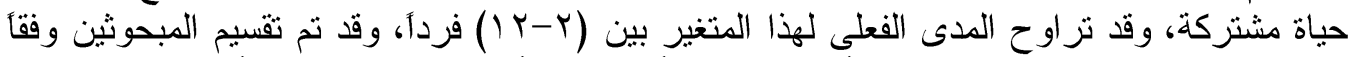

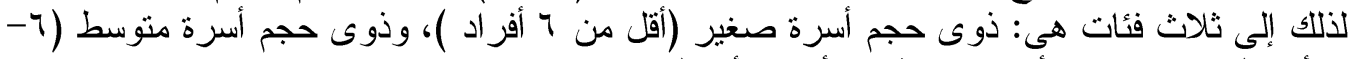

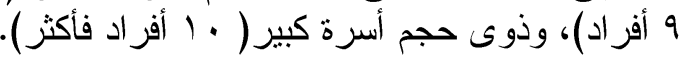

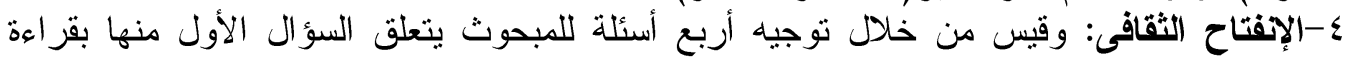

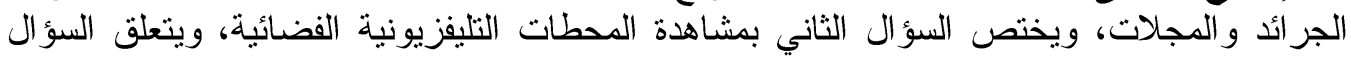

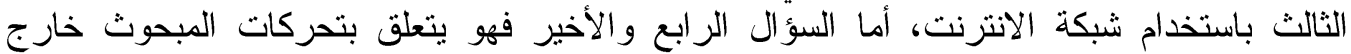

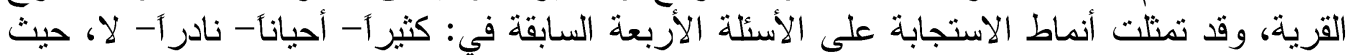

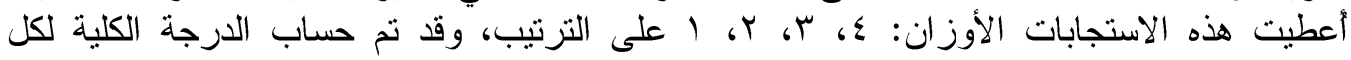

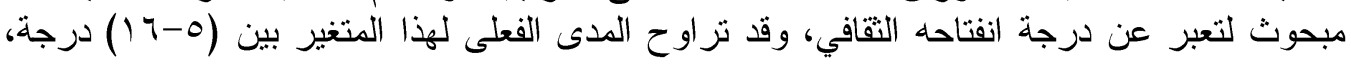

Fayoum J. Agric. Res. \& Dev., Vol. 33, No.2, July, 2019 


\section{Y}

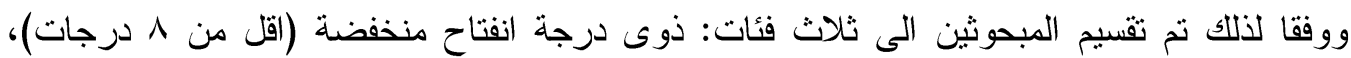

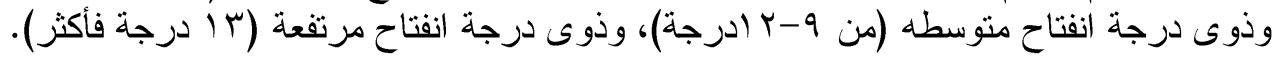

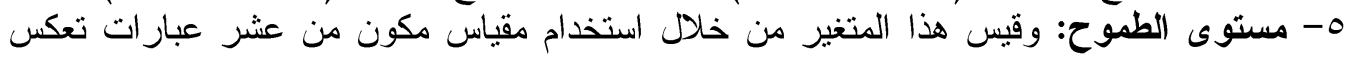

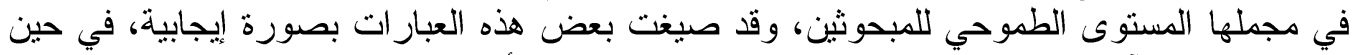

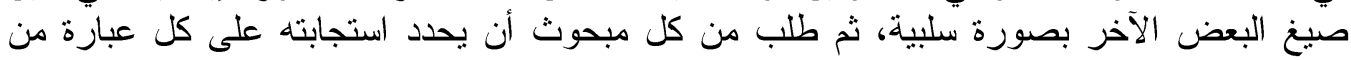

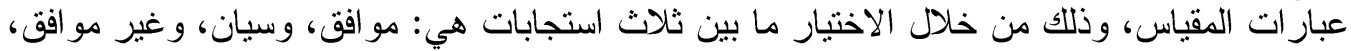

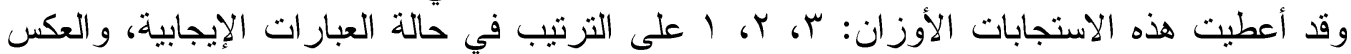

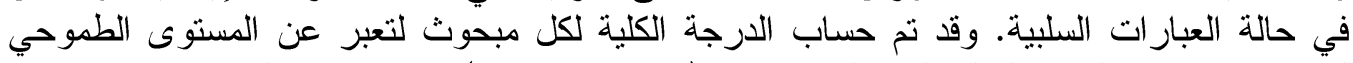

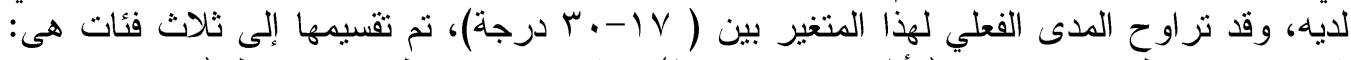

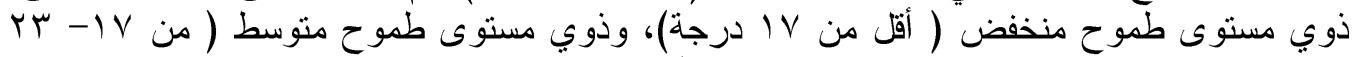

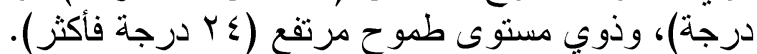

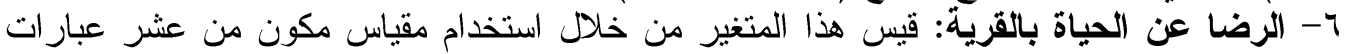

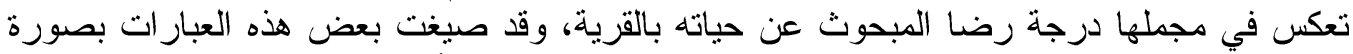

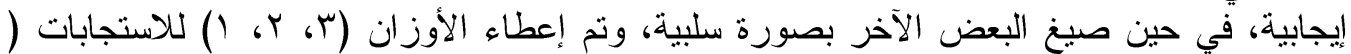

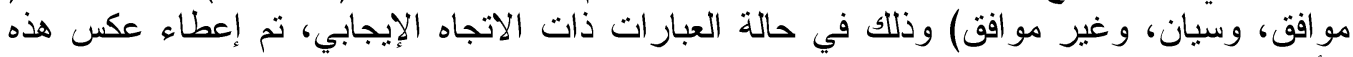

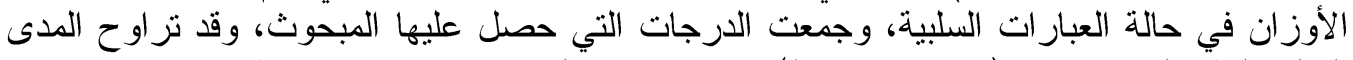

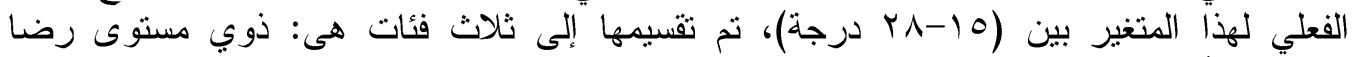

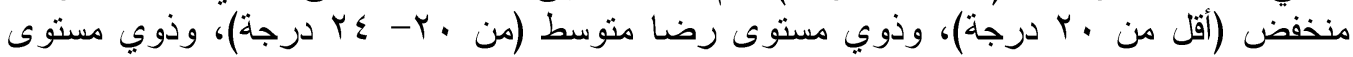

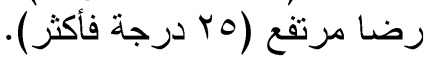

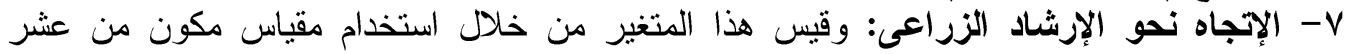

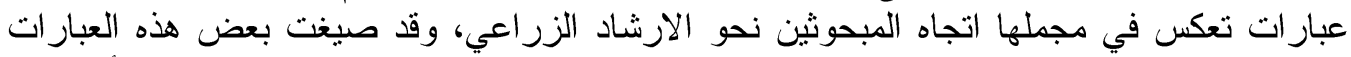

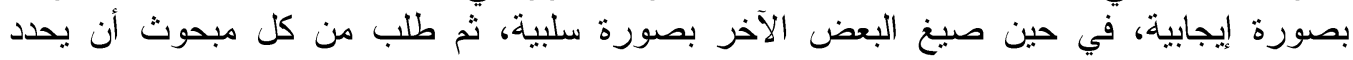

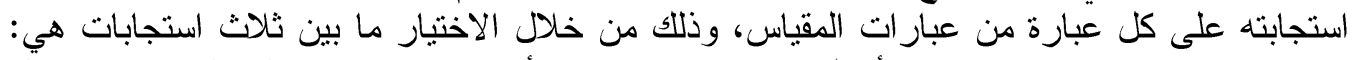

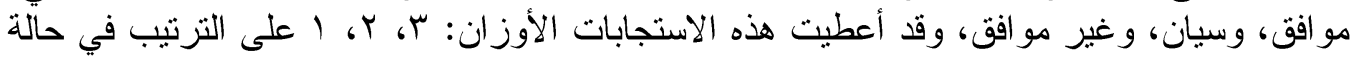

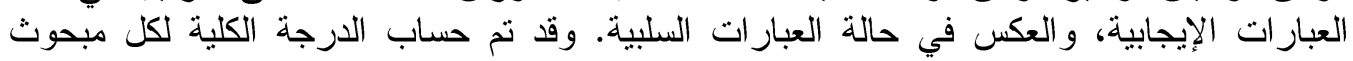

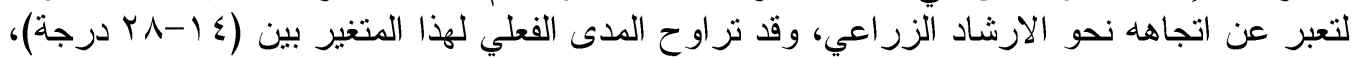

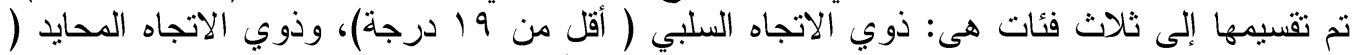

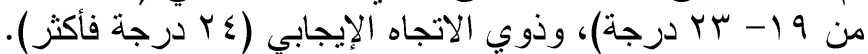

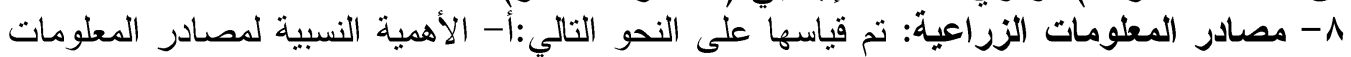

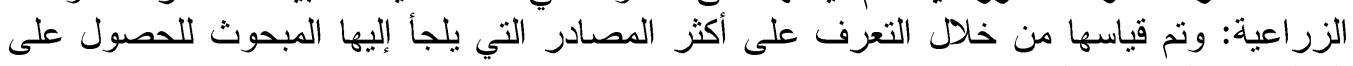

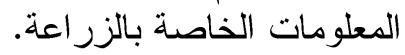

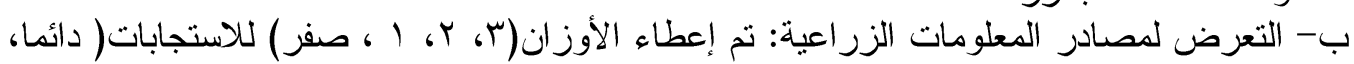

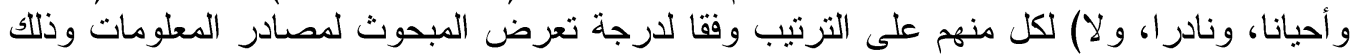

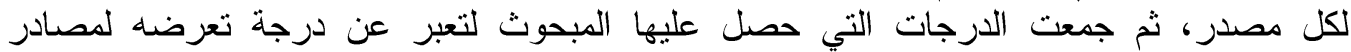

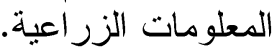

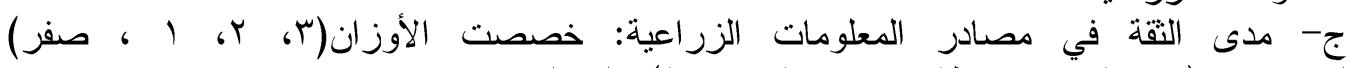

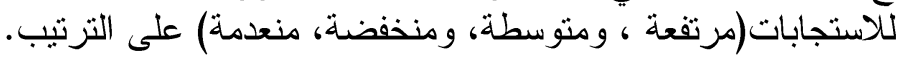

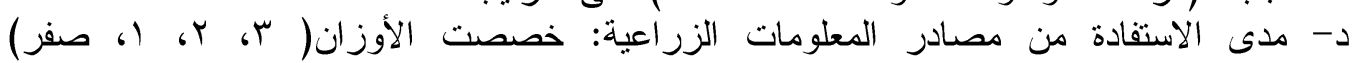

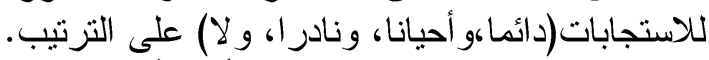

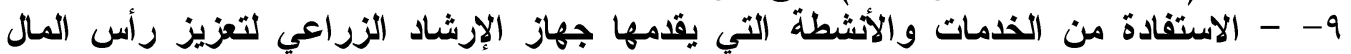

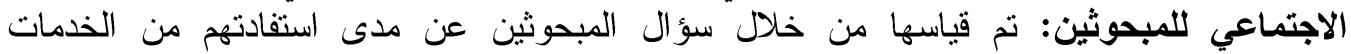
والأنشطة التي يقدمها الإرشاد الزراعي وذلك في ثمانية مجالات أساسية يعمل في إطارها الإرشاد

Fayoum J. Agric. Res. \& Dev., Vol. 33, No.2, July, 2019 
الزراعي، وتم إعطاء الأوزان (با، و ب، و ا، وصفر) للاستجابات (استفادة مرتفعة، ومتوسطة،

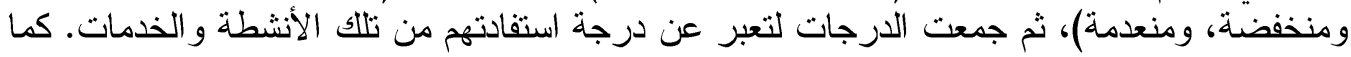

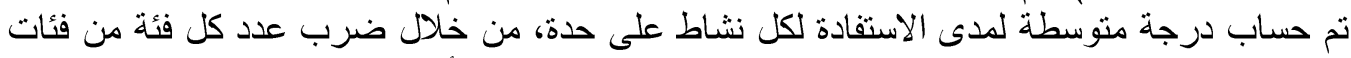

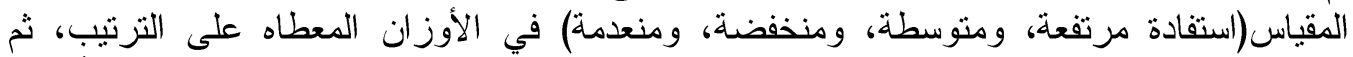

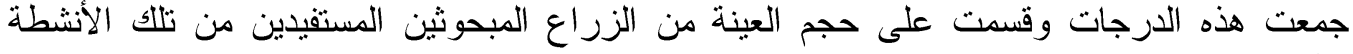

ب: المتفير التابع: رأس المال الاجتماعي

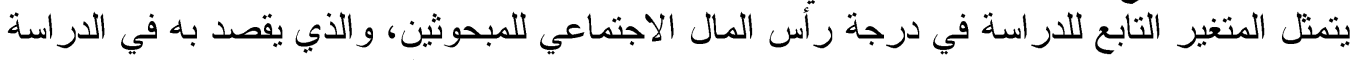

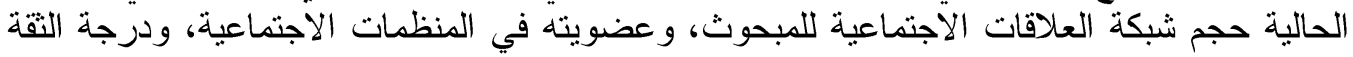

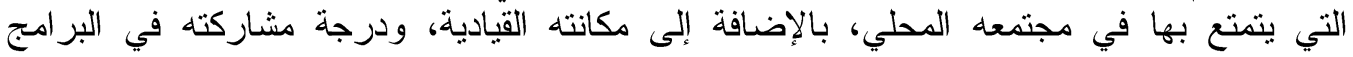

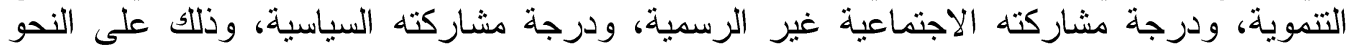

المحور الأول: حجم شبكة العلاقات الاجتماعية: وقيس من خلال توجيه خمس أسئلة للمبحوث وهئ:

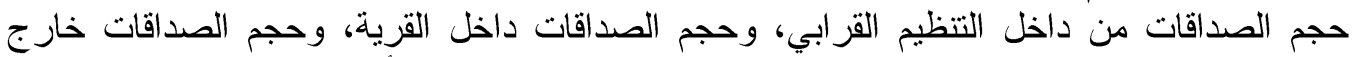

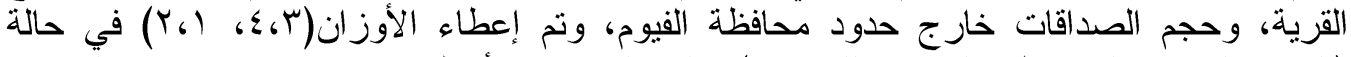

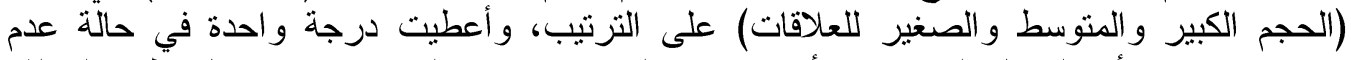

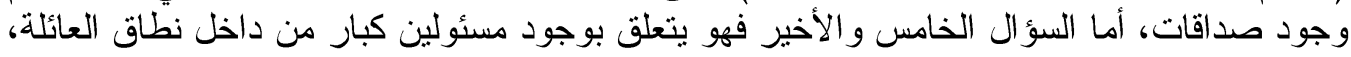

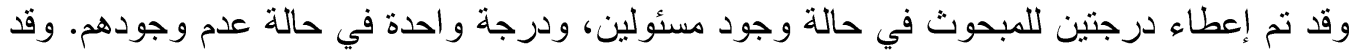

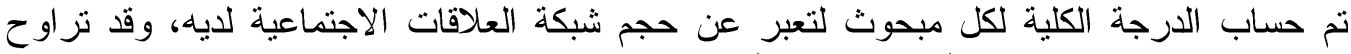

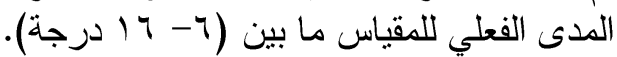

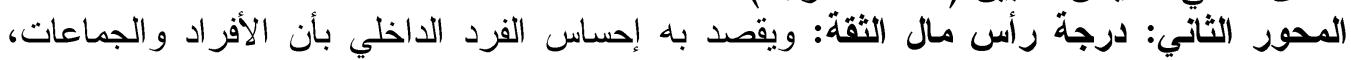

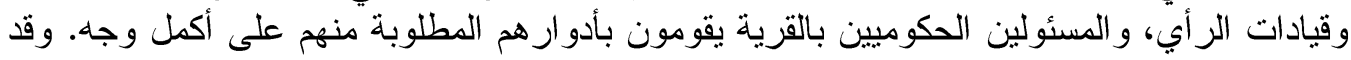

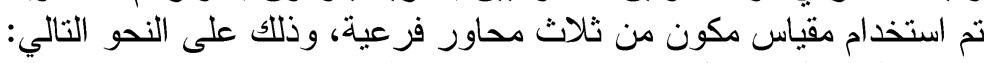

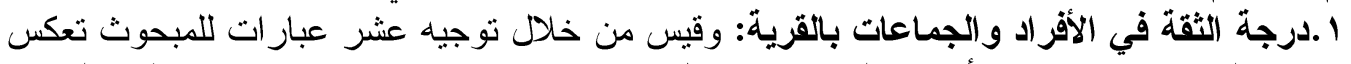

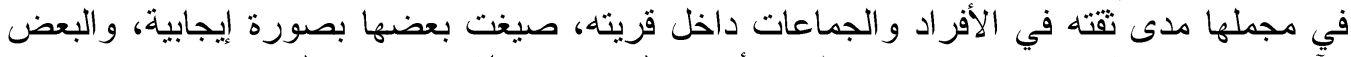

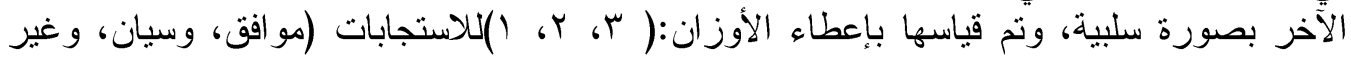

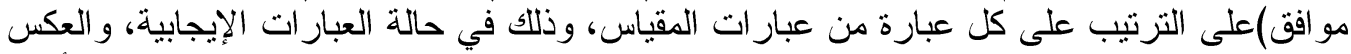

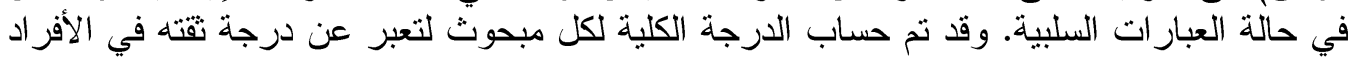

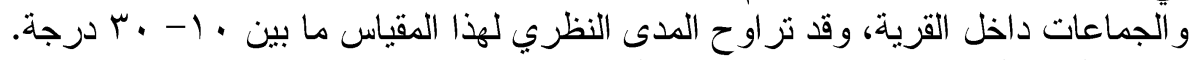

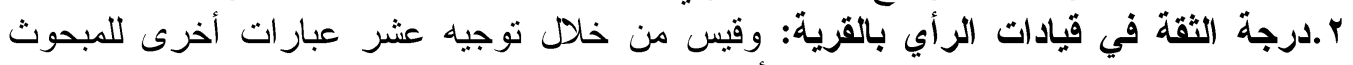

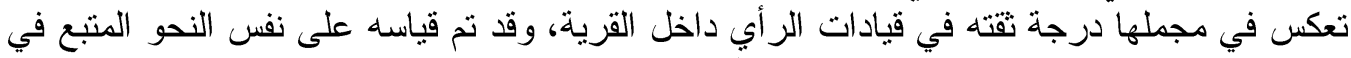

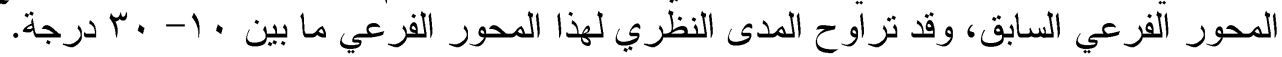

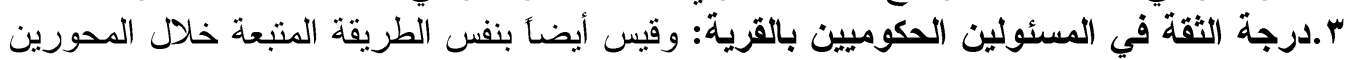

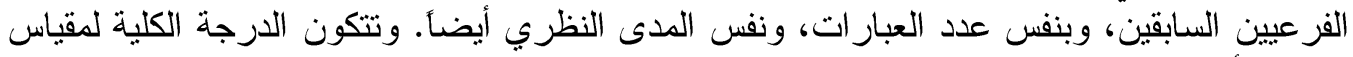

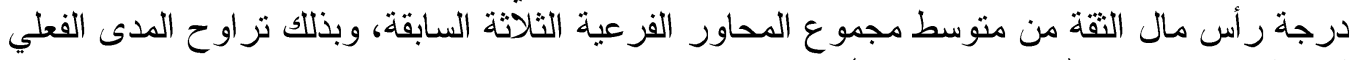

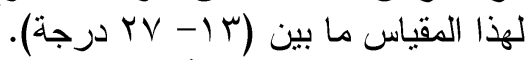

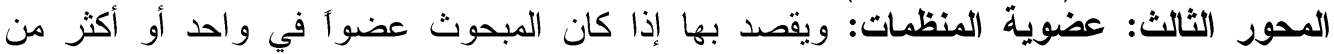

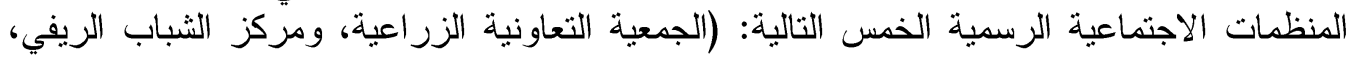

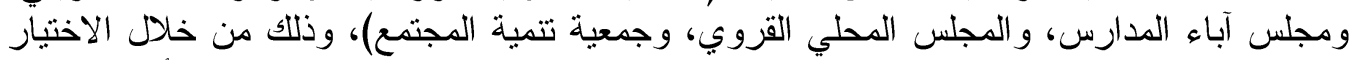

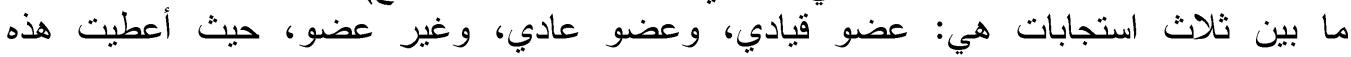

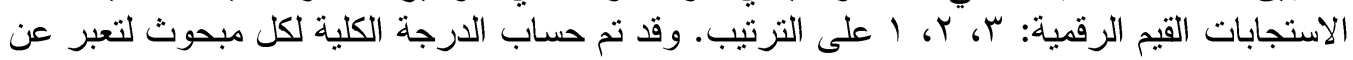

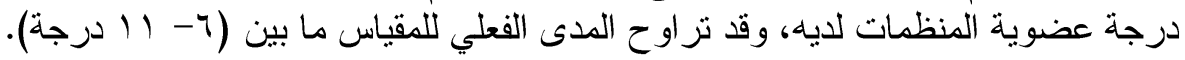

Fayoum J. Agric. Res. \& Dev., Vol. 33, No.2, July, 2019 


\section{Y}

المحور الرابع: المكانة القيادية: ويقصد بها قدرة الفرد على التأثير في سلوك الآخرين و التأثر بهر

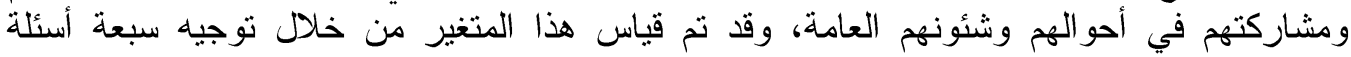

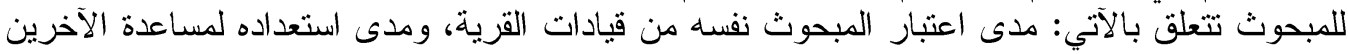

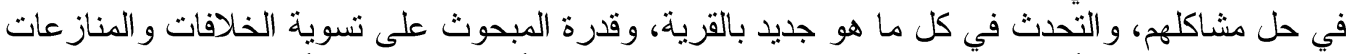

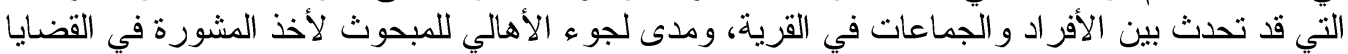

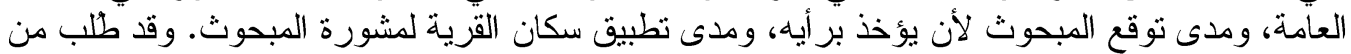

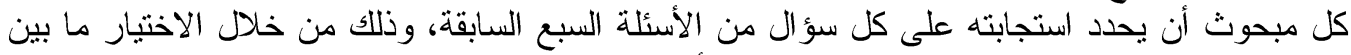

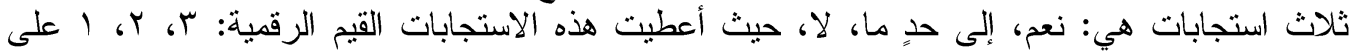

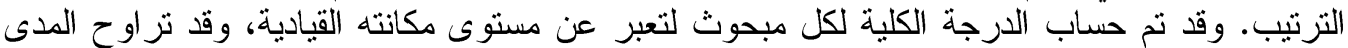

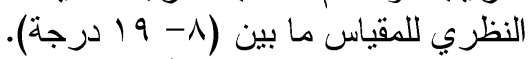

المحور الخامس: المشاركة في المشروعات التنموية: وقيست من خئة خلال سؤال المبحوث عن مدىى

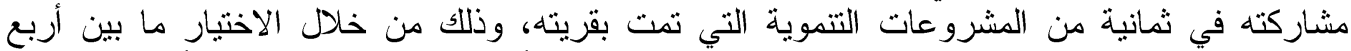

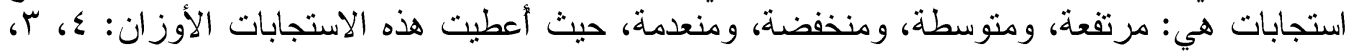

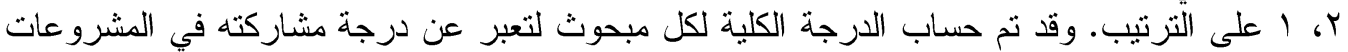

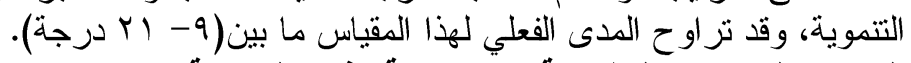

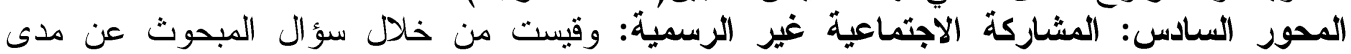

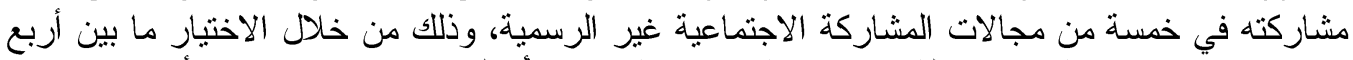

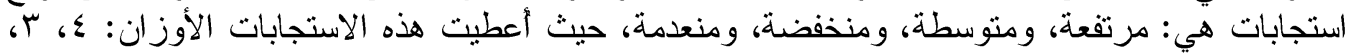

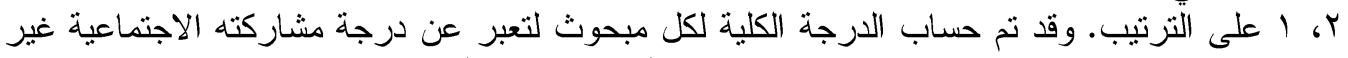

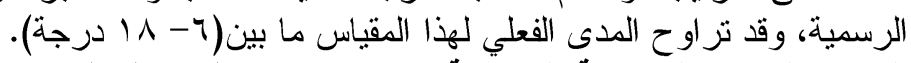

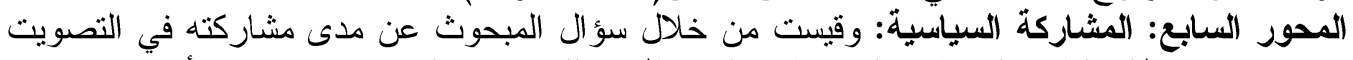

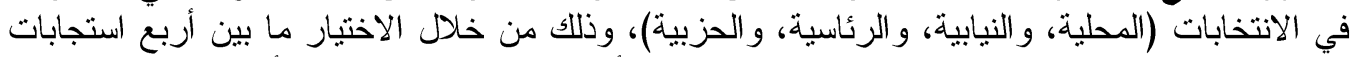

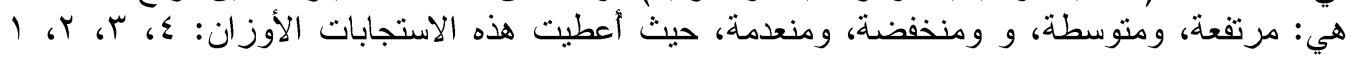

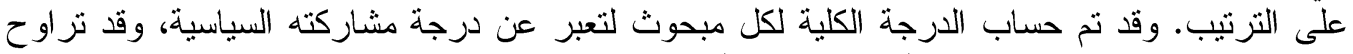

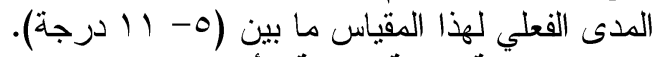
حساب الارجة الكلية لارجة رأس المال الاجتماعي: حسبت الدأل الدرجة الكلية لارجة رأس المال الاجتماعي

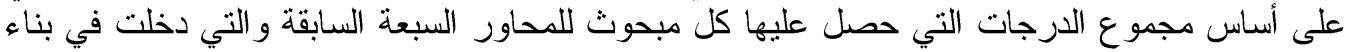

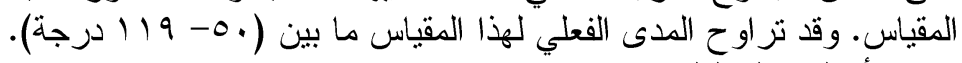
رابعا: أساليب التحليل الاحصائي

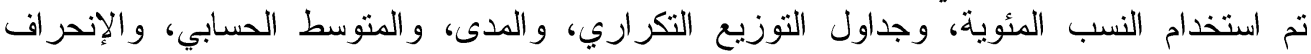

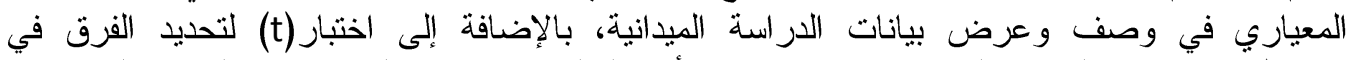

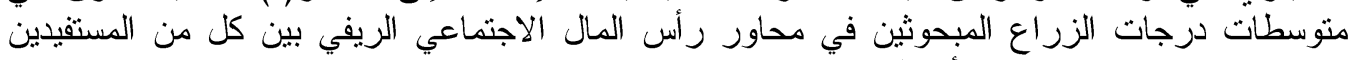

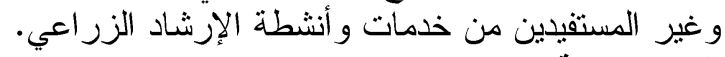

النتائج ومناقشتها

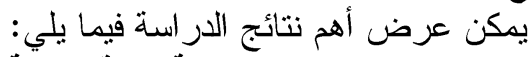

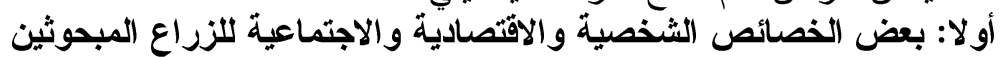

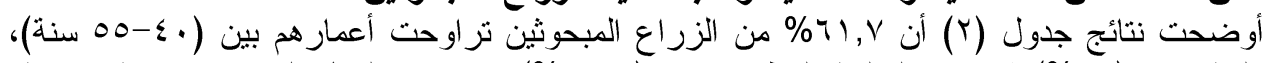

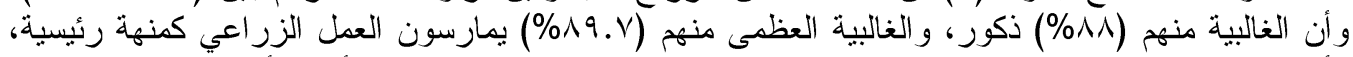

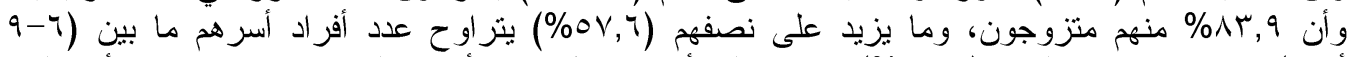

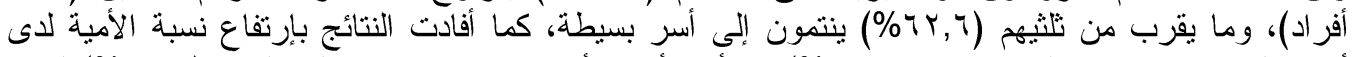

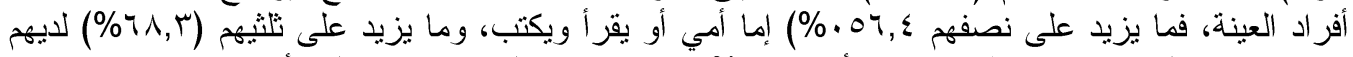

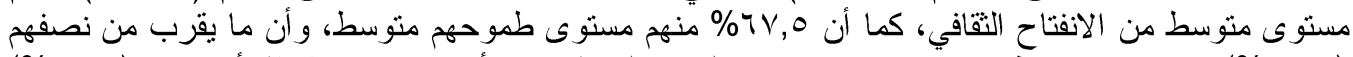

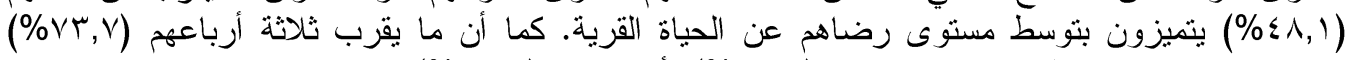

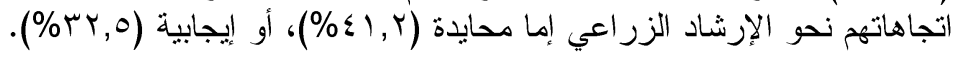

Fayoum J. Agric. Res. \& Dev., Vol. 33, No.2, July, 2019 
جدول (r) توزيع المبحوثين وفقاً لبعض متغيرات الادراسد

\begin{tabular}{|c|c|c|c|c|c|c|}
\hline \multirow{2}{*}{$\%$} & \multirow{2}{*}{ ن الاجمالي } & \multicolumn{2}{|c|}{ 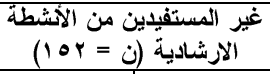 } & \multicolumn{2}{|c|}{ 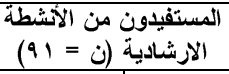 } & \multirow[t]{2}{*}{ المتغير ات } \\
\hline & & $\%$ & عدد & $\%$ & عدد & \\
\hline 11.0 & $\varepsilon 0$ & 19.1 & rq & $1 V .7$ & 17 & 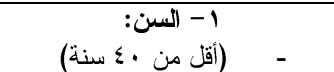 \\
\hline $71 . V$ & 10. & $71 . r$ & 91 & $7 Y .7$ & OV & 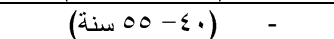 \\
\hline 19.1 & $\leq \Lambda$ & 19.8 & $r$. & 19.1 & 11 & (أكبر من 00 سنة) \\
\hline$\wedge \Lambda .1$ & YI & ᄉт.А & ITr & $9 \cdot .1$ & Ar & 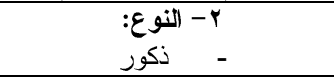 \\
\hline 11.9 & rq & IT.r & $r$. & 9.9 & 9 & - \\
\hline А . . & Y) & $9 \cdot .1$ & ITV & ᄉ .. & $\wedge$ & - - المهنة الرئيسية: \\
\hline $1 \cdot . r$ & ro & 9.9 & 10 & $11 .$. & 1. & - غير زر اعية \\
\hline$\varepsilon .9$ & Ir & $0 . r$ & $\wedge$ & $\leqslant . \varepsilon$ & $\varepsilon$ & ع - الحالة الززواجية: \\
\hline Nr.9 & $r \cdot \varepsilon$ & AY.r & 1ro & $\wedge \neg . \wedge$ & Vq & متزوج \\
\hline$\varepsilon .9$ & Ir & $\varepsilon .7$ & V & 0.0 & 0 & أزمل \\
\hline $7 . Y$ & 10 & 8.9 & Ir & r.r & $r$ & مطلق \\
\hline$r \leq . r$ & 09 & $r \leq . r$ & rV & $r \leq . r$ & Yr & (أقل من الأسرة 7 أفر اد) \\
\hline $0 V .7$ & $1 \leq$. & OV.r & AV & oג.r & or & - - - - - 9 (أفر اد) \\
\hline 11.1 & $\leqslant \varepsilon$ & $1 \wedge .5$ & rA & $1 V .7$ & 17 & (أكبر من 9 أفر اد) \\
\hline 7 7.7 & lor & $7 . \wedge$ & $9 V$ & $7 \cdot .5$ & 00 & 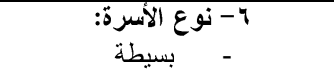 \\
\hline TV.s & 91 & (ז.r & 00 & 19.7 & ry & ممتدة \\
\hline M.r & VY & rA.r & $\leqslant r$ & rา. & $r \leq$ & - - المستوى التعليمي: - أمي: \\
\hline Yo.1 & 71 & ro.V & rq & $r \leq .1$ & rr & يقز أ ويكتب \\
\hline 11.9 & rq & 11.1 & 11 & $|Y|$. & 11 & ابتذائي \\
\hline $1 \% .7$ & אץ & $11 . \Lambda$ & YI & IT.r & ir & إعدادي \\
\hline 9.0 & rt & 1.7 & 14 & $11 .$. & 1. & ثثانوي \\
\hline IT.r & r. & 11.1 & 11 & IT.r & ir & جامعي \\
\hline 9.9 & $r \leq$ & 9.9 & 10 & 9.9 & 9 & ـ - م- مسفتوى الأفتاح (الثقافي: من د درجات) \\
\hline $7 \wedge . \Gamma$ & 177 & 79.8 & 1.7 & 70.9 & 7. & - متوسط (9- r ( درجات) \\
\hline YI.A & or & $Y \cdot . \Sigma$ & ו & $r \leq . r$ & rr & مرتفع (ب ا درجة فأكثز) \\
\hline $1 \cdot r$ & ro & 9.9 & 10 & 11. & $1 \cdot$ & ه - المستوى الطموحي: \\
\hline $7 V .0$ & $17 \varepsilon$ & 79.1 & 1.0 & $7 \leq . \Lambda$ & 09 & متوسط (V ( \\
\hline TY.Y & of & Yl.. & rr & YE.Y & Kr & مرتفع (క ب درجة فأكثر) \\
\hline r9.1 & 90 & $\leqslant 1 . \leqslant$ & 7 & ro.r & 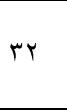 & 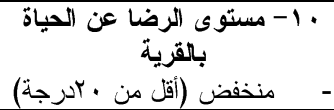 \\
\hline$\leq \wedge .1$ & $11 \mathrm{~V}$ & $\leq 7.1$ & $V \cdot$ & 01.7 & $\varepsilon V$ & - - متوسط (•r- گ Y درجة) \\
\hline IY.A & M & $1 Y .0$ & 19 & IT.Y & Ir & - مرتفع (0 برجة فأكثر) \\
\hline$r \bar{r}$ & $7 \leq$ & rA,r & $\leqslant r$ & $r m, 1$ & Y) & 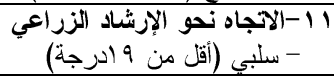 \\
\hline$\Sigma 1, Y$ & $1 \cdots$ & $\leqslant 1, \varepsilon$ & 7 & $\varepsilon \cdot, 7$ & re & محايد (19 - rr درجة) \\
\hline TY,O & Vq & $r \cdot r$ & $\leqslant 7$ & r & 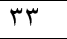 & إيجابي (كا درجة فأكثر) \\
\hline
\end{tabular}

المصدر: بيانات الار اسة اسة

Fayoum J. Agric. Res. \& Dev., Vol. 33, No.2, July, 2019 
ثانيا: الأهمية النسبية لمصادر المعلومات الزراعية لاى الزراع المبحوثين: تم تناولها من خلال:

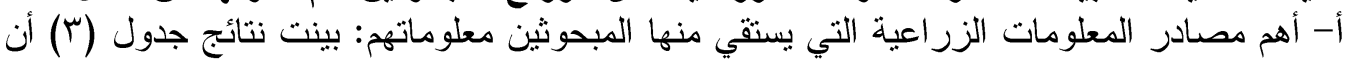

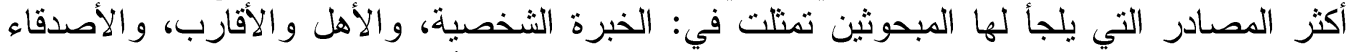

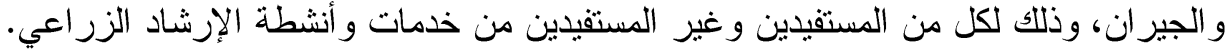

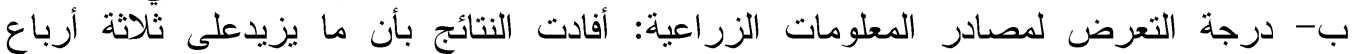

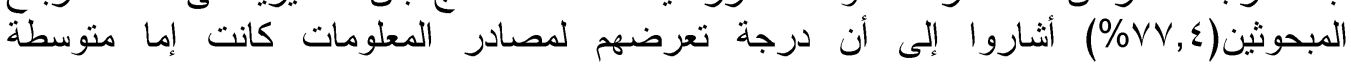

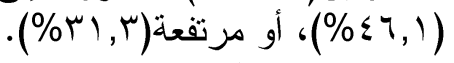

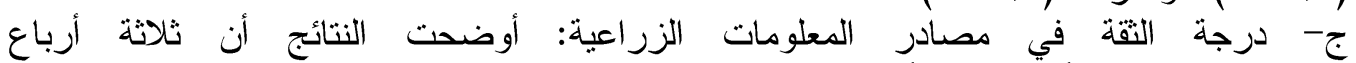

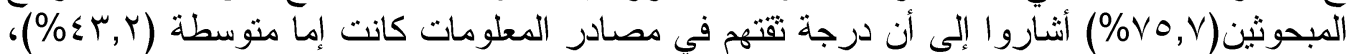

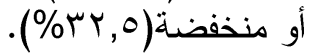

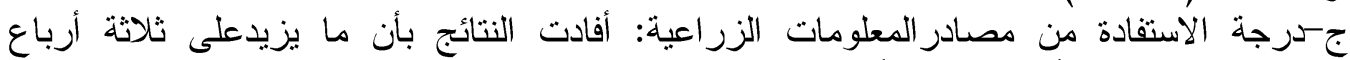

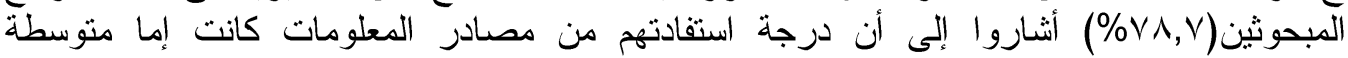

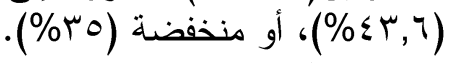

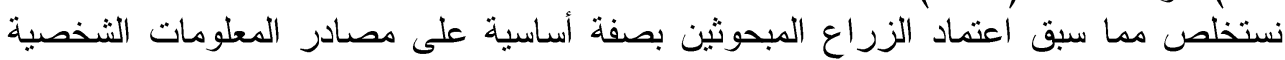

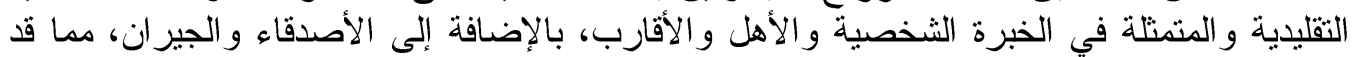

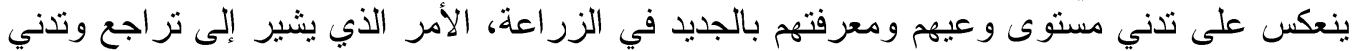

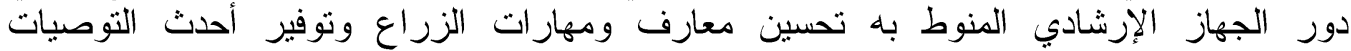

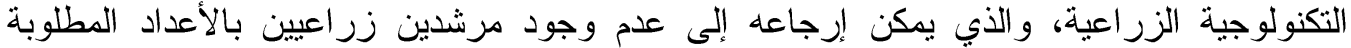

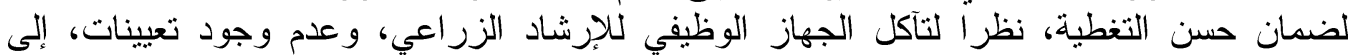

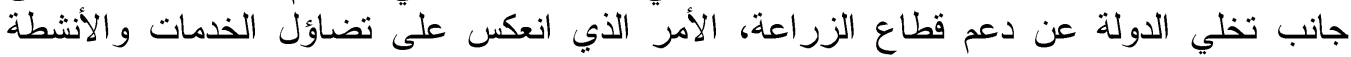

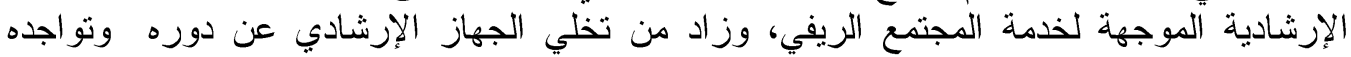

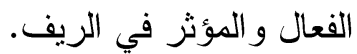
جدول (ץ) توزيع المبحوثين وفقا للأهمية النسبية لمصادر المعلومات الزراعية

\begin{tabular}{|c|c|c|c|c|c|c|c|c|}
\hline \multicolumn{2}{|c|}{ الإجمالي(ن= } & \multicolumn{3}{|c|}{ غير المستفيدون(ن=r) } & \multicolumn{3}{|c|}{ المستقفيلون(ن= = 9) } & \multirow[b]{2}{*}{ المصدر } \\
\hline$\%$ & تكرار & الترتيب & $\%$ & تكرار & التزتيب & $\%$ & تكرار & \\
\hline$\pi, r$ & 11 & 1 & $r 9,0$ & 7. & 1 & $r \cdot, \Lambda$ & YA & 1-الخبرة الثخصية \\
\hline 11,9 & $\leqslant \uparrow$ & r & $19, \mathrm{~V}$ & r. & r & $1 V, T$ & 17 & r- الأهل و الأقارب \\
\hline$I V, r$ & $\varepsilon r$ & r & $1 V . \Lambda$ & TV & $r$ & 17,0 & 10 & بَ- الأصدقاء و الجير ان \\
\hline 11,1 & rq & $\varepsilon$ & 9,9 & 10 & $\varepsilon$ & 10,4 & $1 \varepsilon$ & ع- المرشد الزر اعي \\
\hline 0,1 & $1 \varepsilon$ & 0 & $0, Y$ & $\Lambda$ & 0 & 7,7 & 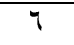 & 0- الدور ات التدرييية \\
\hline$\varepsilon, 1$ & 1. & 7 & $r, r$ & 0 & 7 & 0,0 & 0 & 1- النشر ات الفنية \\
\hline$\varepsilon, 1$ & 1. & 7 & $\Gamma, \Gamma$ & 0 & 7 & 0,0 & 0 & ب الالتليفزيون الريفية \\
\hline$r, q$ & V & V & $r, T$ & $\varepsilon$ & $\wedge$ & $r, r$ & r & 1 - البر ادج الريفية \\
\hline$r, q$ & $\mathrm{~V}$ & $\wedge$ & r & $\mu$ & $\mathrm{V}$ & $\{, \varepsilon$ & $\varepsilon$ & 9-كلية الزر اعة ومركز \\
\hline
\end{tabular}

Fayoum J. Agric. Res. \& Dev., Vol. 33, No.2, July, 2019 
جدول (ع) توزيع المبحوثين وفقا للأهمية النسبية لمصادر المعلومات الزراعية ودرجة التعرض لها

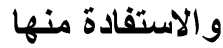

\begin{tabular}{|c|c|c|c|c|c|c|}
\hline \multicolumn{2}{|c|}{ الإجمالي(ن=r = Y Y) } & \multicolumn{2}{|c|}{ غير المستفيدون(ن=ror) } & \multicolumn{2}{|c|}{ المستفيدون(ن= = 9) } & \multirow[b]{2}{*}{ 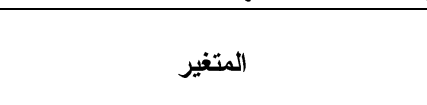 } \\
\hline$\%$ & عدد & $\%$ & عدد & $\%$ & 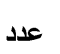 & \\
\hline & & & & & & أ-درجة التعرض لمصادر المعلومات \\
\hline YY,T & 00 & TO & ru & $1 \Lambda, V$ & IV & منخفضة ( أقل من ك 1 درجة) \\
\hline$\sum 7,1$ & 114 & $\varepsilon \vee, \varepsilon$ & VY & $\varepsilon \varepsilon$ & $\varepsilon \cdot$ & متوسطة(من 1 (- گ זدرجة) \\
\hline \multirow[t]{2}{*}{$r, r$} & $V Y$ & $r V, \uparrow$ & $\varepsilon r$ & $r v, r$ & $r \varepsilon$ & مرتفعة(0 درجة فأكثر) \\
\hline & & & & & & بــرجة الثقة في مصادر المعلومات \\
\hline$r r, 0$ & $\mathrm{vq}$ & $\varepsilon \cdot, \Lambda$ & $4 \pi$ & $1 \Lambda, V$ & IV & منخفضة (أقلَ من 7 ادرجة) \\
\hline$\varepsilon r, r$ & 1.0 & $r \wedge, \wedge$ & 09 & $0 ., 0$ & $\sum 9$ & متوسطة (من 1 - ع זدرجة) \\
\hline \multirow[t]{2}{*}{$r \leq, r$} & 09 & $r \cdot, \varepsilon$ & r & $r \cdot, \Lambda$ & Y^ & مر تفعة (Y درجة فأكثز) \\
\hline & & & & & & جـدرجة الاستفادة في مصادر المعلومات \\
\hline ro & 10 & $\varepsilon r, \Lambda$ & 70 & TY & T. & منخفضة (أقل من ادرجة) \\
\hline$\varepsilon r, \uparrow$ & 1.7 & $r \wedge, \wedge$ & 09 & 01,4 & $\varepsilon V$ & متوسطة (من 1 - ع זدرجة) \\
\hline Y I, ६ & Or & $1 \wedge, \varepsilon$ & rA & Yч, & $T \varepsilon$ & مرتفعة ( Yo درجة فأكثز) \\
\hline
\end{tabular}

المصدر : بيانات الأراسة

\section{ثالثا: توصيف مستويات رأس المال الاجتماعي الريفي

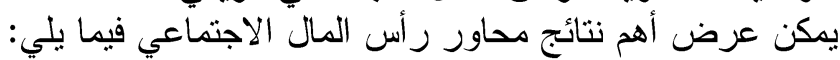

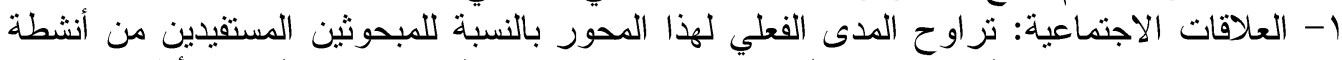

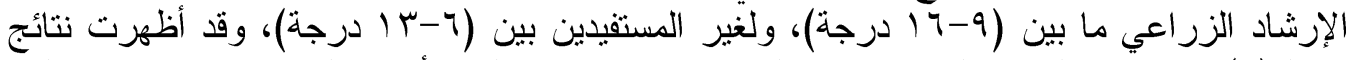

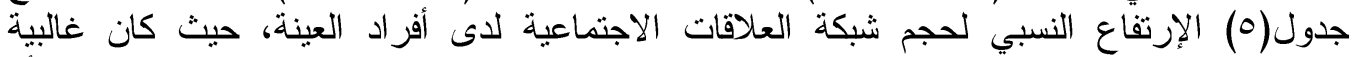

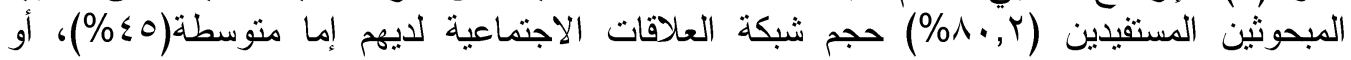

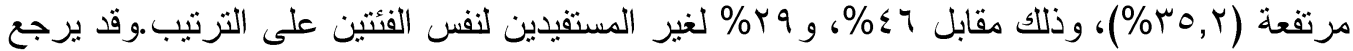

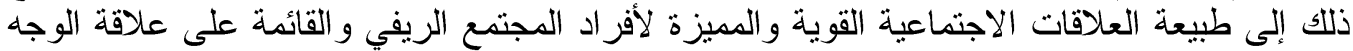

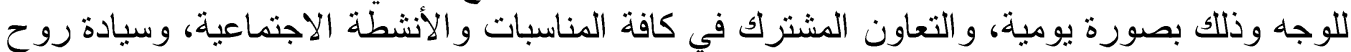

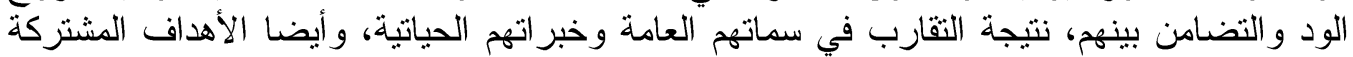

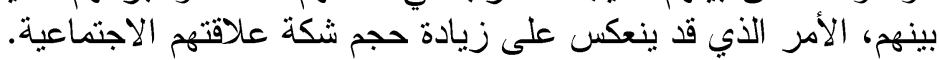

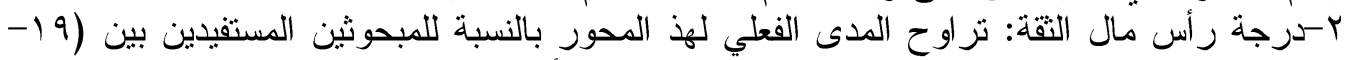

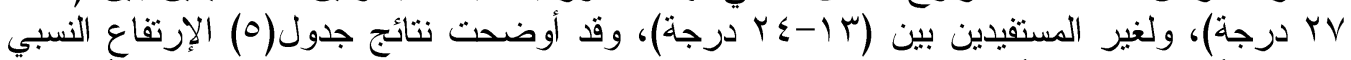

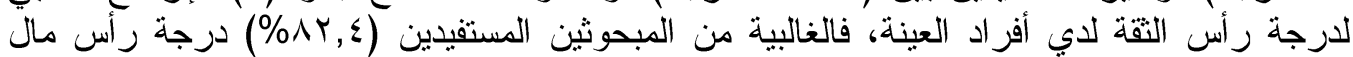

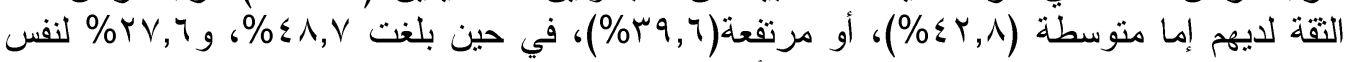

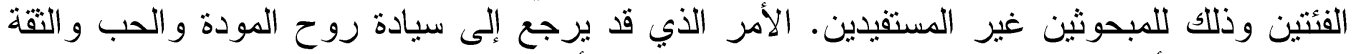

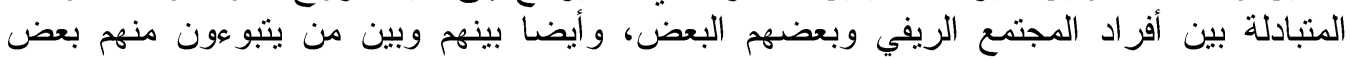

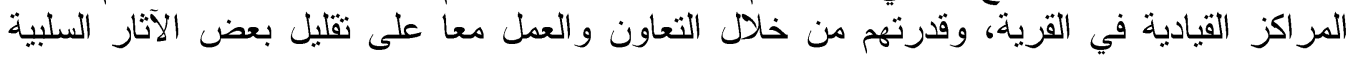

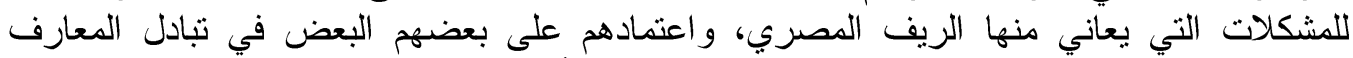

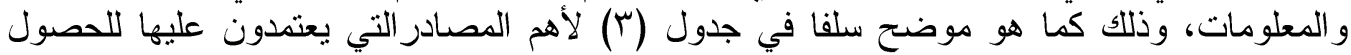

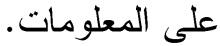

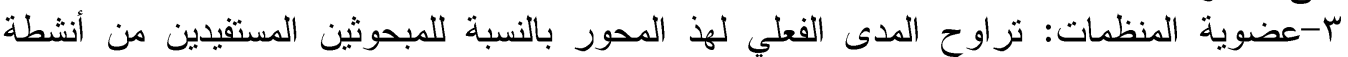

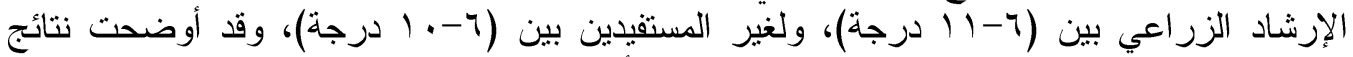

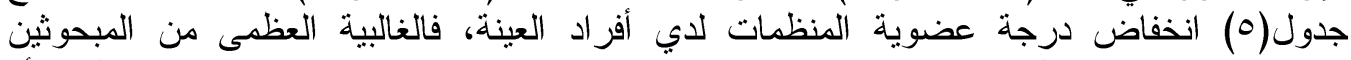

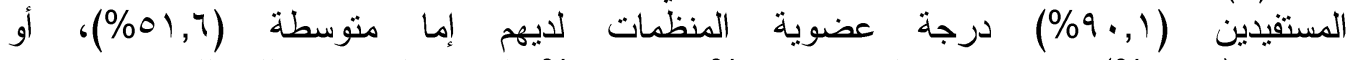

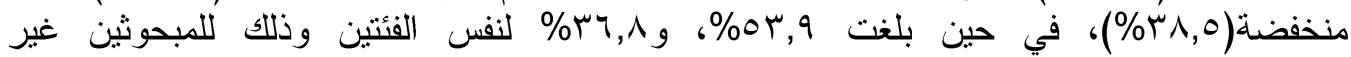

Fayoum J. Agric. Res. \& Dev., Vol. 33, No.2, July, 2019 
$1 \%$.

المستفيدين.وقد يرجع ذلك لانخفاض وعي المبحوثين بأهمية تلك المنظمات، ودورها في تتمية

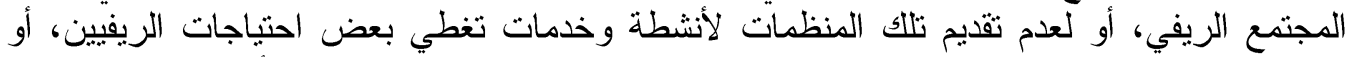

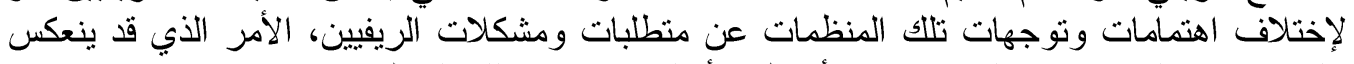
على عزوف الريفيين في المشاركة في أنشطتها أو العضوية في تلاتك التكات المنظمات.

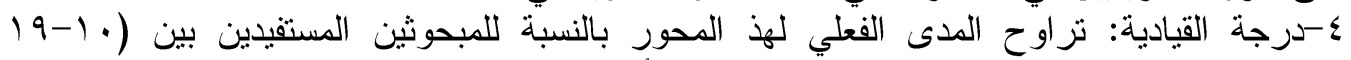

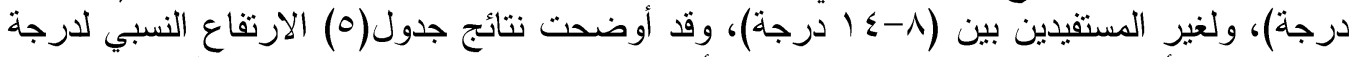

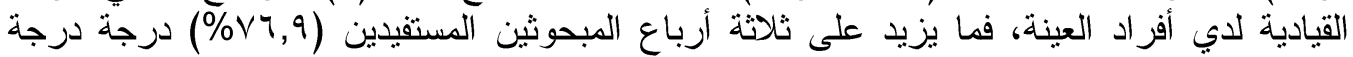

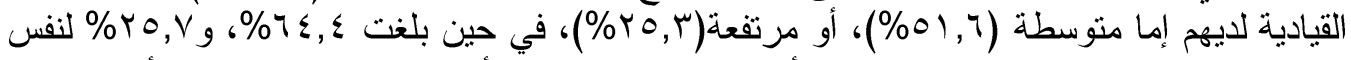

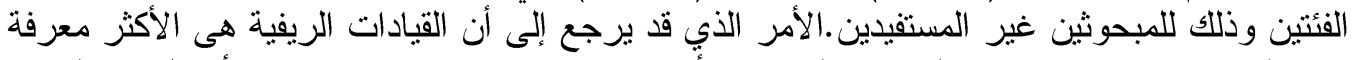

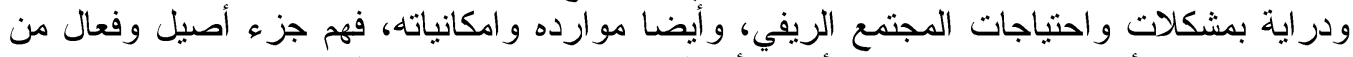

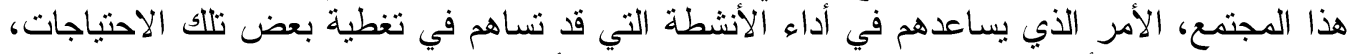

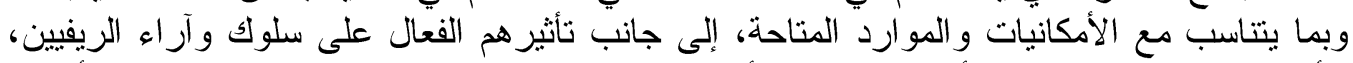
الأمر الذي يزيد من كسب تأييدهم و إقناعم بأهمية تعاونهم معا وكسب تقتهم ومشاركتهم في الأنشطة التي تعود بالنفع على القرية.

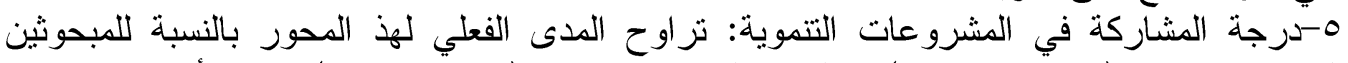

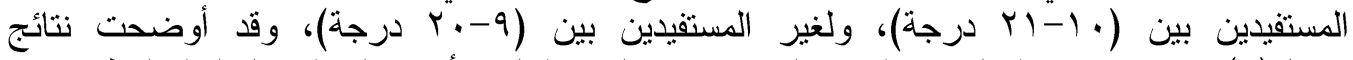

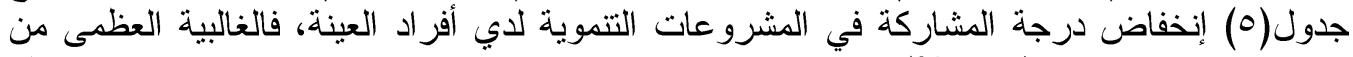

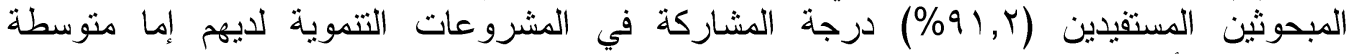

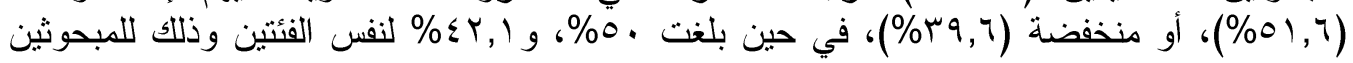

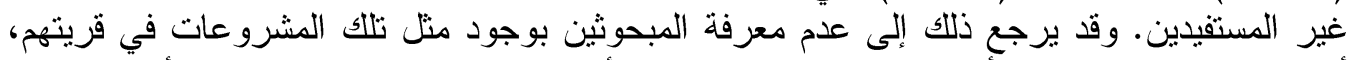

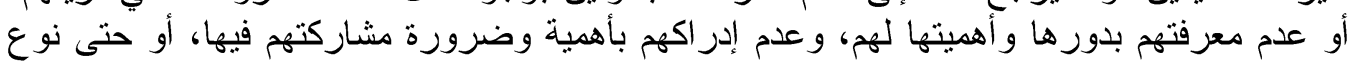

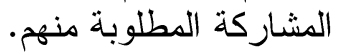

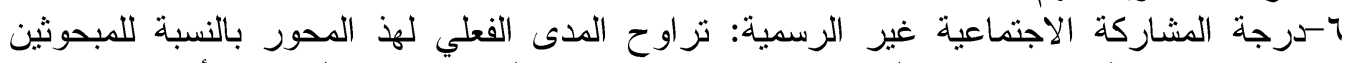

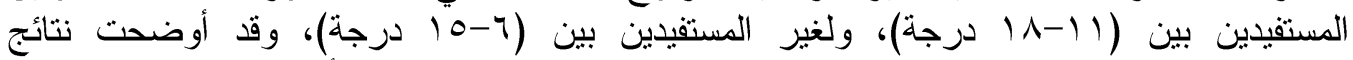

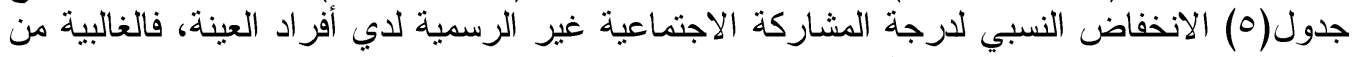

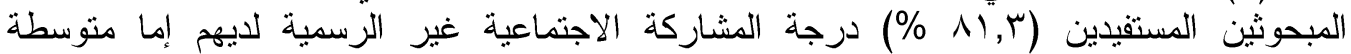

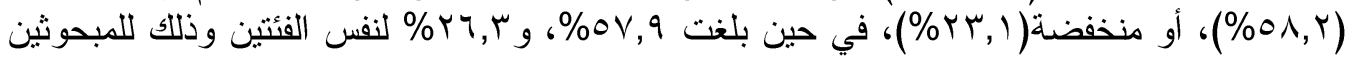

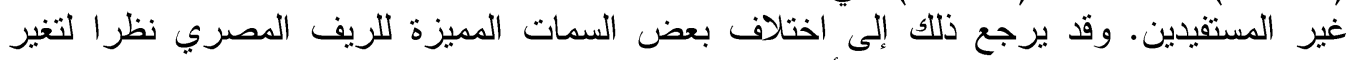

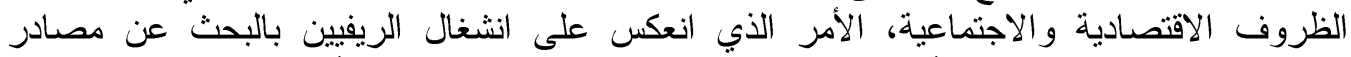

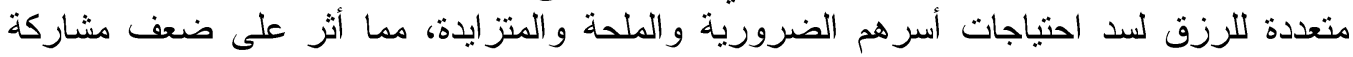

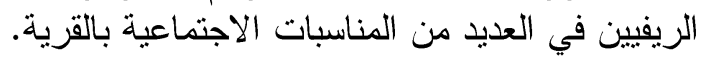

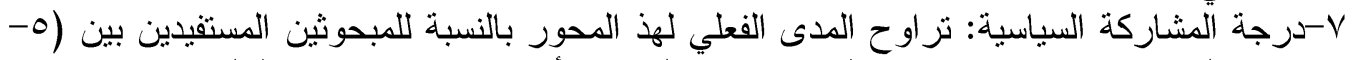

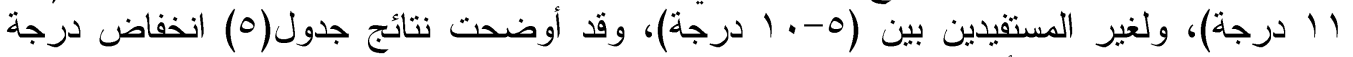

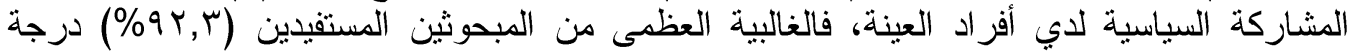

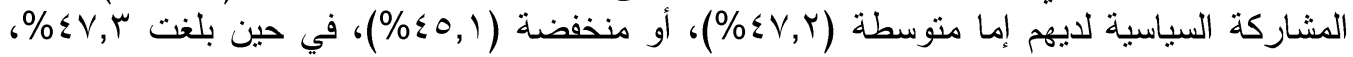

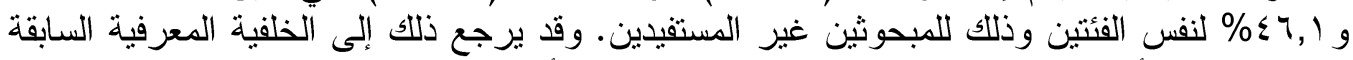

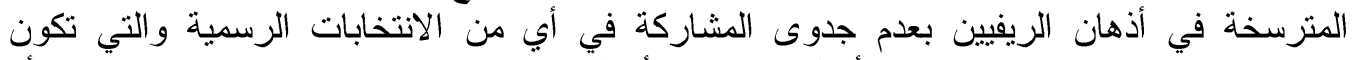

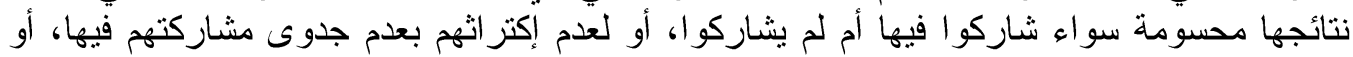

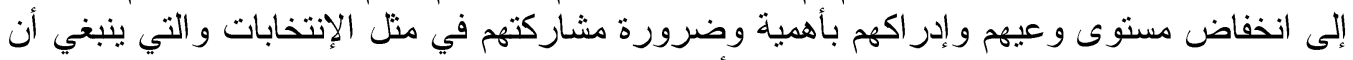

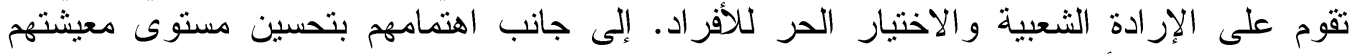
وزيادة دخولهم كأولوية بدلا من تضييع وقتهم في منل تلأك المحافل البعيدة عن حياتهم وظروفهر التهر و أوضاعهم.

Fayoum J. Agric. Res. \& Dev., Vol. 33, No.2, July, 2019 
$|r|$

1-الدرجة الكلية لرأس المال الاجتماعي: تراوح المدى الفعلي لهذ المحور بالنسبة للمبحوثين

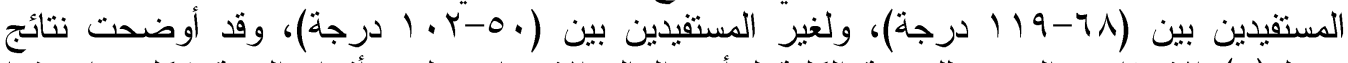

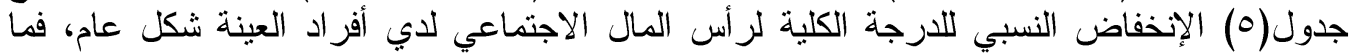

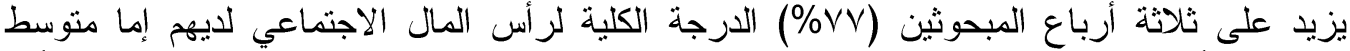

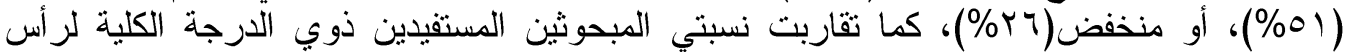

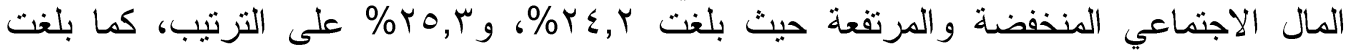

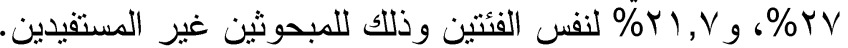

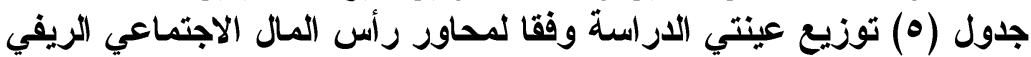

\begin{tabular}{|c|c|c|c|c|c|c|}
\hline \multirow[t]{2}{*}{$\%$} & \multirow{2}{*}{ ناجمالي } & \multicolumn{2}{|c|}{ 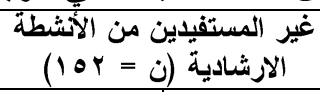 } & \multicolumn{2}{|c|}{ 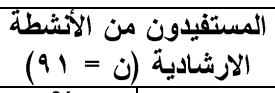 } & \multirow[t]{2}{*}{ المحاور } \\
\hline & & $\%$ & عدد & $\%$ & عدد & \\
\hline r & 07 & ro & $r \Lambda$ & 19,1 & 11 & 1- العلاقات الاجتماعية \\
\hline$\varepsilon 0, V$ & 111 & $\{7,1$ & $\checkmark \cdot$ & $\leqslant 0$ & \& & - متوسط \\
\hline$r, r$ & $\sqrt{ } 4$ & $r \wedge, 9$ & $\leqslant \leqslant$ & $r 0, r$ & rt & مرتفع \\
\hline r), $\Sigma$ & or & $r t, V$ & ry & $1 V, 7$ & 17 & - - - رأس مال الثقة \\
\hline$\sum 7,0$ & 114 & $\sum \wedge, \vee$ & $V \leqslant$ & $\varepsilon r, \Lambda$ & rq & متو سط \\
\hline$r r, 1$ & $\vee \wedge$ & $r V, T$ & $\leqslant Y$ & $r 9,7$ & rq & مرتفع \\
\hline$r v, \varepsilon$ & 91 & $r q, \Lambda$ & 04 & $r \wedge, 0$ & ro & r- - عضوية المنظمات \\
\hline or, 1 & 119 & or, 9 & NT & 01,7 & $\varepsilon V$ & - - متوسط \\
\hline 9,0 & tr & $9, r$ & $1 \leq$ & ro,r & 9 & مرتفع \\
\hline$r \leqslant, V$ & 7. & $r o, V$ & rq & $r+1$ & rI & ع - درجة القيادية \\
\hline $09, \mathrm{~V}$ & $1 \leqslant 0$ & $T \varepsilon, \varepsilon$ & 91 & 01,7 & $\varepsilon V$ & - - متوسط \\
\hline 10,7 & rᄉ & 9,9 & 10 & $r 0, r$ & tr & - - مرتفع \\
\hline$\varepsilon 1, r$ & $1 \cdots$ & $\leq Y, 1$ & $7 \varepsilon$ & $r q, 7$ & ri & ه- المشاركة في المشروعات \\
\hline $0 ., 7$ & IrT & 0. & $\vee 7$ & 01,7 & $\leq V$ & - - متوسط \\
\hline$\Lambda, r$ & $r$. & $v, 9$ & IT & $\wedge, \wedge$ & $\wedge$ & - - مرتفع \\
\hline ro, 1 & 71 & r & $\varepsilon$. & $r+1$ & r) & 1- المشاركة الاجتماعية غير \\
\hline 01 & $1 \leqslant 1$ & ov, 9 & $\wedge \wedge$ & $0 \wedge, Y$ & or & - - متوسط \\
\hline 17,9 & $\leqslant$ & 10,1 & $r \leqslant$ & $1 \wedge, V$ & IV & - - مرتفع \\
\hline$\varepsilon 0, V$ & 111 & $\leq 7,1$ & $\vee \cdot$ & $\leq 0,1$ & « & V- - المثاركة السياسية \\
\hline$\sum V, r$ & 110 & $\varepsilon V, r$ & $V Y$ & $\Sigma V, Y$ & $\varepsilon r$ & - - متوسط \\
\hline V & IV & 7,7 & 1. & $\mathrm{~V}, \mathrm{~V}$ & V & - - مرتفع \\
\hline$r_{0,9}$ & זי & $r v$ & $\leqslant 1$ & $r \leqslant, r$ & rt & 1-الارجة الكلية لرأس المال \\
\hline 01 & $1 Y \leq$ & $01, r$ & $\vee \wedge$ & $0 ., 0$ & $\leq 7$ & - متوسط \\
\hline$r+1$ & 07 & YI,V & r & $r 0, r$ & r & - مرتفع \\
\hline
\end{tabular}

المصدر: بيانات الاراسة

Fayoum J. Agric. Res. \& Dev., Vol. 33, No.2, July, 2019 
Irr

رابعا: الاستفادة من الخدمات والأشطة الإرشادية الزراعية التي تعزز رأس المال الاجتماعي

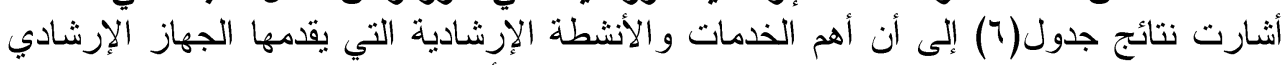

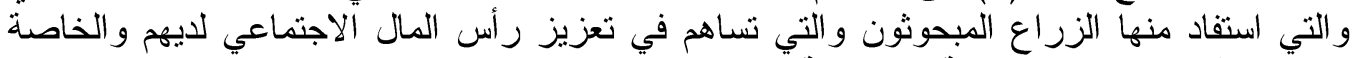

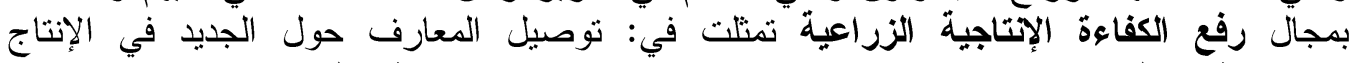

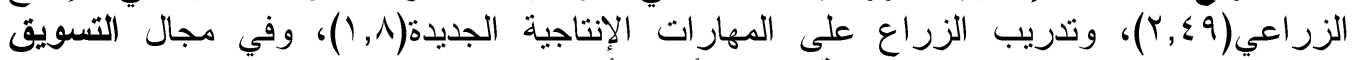

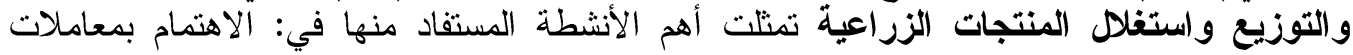

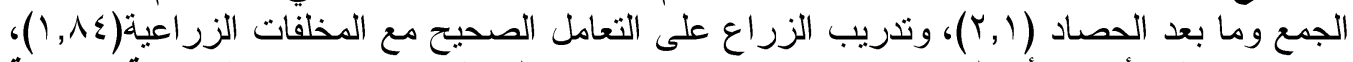

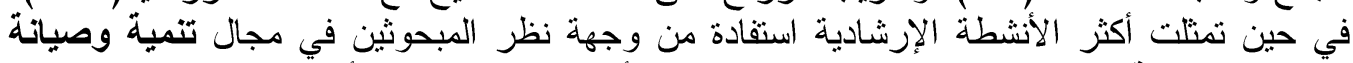

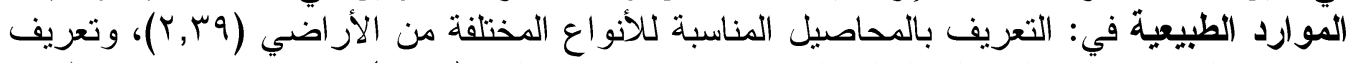

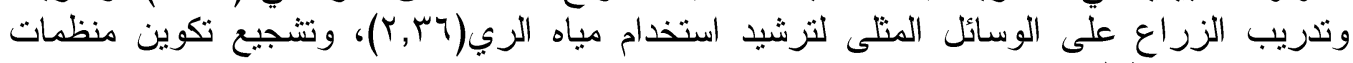

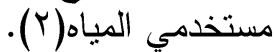

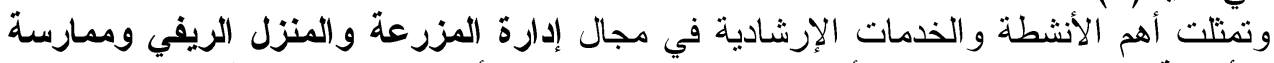

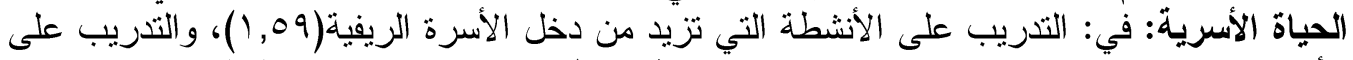

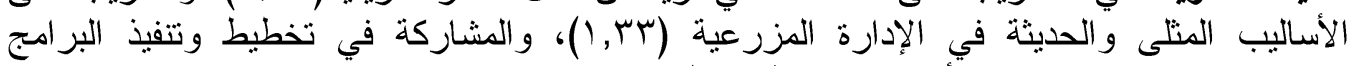

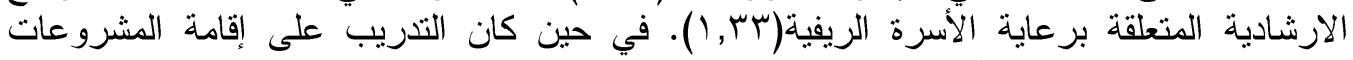

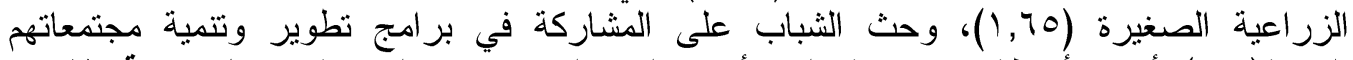

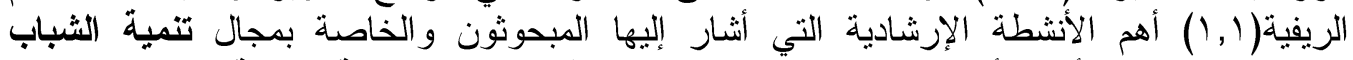

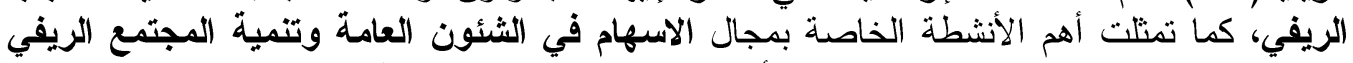

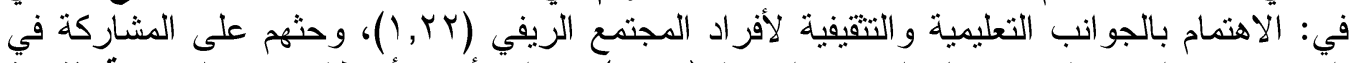

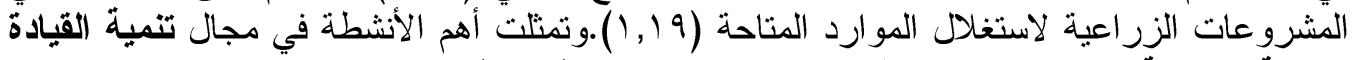

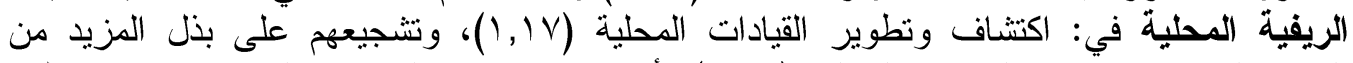

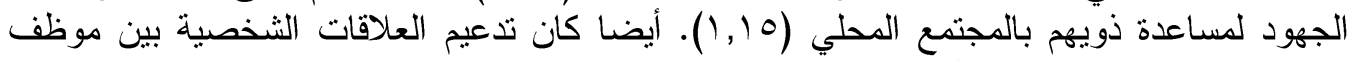

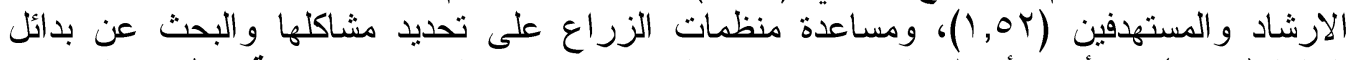

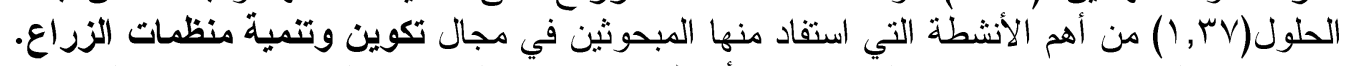

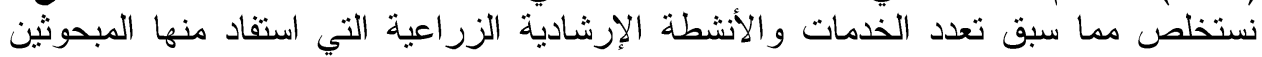

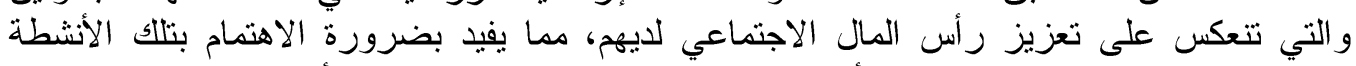

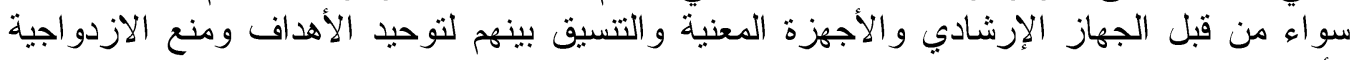

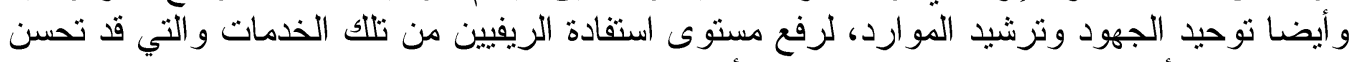

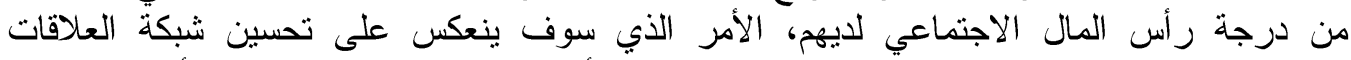

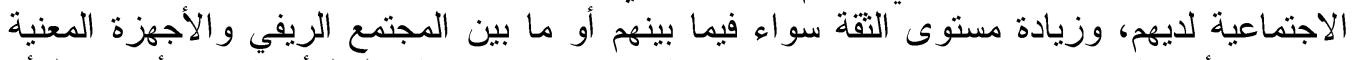

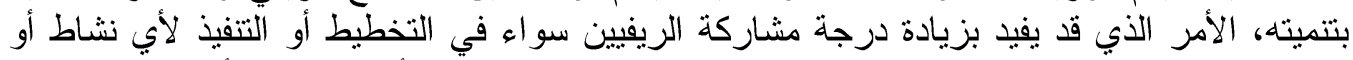

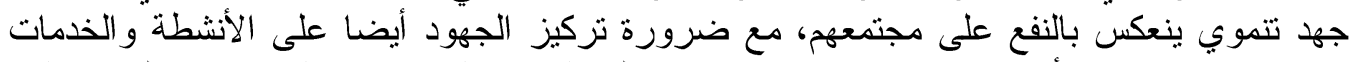

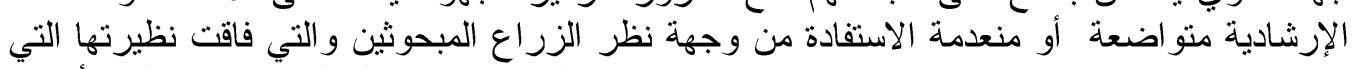

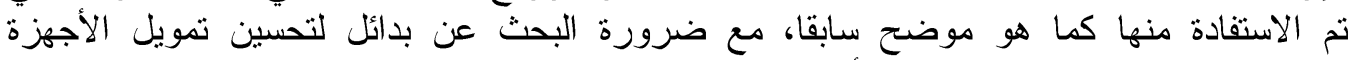

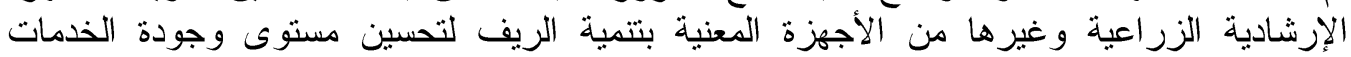

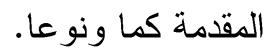

Fayoum J. Agric. Res. \& Dev., Vol. 33, No.2, July, 2019 


\begin{tabular}{|c|c|c|c|c|c|c|c|c|c|c|}
\hline \multirow{3}{*}{ | المتوسطة } & \multirow{3}{*}{ 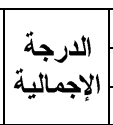 } & \multicolumn{8}{|c|}{ مدى الاستفادة (ن = (9) } & \multirow{3}{*}{ المجال / الخذمة أو النشاط الارشادي } \\
\hline & & \multicolumn{2}{|c|}{ منعدمة } & \multicolumn{2}{|c|}{ ضعيفة } & \multicolumn{2}{|c|}{ متوسطة: } & \multicolumn{2}{|c|}{ عالية } & \\
\hline & & $\%$ & عدد & $\%$ & عدد & $\%$ & عدد & $\%$ & علد & \\
\hline & & & & & & & & & & أولاً: مجال رفع الكفاءة الإتتاجية الزراعية: \\
\hline$\cdot, 91$ & $\wedge 9$ & r^, & $r_{1}$ & $\varepsilon 1, \wedge$ & rᄉ & 17,0 & 10 & $\mathrm{~V}, \mathrm{~V}$ & v & ا.مساعدة الزر اع على معرفة قدرات مواردهم \\
\hline$r, \leqslant 9$ & YTV & 0,0 & 0 & $\varepsilon, \varepsilon$ & $\varepsilon$ & ro,r & r & $\Upsilon \varepsilon, \Lambda$ & 09 & r.توصيل المعارف حول الجديد في الإنتاج \\
\hline 1,1 & $17 \varepsilon$ & $V, V$ & V & r & r & $r \varepsilon, r$ & YY & $r 1,9$ & rq & ك.تدريب الزراع على المهارات الإنتاجية \\
\hline $0, r V$ & & & & & & & & & & المتوسط العام \\
\hline & & & & & & & & & & ثانياً: التسويق والتوزيع واستغلال المنتجات \\
\hline $1, \varepsilon r$ & 149 & $1 \leqslant, r$ & ir & $\varepsilon 9,0$ & $\leq 0$ & 17,0 & 10 & 19,1 & 11 & 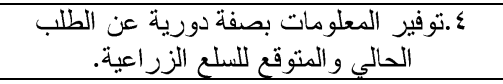 \\
\hline $1,1 \mathrm{~V}$ & 1.7 & $\backslash \wedge, \vee$ & IV & $o v, 1$ & or & $1 r, r$ & Ir & 11 & 1. & ه.التنريب على مهارات رفع جودة المنتج \\
\hline$r, 1$ & 119 & $\wedge, \wedge$ & $\Lambda$ & $r \cdot, q$ & 19 & $r \leqslant, r$ & rt & $\varepsilon\rceil, r$ & $\varepsilon r$ & 7.الاهنمام بمعاملات الجمع وما بعد الحصاد. \\
\hline $1, \wedge \varepsilon$ & $17 \mathrm{~V}$ & $\mid r, 1$ & 11 & $r \wedge, \uparrow$ & YY & $r+1$ & r) & r & r & V Vتدريب الزراعل على التعامل الصحيح مع الزية. \\
\hline $7,0 \mathrm{H}$ & & & & & & & & & & المتوسط العام \\
\hline & & & & & & & & & & ثالثاً: تنمية وصياتة الموارد الطبيعية: \\
\hline $1, Y \wedge$ & 117 & $\mid r, 1$ & 11 & 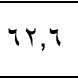 & or & 11 & $1 \cdot$ & $1 \varepsilon, r$ & $1 \pi$ & ^.التعريف بالطرق المثلى لاستخدام الموارد \\
\hline צוז & rio & $v, V$ & V & 9,9 & 9 & $r \cdot, q$ & 19 & 7,0 & 04 & 9.تعريف وتتريب الزتراع اع على الوسائل المثلى الري. \\
\hline$r, r_{q}$ & rIV & 11 & 1. & r, r & $r$ & rt & r. & $i r, \mathrm{r}$ & 01 & • (التعريف بالمحاصيل المناسبة للأنواع المختلفة \\
\hline$r$ & INY & 9,9 & 9 & $r \varepsilon, r$ & tr & YY & $r \cdot$ & $\varepsilon r, q$ & $\varepsilon \cdot$ & | I.تشجيع تكوين منظمات مستخدمي المياه. \\
\hline 1,07 & $1 \leqslant r$ & 11 & $1 \cdot$ & $\{0,1$ & « & $r \cdot, q$ & 19 & $r+$, & r) & ب ا.التو عية بأهمية الاستغلال الأمنل للموارد \\
\hline 9,09 & & & & & & & & & & المتوسط العام \\
\hline & & & & & & & & & & رابعاً: إدارة المزرعة والمنزلة الريفي وممارسةة \\
\hline I,r & $|r|$ & $1 \leqslant, r$ & $1 \pi$ & $0 \leqslant, q$ & 0. & $1 \leqslant, r$ & $1 \pi$ & 17,0 & 10 & r ا.التدريب على الأساليب المثلى و الحديثة في \\
\hline $1, r$ & 1.9 & 17,0 & 10 & ov, 1 & or & 17,0 & 10 & 9,9 & 9 & 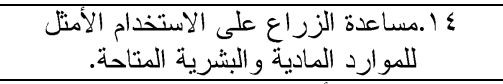 \\
\hline $1, \mathrm{rT}^{-}$ & 110 & $\mid r, 1$ & 11 & $7 \cdot, \varepsilon$ & 00 & 17,0 & 10 & 11 & 1. & ه 1 .تدريب المر أة على إدارة اقتصاديات المنزل \\
\hline 1,09 & $1 \leqslant 0$ & $\wedge, \wedge$ & $\wedge$ & $\varepsilon \vee, r$ & $\varepsilon r$ & 19,1 & 11 & $r \varepsilon, r$ & rt & 17.التدريب على الأنتطة التي تزيد من دخل \\
\hline 1, & $|r|$ & 9,9 & 9 & $09, r$ & $0 \varepsilon$ & $\mid \Lambda, V$ & IV & $\mid r, 1$ & 11 & الارشادية المتعلقة بر عاية الأسرة الريفية البية. \\
\hline 1,19 & $1 \cdot 1$ & $10, \varepsilon$ & $1 \leqslant$ & $09, r$ & $0 \varepsilon$ & 19,0 & 10 & $\wedge, \wedge$ & $\Lambda$ & ^1 ـ.تعريف الأسرة بأهمية الادخار و الاستثمار. \\
\hline I, & 114 & $1 V, T$ & 17 & $0 \leqslant, 9$ & $\circ$. & $1 \leqslant, r$ & ir & Ir, & ir & 9 التدريب على تغيير الأنماط الاستهلاكية \\
\hline$\Lambda, 1 \mu$ & & & & & & & & & & المتوسط العام \\
\hline & & & & & & & & & & خامساً: تنمية الثباب الريفي: \\
\hline$\cdot, \vee \vee$ & iV & $\varepsilon \vee, r$ & $\leqslant r$ & $r V, \varepsilon$ & ז & 9,9 & 9 & 0,0 & 。 & •r.نتشيع إقامة النو ادي الريفية لنتمية الروح \\
\hline 1,1 & $9 V$ & ro,r & $r \mu$ & or,Y & $\varepsilon \lambda$ & $\mid r, 1$ & 11 & 9,9 & 9 & اY ا.حث الثباب على المشاركة في برامج تطوير \\
\hline
\end{tabular}

Fayoum J. Agric. Res. \& Dev., Vol. 33, No.2, July, 2019 


\begin{tabular}{|c|c|c|c|c|c|c|c|c|c|c|}
\hline \multirow{3}{*}{ | - المتوسطة } & \multirow{3}{*}{ - الإجمالية } & \multicolumn{8}{|c|}{ مدى الاستفادة (ن = 19) } & \multirow{3}{*}{ المجال / الخدمة أو النشاط الارشادي } \\
\hline & & \multicolumn{2}{|c|}{ منعدمة } & \multicolumn{2}{|c|}{ ضعيفةٌ } & \multicolumn{2}{|c|}{ متوسطة } & \multicolumn{2}{|c|}{ عالية } & \\
\hline & & $\%$ & عدد & $\%$ & عداد & $\%$ & عدد & $\%$ & عدد & \\
\hline & & & & & & & & & & وتتمية مجتمعاتهم الريفية. \\
\hline$\cdot, 97$ & $\Lambda V$ & r & ru & $\varepsilon 1, \wedge$ & ru & $\mid r, 1$ & 11 & 9,9 & 9 & r.r.تعريف الثباب بالأساليب المثلى لاستغلال \\
\hline 1,70 & 10. & 11 & $1 \cdot$ & $r \leqslant, 1$ & r & rt & r. & r & r. & بr.التدريب على إقامة المشرو عات الزر اعية \\
\hline$\cdot, \mathrm{YT}$ & $r \leqslant$ & $\Lambda \curlyvee, \wedge$ & 19 & $r, r$ & $r$ & 7,7 & 7 & $r, r$ & $r$ & ـr.تدريب الثباب المقبلين على الزواج. \\
\hline \multirow[t]{2}{*}{$\varepsilon, V \varepsilon$} & & & & & & & & & & المتوسط العام \\
\hline & & & & & & & & & & سادساً: الاسهام في الثئون العامة وتنمية \\
\hline 1,1 & 90 & ז, r & ru & $r v, \varepsilon$ & $r \varepsilon$ & $\mid r, 1$ & 11 & $1 \leqslant, r$ & ir & 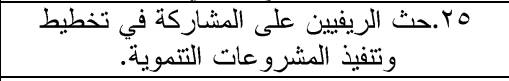 \\
\hline 1,19 & $1 \cdot 1$ & $r \wedge, \uparrow$ & ry & $\sum r, q$ & rq & 9,9 & 9 & $\grave{i}, \mathrm{~V}$ & iv & 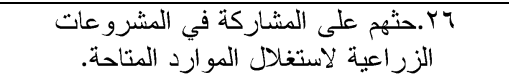 \\
\hline$\cdot, 90$ & 17 & $r 1,9$ & rq & $0 ., 7$ & $\leq 7$ & $\wedge, \wedge$ & $\Lambda$ & $\wedge, \wedge$ & $\Lambda$ & VV.rV التو عية بكل ما يتعلق بالقضايا العامة للريف. \\
\hline $1, r$ & 111 & 19,1 & 11 & 01,4 & $\leqslant \vee$ & $10, \varepsilon$ & $1 \varepsilon$ & $1 r, r$ & ir & 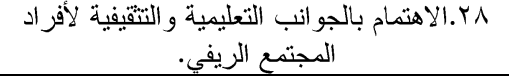 \\
\hline \multirow[t]{2}{*}{$\varepsilon, \leqslant \uparrow$} & & & & & & & & & & المتوسط العام \\
\hline & & & & & & & & & & سابعاً: تنمية القيادة الريفية المحلية: \\
\hline $1,1 \mathrm{~V}$ & 1.4 & $1 \wedge, V$ & IV & $o v, 1$ & or & $1 r, r$ & Ir & 11 & 1. & qج.اكتثاف وتطوير القيادات المحلية. \\
\hline 1,10 & 1.0 & 17,0 & 10 & 71,0 & 07 & $\mid r, 1$ & 11 & 9,9 & 9 & • r.تتجيعهم على بذل المزيد من الجهود لمساعدة \\
\hline 1,1 & $1 \cdots$ & $1 V, 7$ & 17 & it, & 01 & 9,9 & 9 & $\wedge, \wedge$ & $\wedge$ & اب.تذريبهم على ممارسة مهامهم ومسئولياتهم \\
\hline 1,1 & $9 \vee$ & $\lfloor\wedge, \vee$ & iv & re, & 01 & 9,9 & 9 & $\mathrm{~V}, \mathrm{~V}$ & v & r.r.التنريب على متابعة و تقييم أنشطة القيادات \\
\hline \multirow[t]{2}{*}{$\varepsilon, 0 Y$} & & & & & & & & & & المتوسط العام \\
\hline & & & & & & & & & & ثامناً: منظمات الزراع: \\
\hline$\cdot, 70$ & 09 & 70,9 & 7. & Ir, & ir & 11 & $1 \cdot$ & 9,9 & 9 & 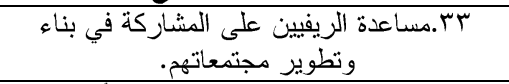 \\
\hline 1,10 & 1.0 & $\leq ५, r$ & $\leqslant r$ & $1 r, r$ & ir & 19,1 & 11 & $r \cdot, q$ & 19 & 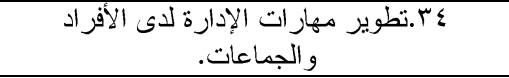 \\
\hline $1, r v$ & Iro & $r \longleftarrow, \varepsilon$ & $r \varepsilon$ & $r_{1}, 9$ & rq & 19,1 & 11 & tr & r. & 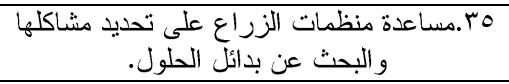 \\
\hline 1,10 & 1.0 & $r q, v$ & rV & $\varepsilon \cdot, \vee$ & rv & $1 \varepsilon, r$ & ir & $10, \varepsilon$ & $1 \varepsilon$ & 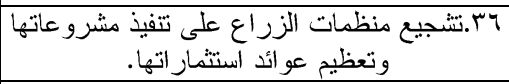 \\
\hline 1,1 & $9 \mathrm{~V}$ & $r 1,9$ & rq & $\sum \zeta, Y$ & $\sum r$ & 9,9 & 9 & $\mid r, 1$ & 11 & VV.تدريبهم على كيفية تطوير وتقوية منظماتهم. \\
\hline זיז, & ov & $r \wedge, \uparrow$ & ry & $\varepsilon \wedge, \varepsilon$ & $\varepsilon \varepsilon$ & 11 & 1. & $1 r, 1$ & 11 & 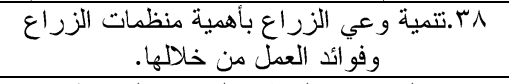 \\
\hline 1 & 91 & ru & r. & $\varepsilon r, q$ & rq & $10, \varepsilon$ & $1 \varepsilon$ & $\wedge, \wedge$ & $\wedge$ & 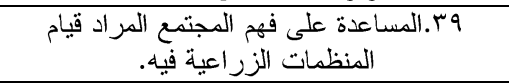 \\
\hline $1,0 \mathrm{r}$ & Irs & 17,0 & 10 & $r v, \varepsilon$ & $r \varepsilon$ & $r \varepsilon, r$ & rY & rt & r. & • ـ ـتدعيم العلاقات الثخصية بين موظف الازشاد \\
\hline $7, .0$ & & & & & & & & & & المتوسط العام \\
\hline
\end{tabular}

خامسا: تدليد الفروق في درجة رأس المال الاجتماعي الريفي بين كل من المستفيدين وغير المستفيدين من

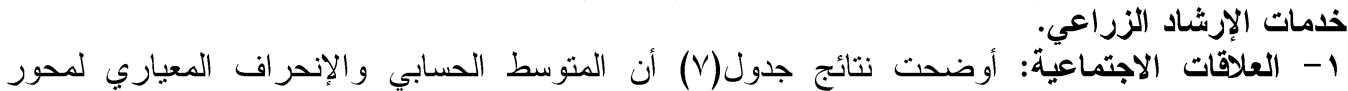

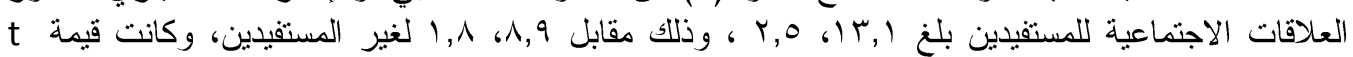

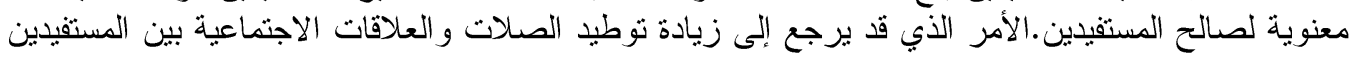

Fayoum J. Agric. Res. \& Dev., Vol. 33, No.2, July, 2019 


\section{ino}

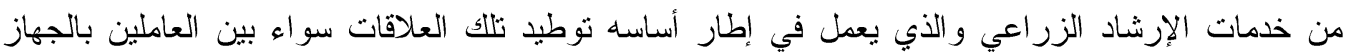

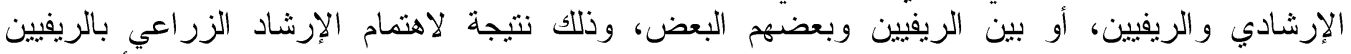

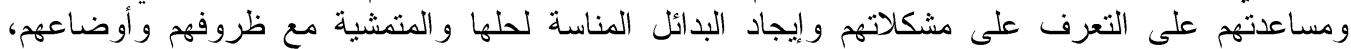

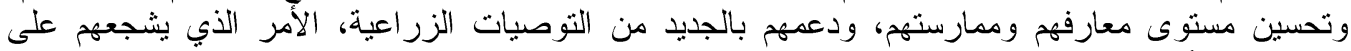

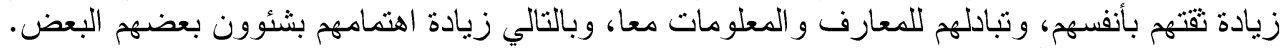

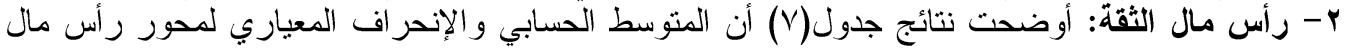

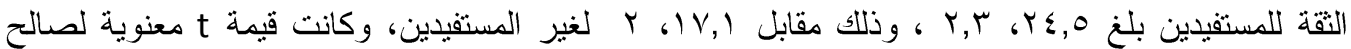

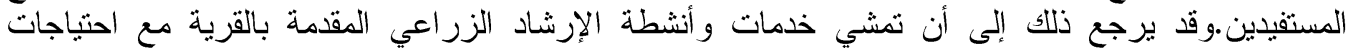

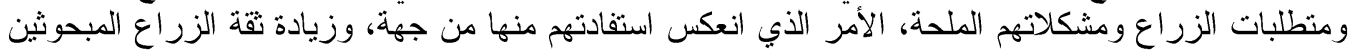

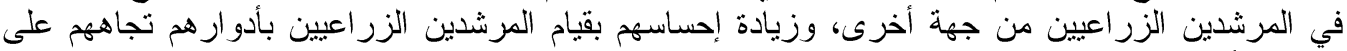

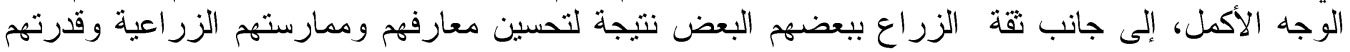

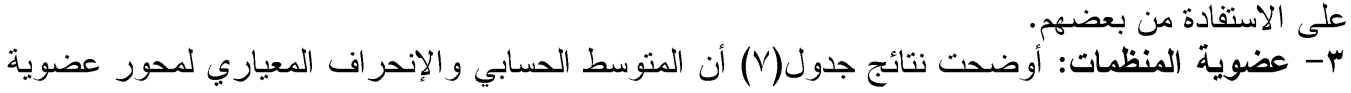

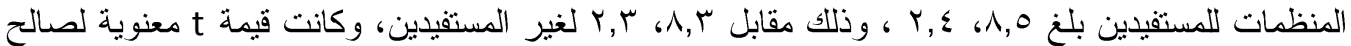

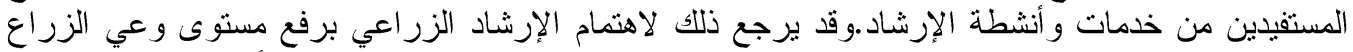

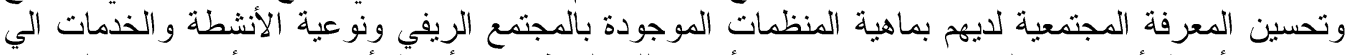

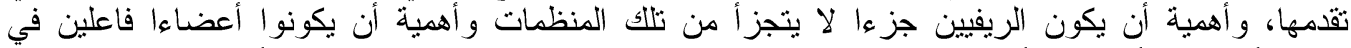

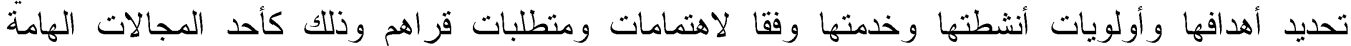

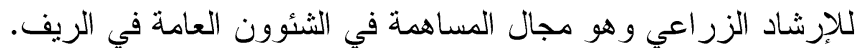

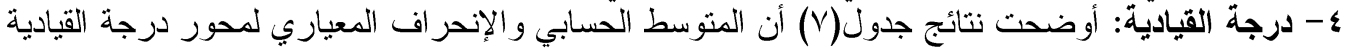

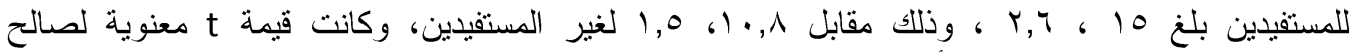

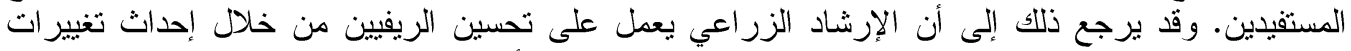

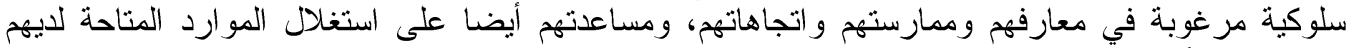

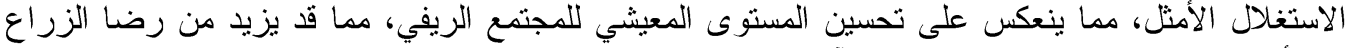

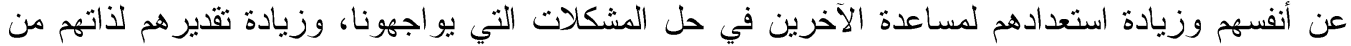

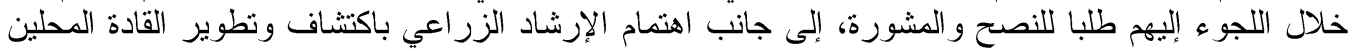

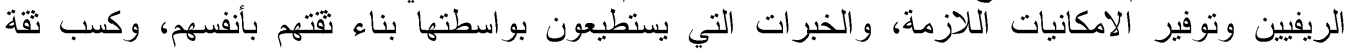

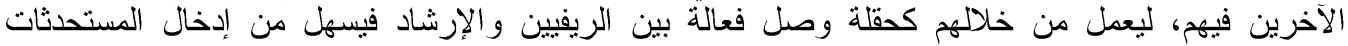

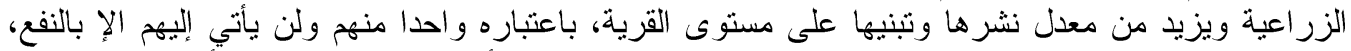

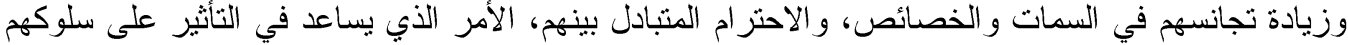

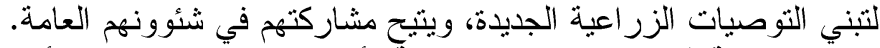

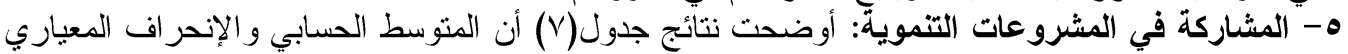

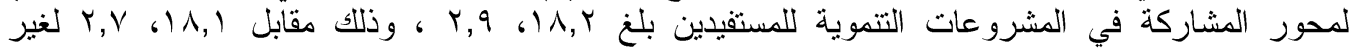

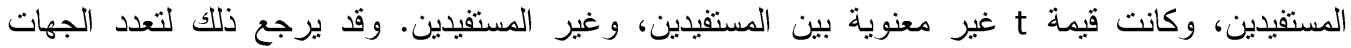

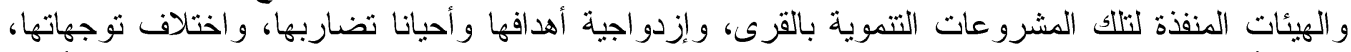

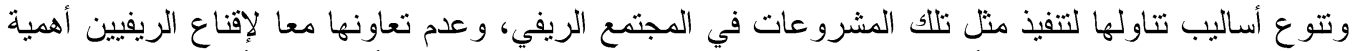

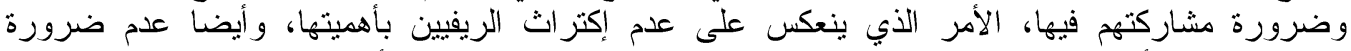

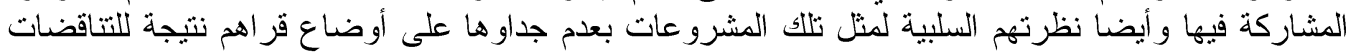

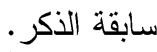

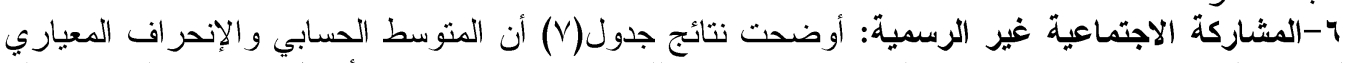

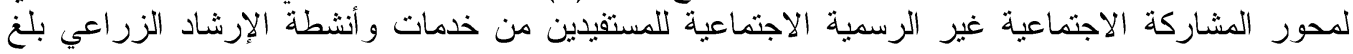

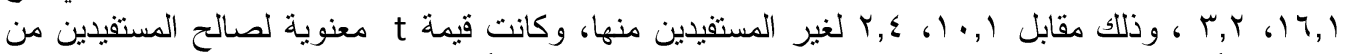

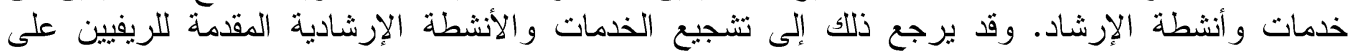

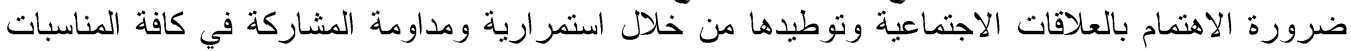

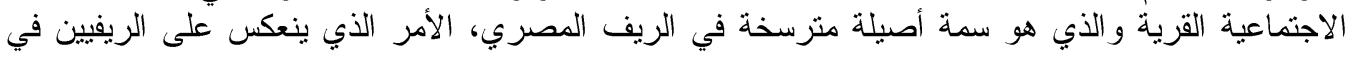

Fayoum J. Agric. Res. \& Dev., Vol. 33, No.2, July, 2019 
$1 \% 9$

زيادة تماسكهم اجتماعيا ودعمهم نفسيا وذاتيا لبعضهم البعض، وقوة نسيجهم الاجتماعي، الأمر الذي قد ينعكس

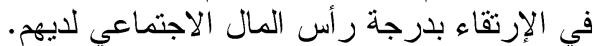

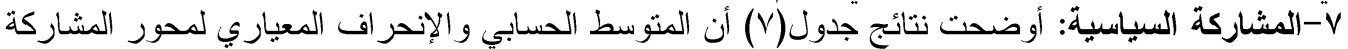

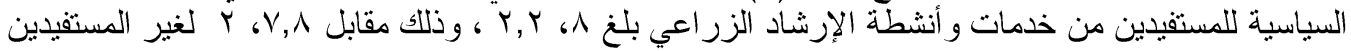

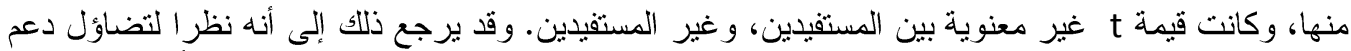

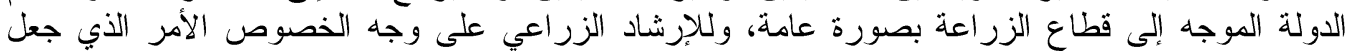

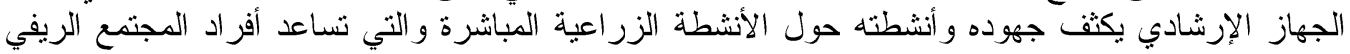

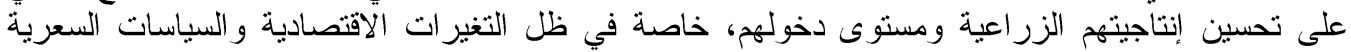

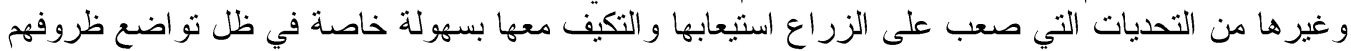

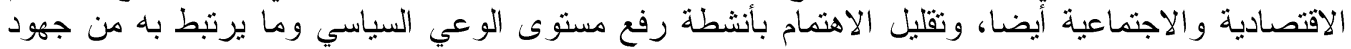

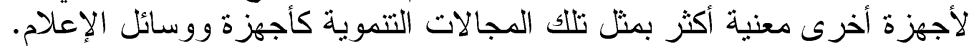

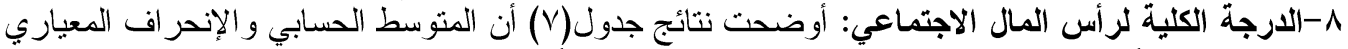

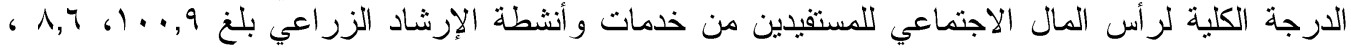

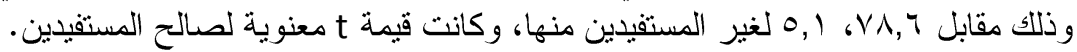

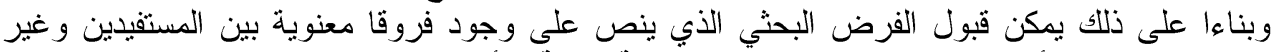

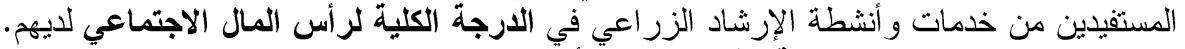

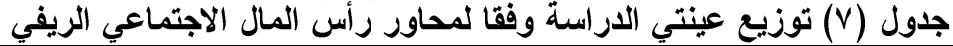

\begin{tabular}{|c|c|c|c|c|c|}
\hline \multirow[b]{2}{*}{ قيمة t } & \multicolumn{2}{|c|}{ 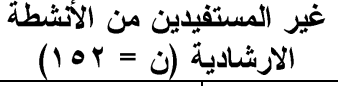 } & \multicolumn{2}{|c|}{ 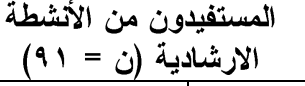 } & \multirow{2}{*}{ المحور } \\
\hline & الإنحرياري اف المياري & المتوسط & المعياري الإندر & المتوسط & \\
\hline$* * 1,1$ & $1, \wedge$ & $\Lambda, q$ & $r, 0$ & $1 \%, 1$ & 1 - العلاقات الاجتماعية \\
\hline$* * r \vee, 1$ & $r$ & $I V, 1$ & $r, r$ & $r \leqslant, 0$ & ب- رأس مال الثقة \\
\hline$* * 1, r$ & T,r & $\Lambda, \Gamma$ & 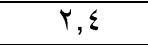 & $\Lambda, 0$ & r- عضوية المنظمات \\
\hline$* * Y,, Y$ & 1,0 & 1,1 & $r, T$ & 10 & ع - درجة القبادية \\
\hline$\cdot, 0$ & $Y, Y$ & $1 \wedge, 1$ & r,q & $1 \Lambda, r$ & ه- المشاركة في المشروعات \\
\hline$* * \mu \cdot, \varepsilon$ & Ү, ६ & $1 \cdot, 1$ & $r, r$ & 17,1 & צ- المشاركة الاجتماعية غير \\
\hline $1, r$ & $r$ & $Y, \Lambda$ & $r, Y$ & $\Lambda$ & V المشاركة السياسية V V \\
\hline$* * 7,9$ & 0,1 & $\vee \wedge, \uparrow$ & $\Lambda, \uparrow$ & $1 \cdots, 9$ & 1-الارجة الكلية لرأس المال \\
\hline
\end{tabular}

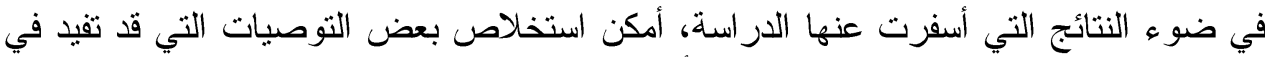

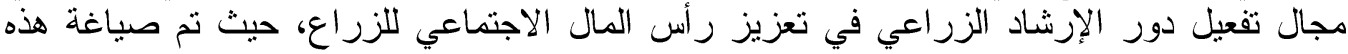

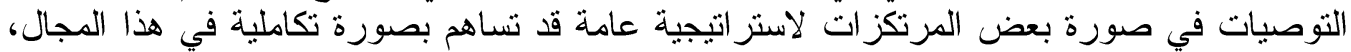
وذلك على النحو التالي (شكل ( ):

Fayoum J. Agric. Res. \& Dev., Vol. 33, No.2, July, 2019 


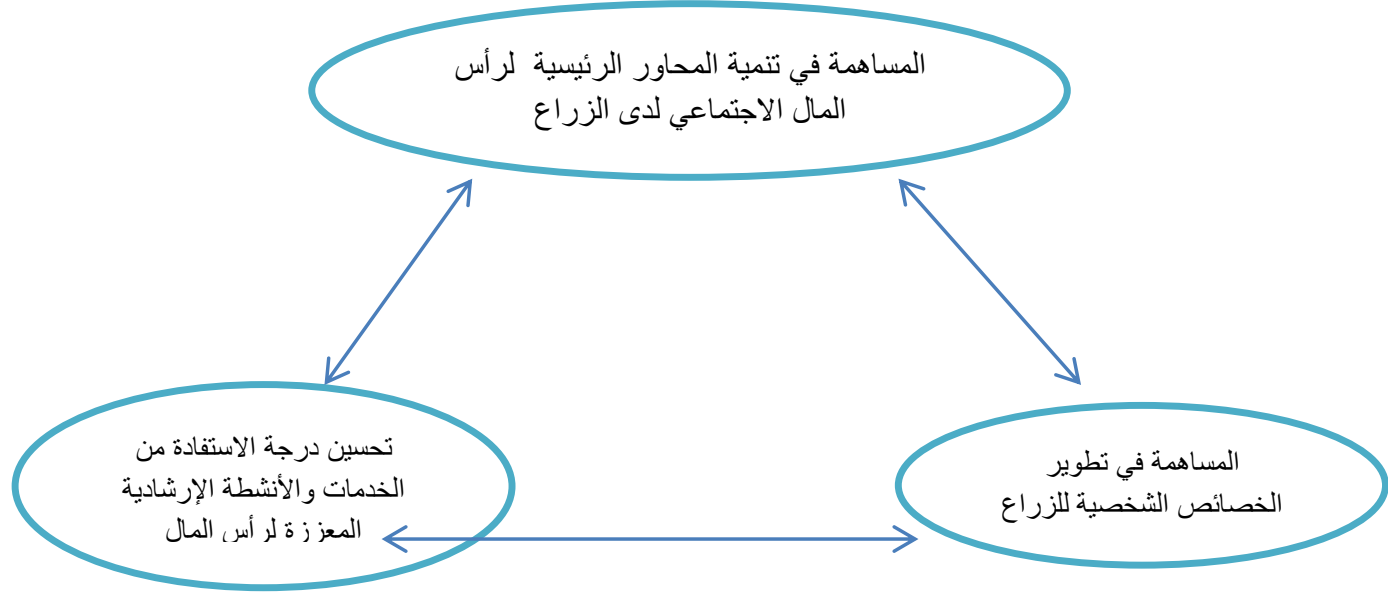

شكل(1) مرتكزات استراتيجية تفعيل دور الإرشاد الزراعي في تعزيز رأس المال الاجتماعي

أ- - المساهمة في تنمية المحاور الرئيسية لرأس المال الاجتماعي لاى الزراع وذلك من خلال الأشثة

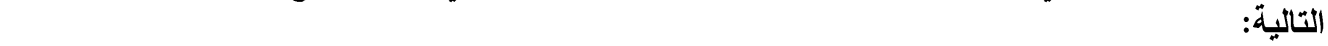

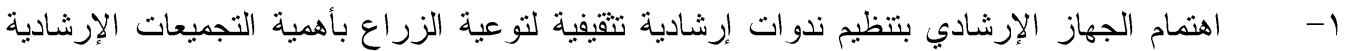

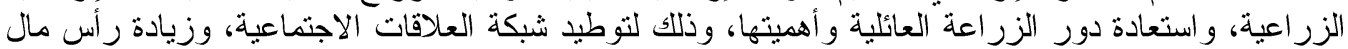
التقة بين الزراع. واعن.

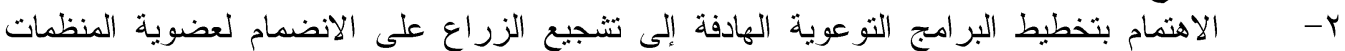

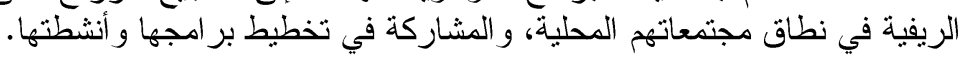

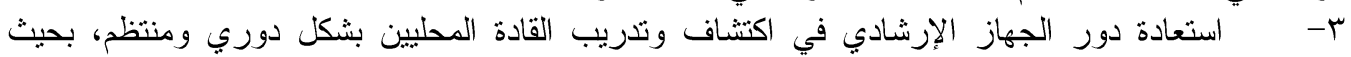

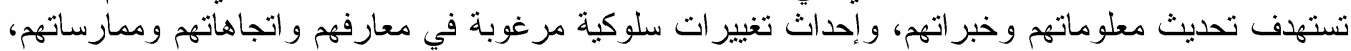

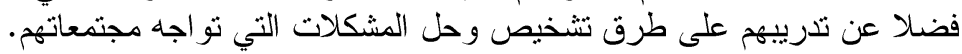

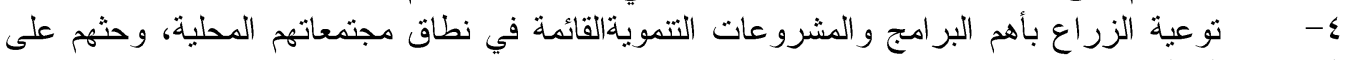
المشاركة الفعالة فيها.

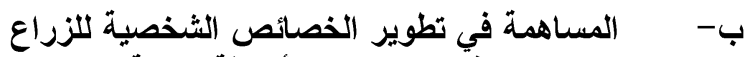
وزذلك من خلال الأنثطة التالية:

أبفا - مث الزراع الأميين على الإلتحاق بفصول محو الأمية، وتو عيتهم بأهمية التعليم بالنسبة لهم و لأبنائهم

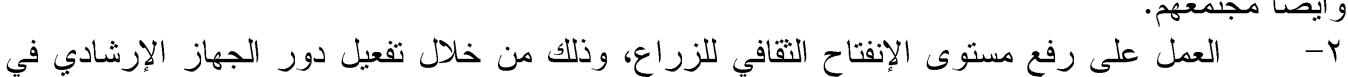

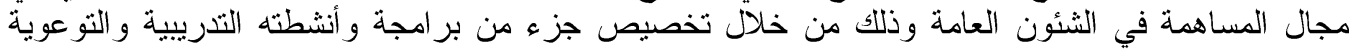

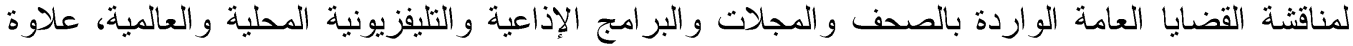

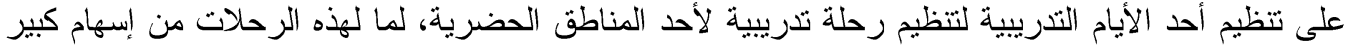

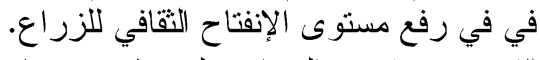

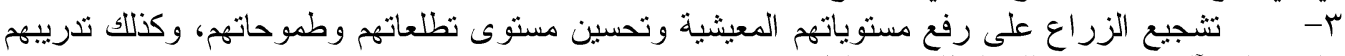

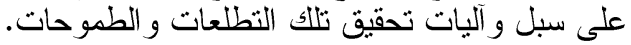

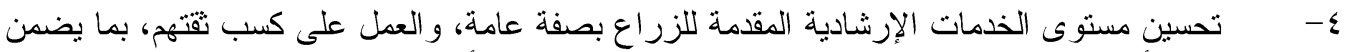

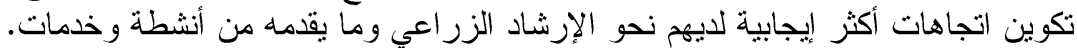

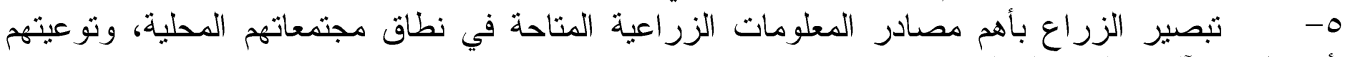
بأهم طرق و آليات الوصول إليها و الاستفادة منها.

Fayoum J. Agric. Res. \& Dev., Vol. 33, No.2, July, 2019 


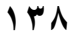

ج- تحسين درجة الاستفادة من الخدمات والأثشطة الإرشادية المعزةة لرأس المال الاجتماعي للزراع وذللك من خلال الأنشطة التالية:

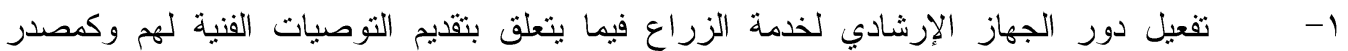

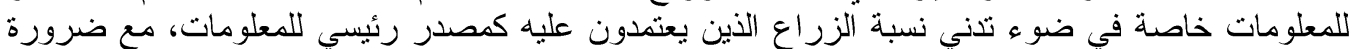

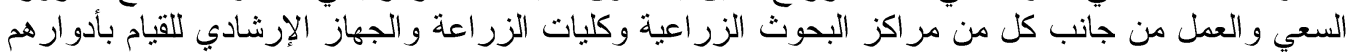

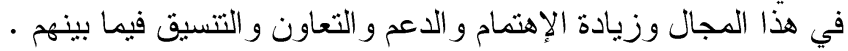

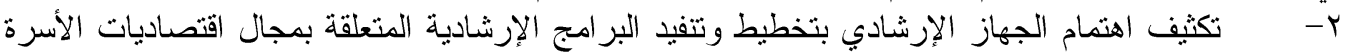

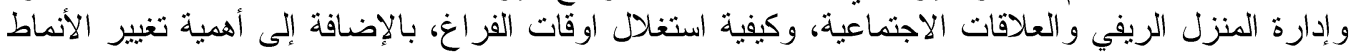

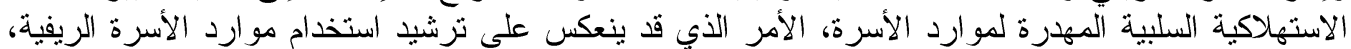

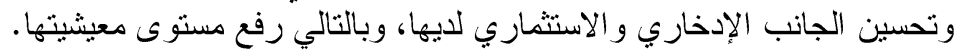

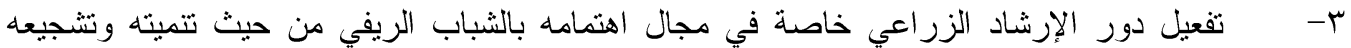

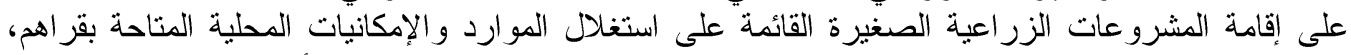

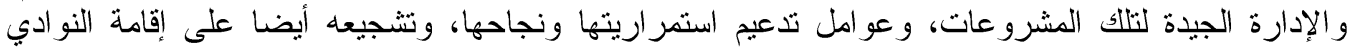

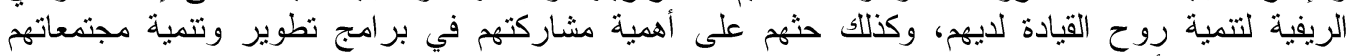

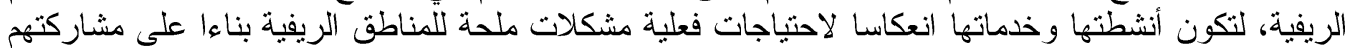

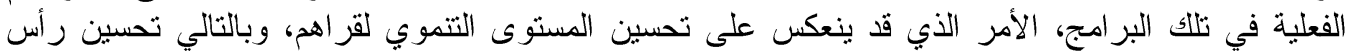

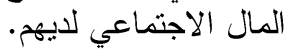

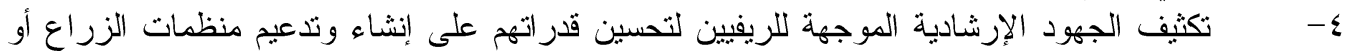

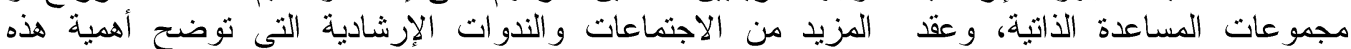

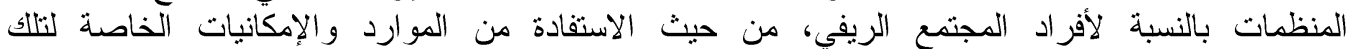

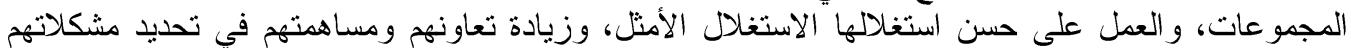

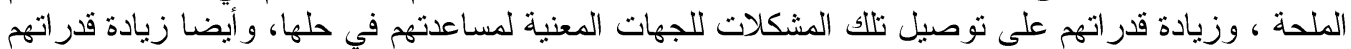

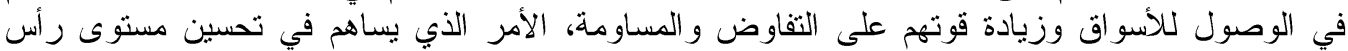

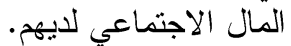

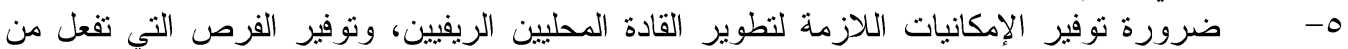

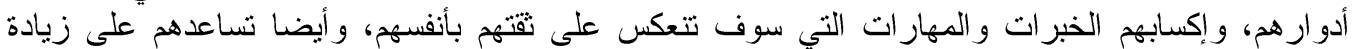
كسب ثقة الآخرين فيهم. المراجع

أبوأبوزيد، سعاد محمد مكي "رأس المال الاجتماعي وأهميته في دعم برامج التنمية المستدامة" جامعة

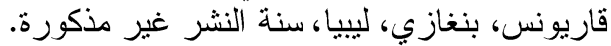

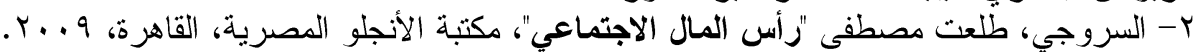
ب- الثاذلي، خلاف "الاتجاهات النظرية والمنهجية الحديثة في رأس المال الاجتماعي"، كلية الآداب، جامعة

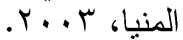
ع- الثافعي، عماد مختار أحمد "بدائل إصلاح الخدمات الإرشادية والاستشارية الزراعية في مصر(أفكار

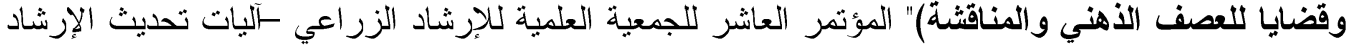

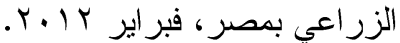

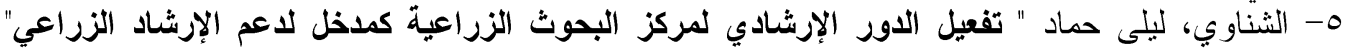

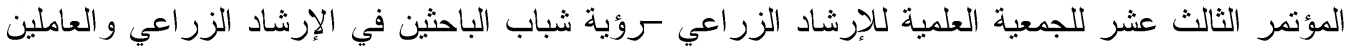

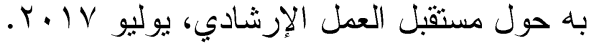

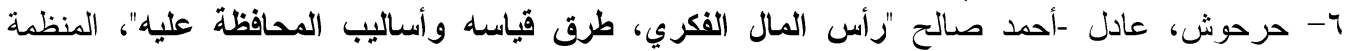

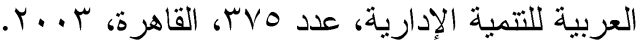
ץ- حمد، إسعاف " رأس المال الاجتماعي- مقاربة تنموية" مجلة جامعة دمشق-المجلد - 31 العدد الثالث، 


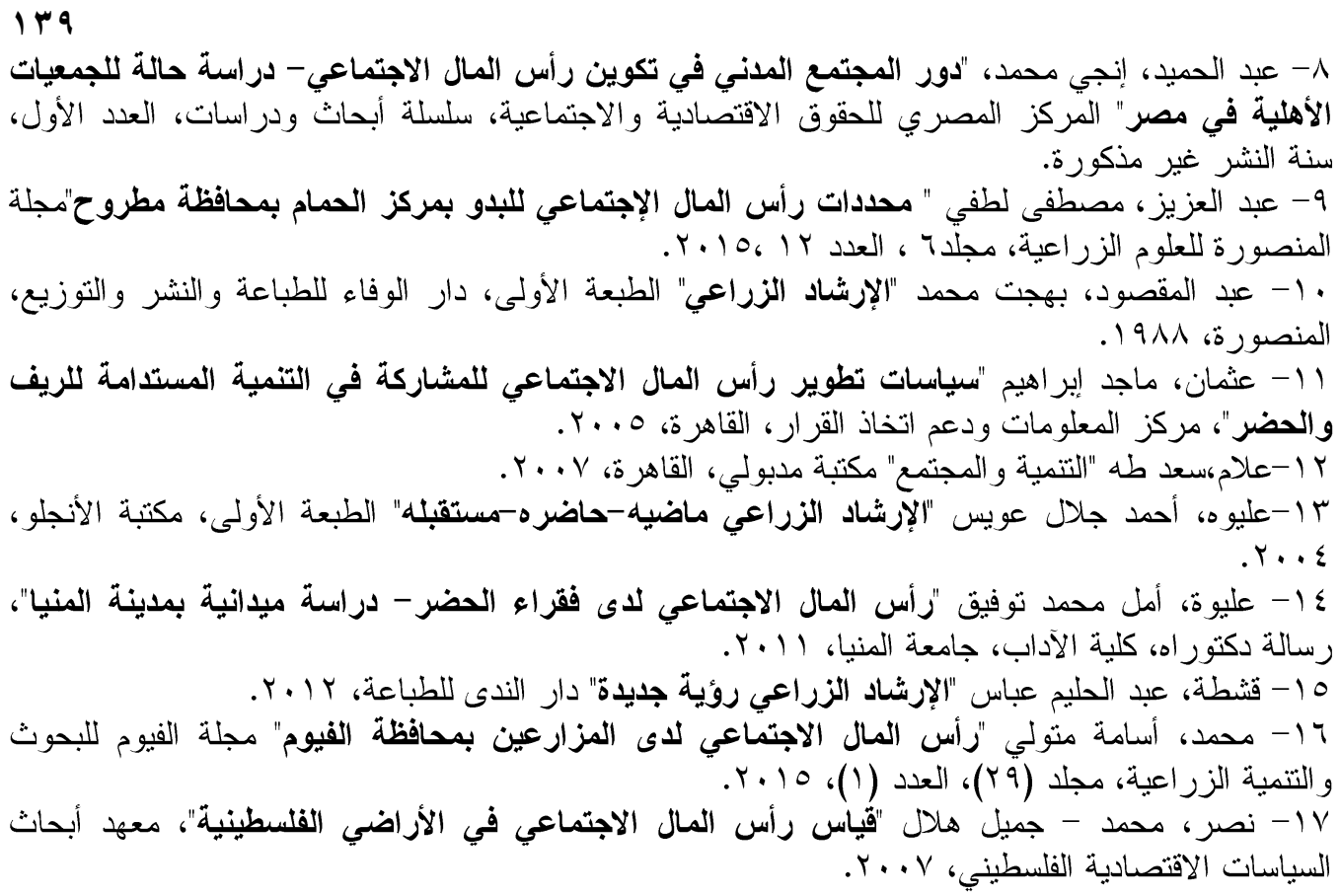

18- Alizadeh, M. "The relationship between social capital and performance of agricultural extension experts", Agricultural Management Department, Shoushtar Branch, Islamic Azad University, Shoushtar.International Journal of Agricultural Science, Research and Technology in Extension and Education Systems, Vol.4 No.3 , Iran, 2014.

19- Arlette, S. S.,- Hickey,G.M.,- Locher, U.,- Phillip, L.E., " Exploring the role of social capital in influencing knowledge flows and innovation in smallholder farming communities in the Caribbean" Springer Science+Business Media Dordrecht and International Society for Plant Pathology, 2016.

20-David, G.A.,-Gangadharappa, N.R., - Chengappa, P.G., - Ganesamoorthi, S.,- Sunil, K., - Sajeev,M.V. "Social Capital and Ability to Change Among Indian Farmers", Proceedings of the 23rd Annual Meeting Polson, Montana. Research gate, 2007.

21-Huneckea Claudia, - Alejandra Engler- Roberto Jara Rojasb- Marijn Poortvliet, "Understanding the role of social capital in adoption decisions: An application to irrigation technology" Science Direct, Agricultural Systems, Volume 153, Pages 221231, May 2017.

22- Lin, Nan "Social Capital", Cambridge University Press, 2001.

23-Micheels, Eric T.,- James F. Nolan" Examining the effects of absorptive capacity and social capital on the adoption of agricultural innovations: A Canadian Prairie case study" ScienceDirect, Agricultural Systems, 2016.

24-Monirul. G, M,.- Alama,b,- Khorshed Alama- Shahbaz Mushtaq " Influence of institutional access and social capital on adaptation decision: Empirical evidence from hazard-prone rural households in Bangladesh"ScienceDirect, Ecological Economics 130 (2016) 243-251. www.elsevier.com/locate/ecolecon

25- Nkonya. Ephraim,- Adewale Adekunle "The impact of agricultural extension services on social capital:an application to the Sub-Saharan African Challenge Program in Lake Kivu region Fe'des van Rijn" 2015.-Swanson.

Fayoum J. Agric. Res. \& Dev., Vol. 33, No.2, July, 2019 
$1 \leq$.

26- Portes, Alejandro "Social Capital: Its Origins and Applications in Modern Sociology", Annual Review of Sociology, Vol. 24, 1998.

27 - Reid, C.,- Lawrence Salmen,- Mamadou Camara,- Cheick Kamaté,- Maimouna Sow Sangaré "UnDerstanding Social Capital Agricultural Extension In Mali: Trust and Social Cohesion" The World Bank, Social Capital Initiative, Working Paper No. 22, Social Development Family, Environmentally and Socially, Sustainable Development Network, Washington, USA, June 2000. gochieng@worldbank.org 28- Silici. Laura, "The Role of Social Capital in the Adoption and the Performance of Conservation Agriculture". , The Practice of Likoti in Lesotho, Executive Summary, Agriculture \& food Organization Project, 2006.

29- Silverman, Robert, "Social Capital", Downside of Encyclopedia of Community, Sage Applications, London, 2003.

30- Swanson. Burton E. - Riikka Rajalahti "Strengthening Agricultural Extension and Advisory Systems: Procedures for Assessing, Transforming, and Evaluating Extension Systems" International Bank for Reconstruction and Development / the World Bank, 2010.

31-Swanson. Burton, E.,-Robert .P, Bentz- Andro. J,Sofranko., "Improving Agricultural Extension" Food and Agriculture Organization of the United Nations, Room, 1997.

32-Takemura. Kosuke.,- Yukiko Uchida., -Sakiko Yoshikawa, "Roles of Extension Officers to Promote Social Capital in Japanese Agricultural Communities", journal.pone PLoS ONE 9(3), , Ma“lardalen University, Sweden, March 18, 2014.

33-Teshome, A, - Graaffa, J- Kessler, A "Investments in land management in the north-western highlands of Ethiopia: The role of social capital" Land Use Policy, 2016. www.elsevier.com/locate/landusepo.

34-Tumbo. S.D.,- K.D. Mutabazia,- K.F.G. Masukib,- F.B. Rwehumbizaa,- H.F. Mahooa,- S.J. Nindic, J.G. Mowo, "Social capital and diffusion of water system innovations in the Makanya watershed, Tanzania " ScienceDirect,The Journal of Socio-Economics, 43 (2013) 24- 36. www.elsevier.com/locate/soceco

35- Woolcock, Michael "The Place of Social Capital in Understanding SocioEconomic Outcomes", Canadian Journal of Policy Research, Vol. 10, No. 1., 2001.

\title{
EFFECT OF AGRICULTURAL EXTENSION SERVICES ON THE ENHANCEMENT OF SOCIAL CAPITAL IN SOME VILLAGES IN FAYOUM GOVERNORATE
}

\begin{abstract}
The objectives of the study were to: identify some socio- economic characteristics of farmers, describe the rural social capital levels in the studied area, identify the extent to which farmers benefited from some Extension services and activities to Enhance the Social capital, and identification of differences in the degree of social capital between both beneficiaries and non-beneficiaries of extension services. Fayoum destrict was chosen from Fayoum governorate in terms of the number of farmers holding. Three villages were randomly selected: Demo, Sakran and Manachi Al-Khatib. A random sample of $10 \%$ of the total number of farmers in the three villages was selected. The sample consisted of 243 farmers, of which 91 were beneficiaries of agricultural extension services and activities, and 152 were non-beneficiaries of these.The main
\end{abstract}

Fayoum J. Agric. Res. \& Dev., Vol. 33, No.2, July, 2019 
$1 \leq 1$

findings of the study were: The most important sources of agricultural information were: personal experience, parents, relatives, friends and neighbours, for both beneficiaries and non-beneficiaries of agricultural extension services and activities. More than three quarters (77.4\%) Indicated that their degree of exposure to these sources was either moderate $(46.1 \%)$ or high $(31.3 \%)$. Three quarters $(75.7 \%)$ indicated that their confidence in those sources was either moderate $(43 \%(32.5 \%)$, and $78.7 \%$ of them reported that they were either moderately $(43.6 \%)$ or low $(35 \%)$.

The results indicate that the relative degree of social capital for sample as a hole was relatively low, as (77\%) of the total social capital was moderate or low. The percentage was $49.5 \%$ for the beneficiares, compared with $49.4 \%$ for the same categories for not beneficiares.Finding also indicated that the most important of extension services and, which benefited farmers concerning, Enhancement of social capital, in the field of incresing agricultural production, were: the delivery of knowledge in agricultural production (2.49) raising farmers' skills new about applications (1.8). In the field of marketing, and distribution, the most important activities were: harvest and post harvest treatments; and by-productrecycling in the field of development and conservation of natural resources it were: Identify appropriate crops for different types of soil (2.39) and rational use of irrigation water (2.36).

The most important activities and extension services in farm management, it were: training on activities that increase family income (1.59), the best of farm management (1.33) and Training the rural youth to hold small interprices (1.65) and stimulate youth to participate in the development programs of their rural communities (1.1) were the most important extension activities in the field of rural youth development. The main activities in the field of contribution to public affairs and development of rural community were: get attention to education aspects (1.22) and stimulate them to participate in agricultural projects to get use of the available resources (1.19). The most important activities in the field of local rural leadership development were: 1. the discovery and development of local leadership (1.17) increase efforts to help their families in the local community (1.15). The strengthening of personal relations between the extension officer and the target population (1.52), helping farmers' organizations to identify their problems and finding alternatives to solutions (1.37) were the most important activities that benefited the respondents in the field of the forming and developing of agricultural organizations. Results showed significant differences in the rural social capital aspects between beneficiaries and nonbeneficiaries of extension services related to: social relations, trust capital, membership of organizations, leadership degree, degree of informal social participation and total degree of social capital. The results showed also that there were no significant differences in the level of participation in development projects and the degree of political participation between beneficiaries and non-beneficiaries of extension services and activities.

Fayoum J. Agric. Res. \& Dev., Vol. 33, No.2, July, 2019 